\title{
Environmental and Life-history Factors Influencing Juvenile Demography of a Temperate Reef Fish
}

\author{
Anna Clare Smith
}

A thesis submitted to Victoria University of Wellington in fulfillment of the requirements for the degree of Doctor of Philosophy in Marine Biology

Victoria University of Wellington

Te Whare Wānanga o te Ūpoko o te Ika a Māui

2009 


\begin{abstract}
\end{abstract}
Realistic population models and effective conservation strategies require a thorough understanding of the processes that drive variation in individual growth and survival, particularly within life stages that are subject to high mortality. For fragmented marine populations it is also important to consider how processes driving variation performance may vary through space and time. In this study I assess the interaction of two primary factors driving juvenile demography: benthic habitat composition and larval history traits, in a temperate reef fish, Forsterygion lapillum (the common triplefin).

It is well understood that juveniles of many marine organisms are closely associated with structured nearshore habitats as they provide resources (refuge and food sources) that are critical for juvenile growth and/or survival. Nursery habitats are often assessed using measures of fitness of juveniles inhabiting them (e.g. rates of growth). However individual fitness measures may not only be indicative of conditions experienced in the benthic phase, but also an individual's prior history. Recent evidence suggests that variation in larval traits at settlement (e.g., size and age at settlement, larval growth rate) can impact on subsequent ecological performance (e.g., feeding ability and/or predator avoidance) and therefore influence subsequent fitness (i.e. rates of growth and/or probabilities of survival). I used otolith microstructure to assess separate and joint effects of habitat composition and larval traits on the growth of young F. lapillum. Both macroalgal composition of habitat patches and larval traits affected juvenile growth rates, and results suggested that habitat composition may have the potential to mediate fitness-related advantages that may accrue to certain individuals as a result of paternal effects and/or larval dispersal history. 
Quantifying spatio-temporal variability in the post-settlement fitness of Individuals with that differ in larval traits is essential for effective spatial management of marine populations. I further explore the joint effects of macroalgal composition and larval traits, within the context of additional spatial and temporal environmental variation. Results provide direct evidence that habitat can mediate the strength of carryover effects, but that the impact of habitat was variable between local populations and settlement events through time.

In chapter 4 of my thesis, I focus on how small-scale variation in macroalgal composition within a nursery habitat (while controlling for individual variation) can affect the strength of density dependent growth and survival rates of $F$. lapillum. Density-dependent survival is evident during the first 30 days after settlement, and the strength of density dependence varied as a function of macroalgal composition. Resulting variation in estimates of nursery value (i.e., the number of late-stage juveniles produced per area unit of habitat) highlight the importance of incorporating local scale variation in juvenile demography into assessments of nursery habitat.

Lastly, I assess a potential strategy of fishes to persist in a wide range of benthic environments. The ability to adjust traits (i.e., phenotypic plasticity) may allow organisms that encounter a range of unpredictable environmental conditions to maximise fitness within a single generation. In chapter 5 I explore patterns of variation in morphology of juvenile $F$. lapillum from two different subpopulations and from different macroalgal habitats. I evaluate possible evidence for constraints on morphological variation arising from variation in growth rate prior to and following settlement. Results suggest that for organisms with complex life cycles, variation in growth rates experienced during dispersal may constrain plasticity in later stages. 


\section{Acknowledgements}

First I'd like to thank my supervisor, Jeff Shima, who has provided me with constant guidance, encouragement, and inspiration throughout my study. The kind and generous support I have received from both Jeff and Nicole Phillips has been invaluable.

I would also like to thank my second supervisor, Russel Cole for being patient and ever helpful. Thanks to all those at Victoria University that helped me in the field, and in particular for work done in collaboration with Alejandro Perez-Matus. Ale has been a dear friend to me and without his help and support during in those first few months of field work, I'm not sure I'd be writing this today! I have gained much support, encouragement, and advice from all of my friends and colleagues in the department. Thanks to everyone in the Shima-Phillips lab group at Vic including Shane Geange, Bionda Morelissen, Snout (aka Daniel McNaughton) and Philipp Neubauer, who all took the time to read over draft chapters and provide feedback. Thanks to especially to Snout for all the logistical and stats help, and also to Shane who has provided many helpful critiques of the work contained within this thesis (as well as providing mental support during the intense final stages!).

Financial support was generously provided by a collaboration between National Institute of Water and Atmospheric Research (NIWA) and Victoria University of Wellington, Commonwealth Scholarship, New Zealand Agency for International Development (NZAID) (NZAID Postgraduate Field Research Award) and Victoria University of Wellington (PhD Completion Scholarship).

I'd like to thank all my friends for their support during my study, especially Jess Bensemann, Laura Wicks, Jade Berman, Tyler Eddy, Pelayo Salinas de Leon and Jessie Baker. I'd particularly like to thank Andrea Benge - for being a wonderful friend, for 
listening to my endless rambles and rants, and for giving me a place to call home in the last few months!

Luke - thank you for your care, understanding and encouragement, and for helping me to relax and see the bigger picture.

Finally I'd like to thank my family. Thanks to Paul for being my wonderful loving big brother. Words cannot express the thanks I owe to my parents, to whom I dedicate this thesis. Without my mum and dad's unconditional love and total faith in my ability to succeed, my achievements to this day would not have been possible. They have led me to this point in my life by driving me to be strong and to follow my heart. 


\section{Table of Contents}

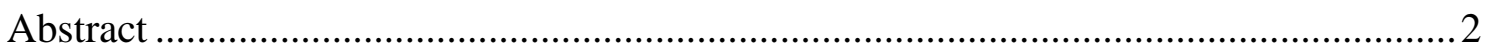

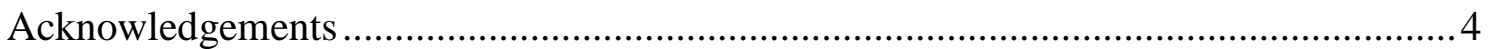

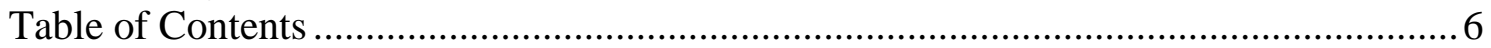

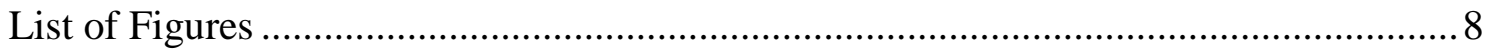

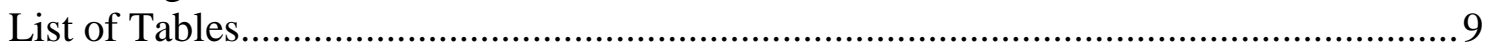

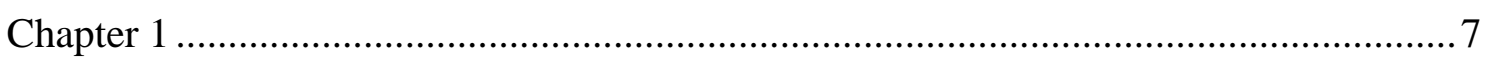

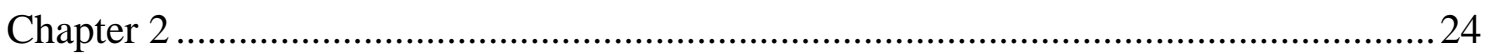

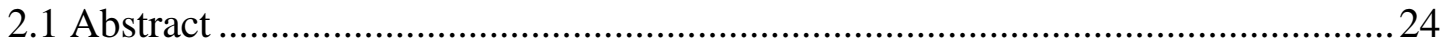

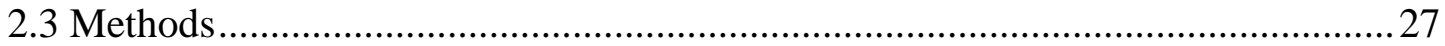

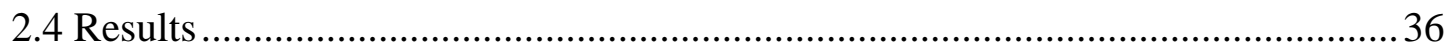

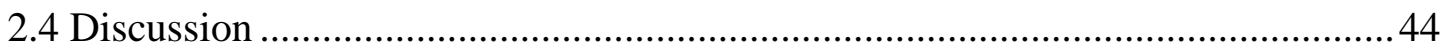

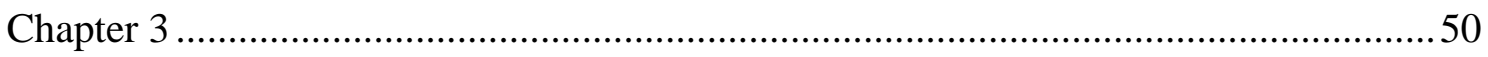

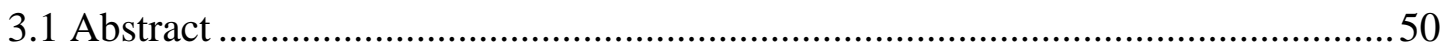

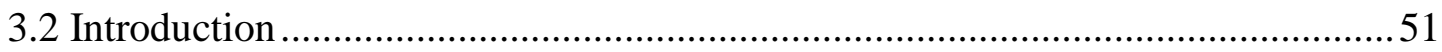

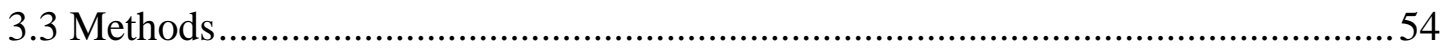

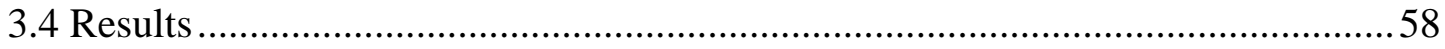

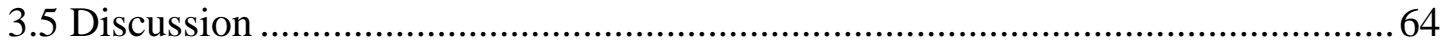

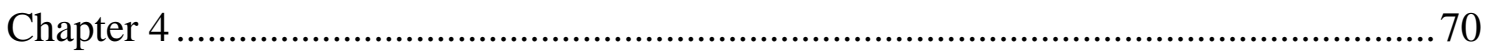

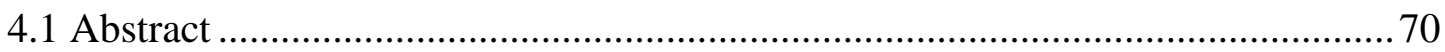

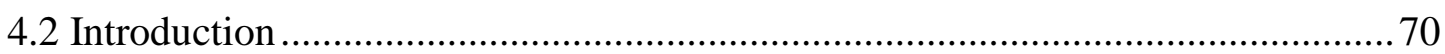

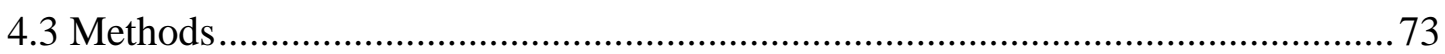

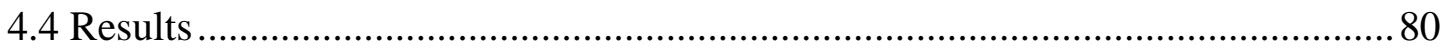

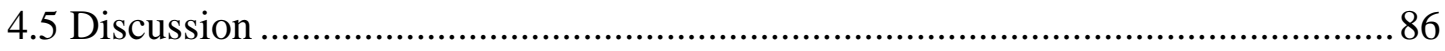

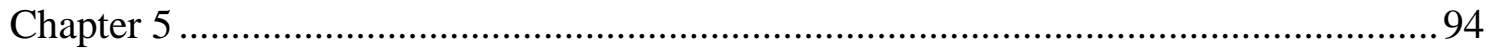

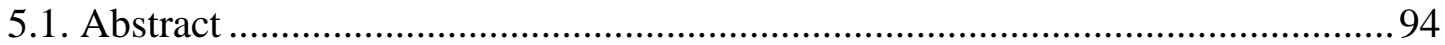

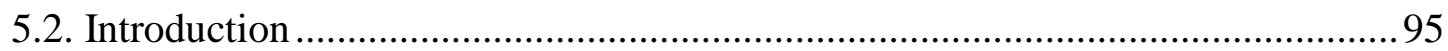

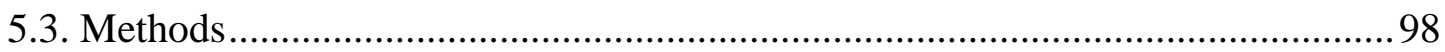

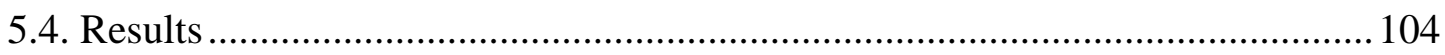

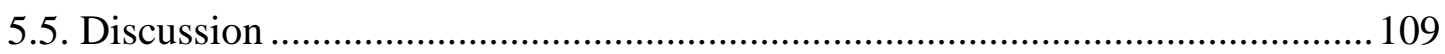

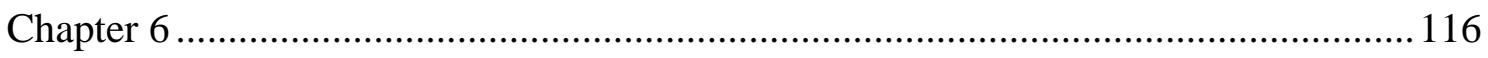

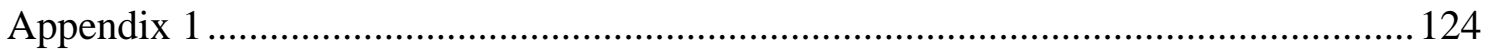

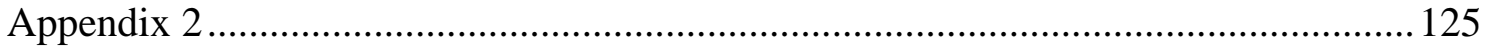

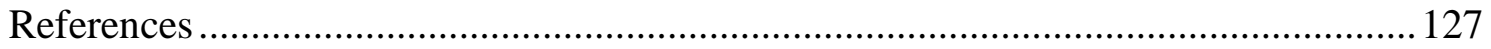




\section{List of Figures}

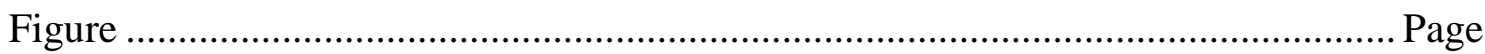

1.1 Map of study sites in the Wellington region, New Zealand.................................20

2.1 The relationship between juvenile growth and larval growth in four habitats.........39

2.2 Histogram showing selective mortality on larval otolith growth rates

2.3 Effect of habitat treatment on a) otolith radius, (b) and growth rate (c) CV of growth rate

2.4 Effect of habitat treatment on body condition index........................................... 44

3.1. Variation in settlement intensity and larval growth of settlers ............................59

3.2 Between-habitat variation in the relationship between juvenile growth and larval growth

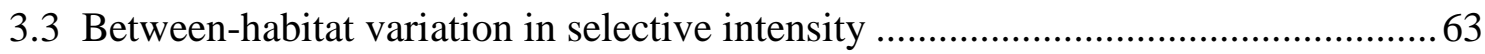

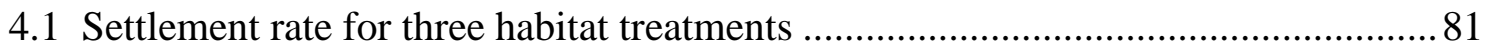

4.2 Relationship between survival and density for three habitats ............................... 82

4.3 Relationship between wet weight and post-settlement age for three habitats..........85

4.4 Estimates nursery value for three habitat treatments ...................................... 86

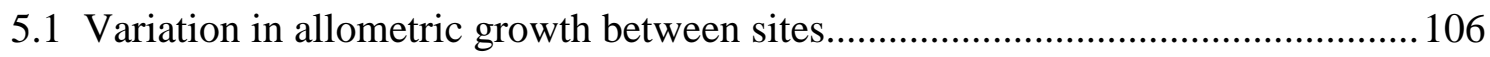

5.2 Association between the difference in larval growth and gape morphology ......... 108

5.3 Magnitude of variation in gape height and variation in larval growth.................. 109 


\section{List of Tables}

Table. Page

2.1 Average values of larval traits at settlement 37

2.2 Summary table of mean \pm SD values for the different variables examined for juvenile fish. 39

2.3 Results of an ANCOVA showing the affect of larval otolith growth and habitat treatment on post-settlement otolith growth

2.4 Repeated-measures MANOVA on otolith radius, growth rate and CV 43

3.1 Variation in fish densities 59

3.2 ANCOVA results for effects of late larval otolith growth and habitat on juvenile otolith growth for south coast, cohort 1.

3.3 ANCOVA results for effects of late larval otolith growth and habitat on juvenile otolith growth for south coast, cohort 2.

3.4 ANCOVA results for effects of late larval otolith growth and habitat on juvenile otolith growth for harbour, cohort 1

3.5 ANCOVA results for effects of late larval otolith growth and habitat on juvenile otolith growth for harbour, cohort 2 .

3.6 Three way ANOVA comparing selective intensity among each location, cohort, and habitat treatment. 63

4.1 Comparison of mean phenotypic traits of settlers among habitat treatments 83

4.2 ANCOVA results for effects of habitat treatment on mass increase with postsettlement age.

5.1 MANCOVA results for how morphology of juvenile fish were affected by larval growth rate 106 
5.2 MANCOVA results for how morphology of juvenile fish were affected by juvenile growth rate. 106

5.3 ANCOVA results for how morphology of juvenile fish were affected by larval... 107 


\section{Chapter 1}

\section{General Introduction}

Identifying processes that are important in determining the size and distribution of a population remains a challenge for ecologists and those concerned about the decline of biodiversity. Most organisms have complex life cycles consisting of two or more temporally and spatially discrete stages (Wilbur 1980) and processes acting to regulate abundance at one stage will influence population dynamics of later stages (Hellriegel 2000). Population changes in the marine environment have been influenced by human activities resulting in such phenomena as depleted fisheries, global climate change and marine pollution (Gossling 2007). Research to gain knowledge on the complex interplay between a population and its environment will aid the effectiveness of conservation and management efforts.

Along coastlines, inshore habitats are often patchily distributed, resulting in the wider populations of many species consisting of fragmented local populations (Sale 1991). Despite their discrete nature, genetic isolation among local populations is prevented by the dispersive pelagic larval phase exhibited by many marine species (Sale 1980). This creates a network of local populations connected via larval dispersal, referred to as metapopulations (sensu Roughgarden and Isawa 1986, Roughgarden et al. 1988).

For reef fish, pre-settlement factors (such as supply of larvae, mortality in the plankton, and condition and competency of larvae) (Gaines et al. 1985, Houde 1987, Roughgarden et al. 1988, Dufour and Galzin 1993) can affect settlement intensity and are known to play a major role in determining the dynamics and structure of populations 
(Sale 1980, Doherty and Fowler 1994, Caley et al 1996, Doherty 2002, Jones and McCormick 2002). Additionally, there is considerable evidence that settlement (the transition from a pelagic to a benthic existence) and post-settlement processes can modify patterns of distribution and abundance generated by variability in pre-settlement processes (Jones 1991, Hixon 1991, Jones and McCormick 2002). The integration of pre-settlement, settlement and post-settlement processes into a common framework is not simple, and the interaction of processes that govern the recruitment of larvae into the juvenile benthic phase is not fully understood. For instance, the performance of individuals that have recently transitioned to benthic habitat will be determined in part by (i) phenotypic variation generated during previous life stages (e.g. in the larval environment; Searcy and Sponaugle 2001, Altwegg and Reyer 2003, Scott et al. 2007), by (ii), demographic variation (e.g. population density; Relyea and Hoverman 2003, McCormick and Meekan 2007), in part by (iii) conditions in the settlement habitat (e.g. food availability; Jones 1986) and in part by (iv) the interaction between these factors (Shima et al. 2008). It is clear, however, that the number and characteristics of individuals that successfully recruit from the larval to juvenile phase can be a principal driver of overall population dynamics (e.g., Hamrin and Persson 1986, Searcy and Sponaugle 2001, Vonesh and De la Cruz 2002).

A growing body of literature suggests that even small phenotypic differences among individuals early in ontogeny can strongly affect survival and performance later in life (e.g., Litvak and Leggett 1992, Sogard 1997, Searcy and Sponaugle 2001, Phillips 2002, 2004, Marshall et al. 2003, Hoey and McCormick 2004, Gagliano et al. 2007, Vigliola et al. 2007, Hamilton et al. 2008). The traits of individuals at settlement (e.g. age, body size and energetic reserves; McCormick and Moloney 1993, Philips 2002) may be a result of parental effects (e.g. maternal condition, genetics; e.g., 
McCormick 2003) and/or pelagic conditions (McCormick and Moloney 1995). During the pelagic phase, larvae may encounter an array of biological and physical conditions that influence their rate of development, larval duration and survival (Hunter 1981). The traits of individuals at settlement can modify subsequent post-settlement performance (e.g., feeding ability, predator avoidance, growth, and fecundity: e.g., Qian and Pechenik 1998, Pechenik and Rice 2001, Shima and Findlay 2002, Gimenez et al. 2004, Hoey and McCormick 2004). Though it is becoming clear that selective pressures acting on larval traits are widespread among marine fishes and invertebrates, the processes that drive the direction and intensity of selective mortality within a single generation are not well understood. Relatively little research has documented how phenotypic variation interacts with other factors (e.g., habitat features) to affect patterns of juvenile abundance and fitness (e.g. growth, body condition) through space and time (but see McCormick and Hoey 2004, Holmes and McCormick 2006, McCormick and Meekan 2007).

Processes driving settlement and post-settlement survival of fishes are often closely associated with differences in benthic habitat characteristics (reviewed in Jaunes 2007). Many conservation and management efforts focus mainly on identifying settlement habitats that will support higher density, growth and survival of juvenile stages and thereby produce a higher number of recruits entering the adult population (i.e., have a higher nursery value, sensu Beck et al. 2001). Larvae of many marine organisms settle to habitats that provide physical structure (i.e., seagrass meadows, coral reefs, rocky reefs, and mangrove forests), which can offer food and refuge from predation (reviewed in Beck et al. 2001). These inshore habitats often consist of a complex mosaic of patches that differ in structural complexity (Dayton and Tegner 1984, Sale and Douglas 1984, Bologna and Steneck 1993, Robbins and Bell 1994, Syms 
and Jones 2000, Hovel and Lipcius 2001). At settlement, larvae can use settlement cues at small spatial scales to detect suitable settlement habitat (reviewed by Kingsford et al. 2002) . Following settlement, juveniles are often relatively site-attached and habitat differences among patches (e.g. structural complexity) can modify processes such as competitive interactions (e.g. Jones 1988) and predation rate (e.g. Almany 2004).

Most studies exploring nursery function of different habitats assume that at entry to a new habitat all individuals are identical (but see Searcy et al. 2007). However variation in the supply and physiological condition of settlers may interact with habitat features to determine recruitment. For example, fish that settle in higher condition may experience stronger intraspecific competition and also more intense effects of density on growth, compared to low condition fish (Johnson 2008), but these processes will also be determined in part by the level of resources available in the current habitat (Jones 1988). Furthermore, larval traits at settlement (e.g. energetic reserves) may affect settlement habitat choice by determining the individual's ability to detect, navigate to, and ultimately chose a particular habitat and/or gain space within that habitat patch (i.e. the "silver spoon effect", sensu Stamps et al. 2004). If settlers actively choose higher quality habitats over poorer quality ones, this may lead to that habitat receiving a disproportionate number of higher quality larvae. Covariation in habitat features with the number and condition of settlers over small spatial scales (e.g. among habitat patches), may lead to processes such as density-dependent mortality being obscured at larger spatial scales (Shima and Osenberg 2003, Shima et al. 2006).

The extent of density-dependent processes occurring in a single life-stage can have profound implications for population-level dynamics (e.g. adult abundance) (Wilbur 1996, Hellriegel 2000). For example, intense density dependent mortality occurring soon after settlement may act to decouple the link between larval supply and 
juvenile or adult abundance. Clearly our understanding of the population dynamics of organisms with complex life cycles is complicated by linkages occurring across stages, such as stage-specific density-dependent mortality and 'carry-over effects'.

Processes that may affect recruitment can occur, and interact, over multiple spatial scales. Individuals with a relatively sedentary juvenile or phase may respond to variation in benthic conditions over small scales, within a single location. However as a consequence of having a dispersive larval phase, fishes often span a large geographical range and local population dynamics may be influenced by broad scale environmental variation (e.g. temperature gradients, oceanographic exposure). Therefore, small scale differences in habitat features may be 'nested' within broad scale variation in environmental factors and/or broad scale variation in pre-settlement processes (e.g. larval supply and the physiological condition of larvae; Jarret and Pechenik 1997, Radtke et al. 2001, Jarrett 2003, Phillips 2006, Shima and Swearer 2009)

One strategy that appears to have evolved to allow organisms with a highly dispersive phase to persist in a wide range of unpredictable environments is phenotypic plasticity (i.e., induced changes resulting in different phenotypes in different environments). An organism's ability to change its phenotype in response to environmental conditions can be critical for its survival (Scheiner 1993, Via et al. 1995). However, there are several costs and limitations associated with phenotypic plasticity. Low energy reserves may constrain the ability to produce plastic morphologies (Olsson et al 2006). Given that variation in larval traits (e.g., late larval growth rate) may affect the physiological conditions of individuals at settlement and subsequent growth and performance, individual variation in larval traits may constrain the extent to which organisms may be able to exhibit morphological plasticity in response to their benthic environment. 
The purpose of my research is to take an integrative approach to better understand what processes drive abundance and persistence of local populations of a temperate reef fish. My work attempts to assess how variation in nursery habitat composition may impact on recruitment within a local population, while concurrently considering the role of two other major factors; phenotypic variation generated prior to and after settlement (Chapter 2) and conspecific density (Chapter 4). I also consider how the relative importance of these factors may vary among spatially discrete populations and through time (Chapter 3). Finally, I examine how covariation between larval history and environmental features on a regional scale can influence variation in juvenile morphology (Chapter 5).

\section{The study system}

My work focuses on the common triplefin (Forsterygion lapillum), an abundant small reef fish (maximum standard length $=6.7 \mathrm{~cm}$; Fricke 1994), of the Family Tripterygiidae, and one of the most abundant species in shallow rocky reef habitats of New Zealand (typically 0-5 metres depth; Clements 2003, Feary and Clements 2006, Wellenreuther et al. 2007). Adults spawn benthic eggs that hatch after 20d, and hatchlings have a pelagic larval duration (PLD) of 50d (Shima and Swearer 2009). In the Wellington region, larval F. lapillum settle to the fronds of several different species of macroalgae between December and April (McDermott and Shima 2006), where they remain for $\sim 40 \mathrm{~d}$ before shifting to open cobble habitats to establish breeding territories (A. Smith, unpublished data). F. lapillum nest sites of are found in a broader range of fine scale habitats compared to other triplefin species, as F. lapillum use habitats such as the top and sides of bolders as well as more sheltered locations such as rock crevices. The diets of adult $F$. lapillum collected from throughout New Zealand were found to be 
dominated by a variety of small food types, mainly archaeogastropods and barnacle cirri (Feary et al. 2009).

The common triplefin lends itself for field-based study as this species settles in relatively high densities (up to $\sim 6$ fish $\mathrm{m}^{-2}$ ) on shallow subtidal reefs $(<\sim 10$ metres deep), at numerous locations around the coast of New Zealand. Previous work by Kohn (2007) has validated the use of daily growth increments in the sagittial otoliths of this species, and also documented the presence of a clear settlement mark (representing transition from the larval to the benthic stage), which further facilitates the use of otolith microstructure analysis. Otolith analysis has become a common tool for the description of growth and mortality patterns during the early life history of reef fishes (e.g., Sponaugle and Grorud-Covert 2006, Searcy et al. 2007, Gagliano and McCormick 2008a). Increment width patterns within otoliths can reveal daily patterns in size at a given age and growth (Stevenson and Campana 1992). In conjunction with longitudinal sampling of the same cohort, otolith microstructure can be used to compare the characteristics of survivors and non-survivors in natural populations and therefore detect patterns of selective mortality (Sogard 1997).

Macroalgal vegetation is a major structural component of temperate reefs, and provides habitats that are used by juveniles of many temperate reef fishes (Wheeler 1980, Jones 1984a, b, Carr 1989, 1991, Holbrook et al. 1990, Levin 1991, 1993). The structure of the macroalgal assemblage on temperate reefs can vary considerably in space and time, and it tends to be more ephemeral than the physical structure in other habitats (e.g. as provided by corals on tropical reefs) (Dayton 1985; Chapman and Johnson 1990, Lambert et al. 1992). Macroalgae are often clumped in stands (metres10 's of metres wide), which may lead to the distribution of juvenile reef fishes also being aggregated (Jones 1984c, Levin 1993). 
Initial field observations led me identify and select two locally common species of macroalgae as potentially important settlement habitats for F. lapillum. These were Carphpyllum maschalocarpum and Cystophora torulosa. The algal species are abundant on shallow subtidal reefs of Wellington harbour and the adjoining (and comparatively wave-exposed) south coast. Carpophyllum maschalocarpum has flattened blades with ellipsoid vesicles. Cystophora torulosa has a canonical holdfast, a zig-zag stipe, rounded blades, and globose vesicles. Both fucaleans are small bushytype plants, reaching up to 0.5 to $1.5 \mathrm{~m}$ in stipe length (for further details see Adams 1997). In the Wellington region C. maschalocarpum and C. retrofexa reach mean densities of 4.1 ( \pm 2.4 S.D.) and $1.0( \pm 1.5$ S.D. $)$ per $\mathrm{m}^{2}$, respectively (A. Smith, unpublished data).

For my study I used two sites in the Wellington region (Fig. 1.1). Sites differed in wave exposure, temperature, and the distribution and relative abundance of fish species. Kau Bay, located within the comparatively sheltered Wellington Harbour, is exposed to northerly winds and protected from southerly swells. The second study site, Island Bay, is partially protected from periodic large southerly swells by a small offshore island (Taputeranga Island). At both sites C. maschalocarpum and C. torulosa are common and form patchily distributed clumps in the shallow ( $<7$ metres deep) subtidal zone. 

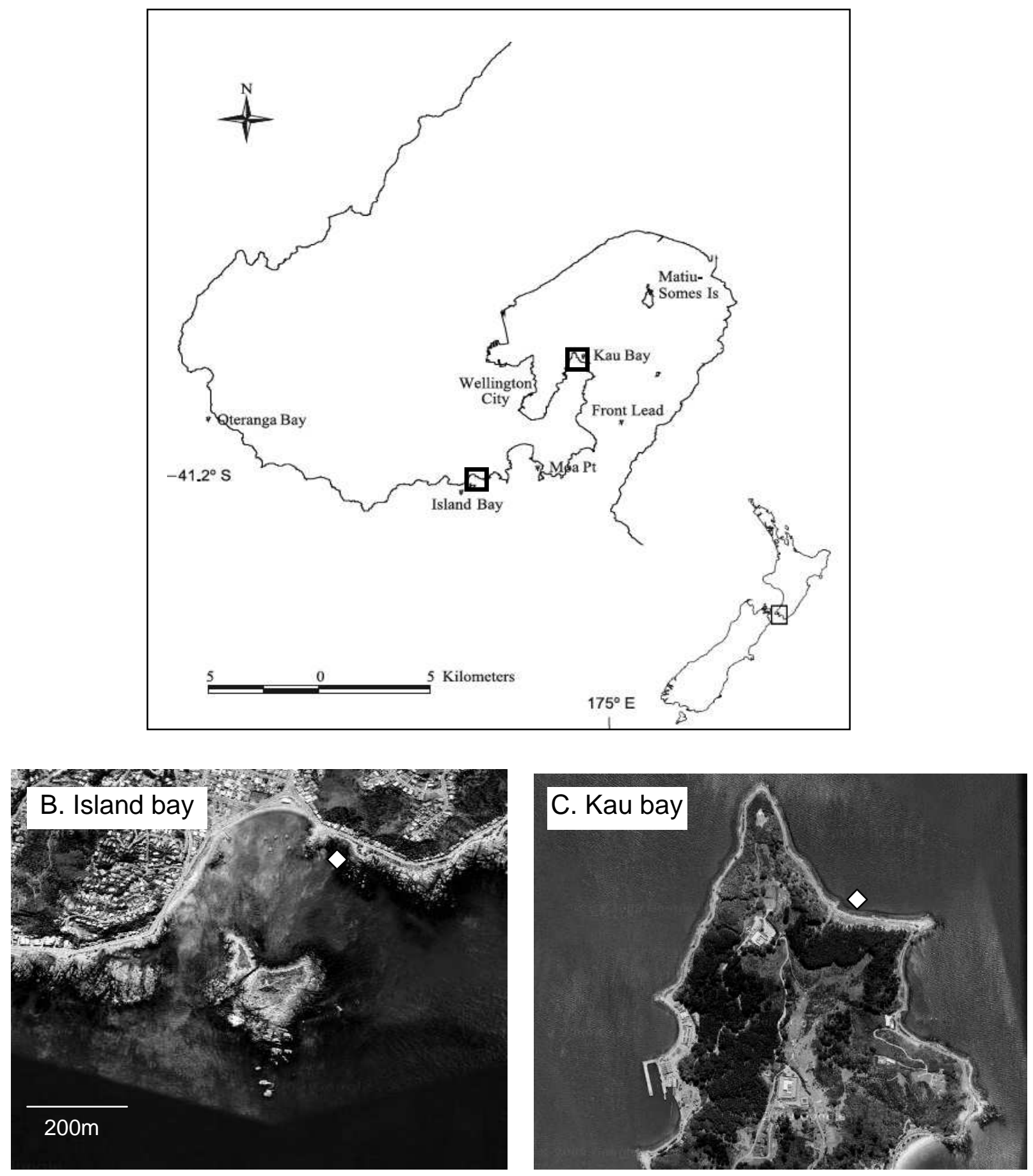

Figure 1.1. Study sites where experimental manipulations of habitat and sampling of juvenile Forsterygion lapillum were carried in A. the Wellington region as denoted by black rectangles. The specific locations of study site are shown in B. Kau bay and C. Island bay by white rectangles. 


\section{Thesis structure}

In Chapter 2, I assess the joint and separate effects of macroalgal habitat composition and prior history on post-settlement growth and body condition of juvenile $F$. lapillum. First, I identify if larval history traits among fish at settlement covaried with habitat features of macroaglal patches. Second, I evaluate correlations between juvenile growth and larval history among habitats, and discuss implications for habitat-specific rates of recruitment.

In Chapter 3, I investigate how the intensity of selective mortality (on larval history traits) varies with macroagal composition. I do this as part of an intensive field assay on naturally settling cohorts of fish, at two distinct locations. This allows me to explore how broad-scale variation in factors such as environmental conditions, larval histories and conspecific density influence the affect of fine-scale variation in macroalgal composition on juvenile demographic rates (e.g., growth and selective mortality).

In Chapter 4, I examine whether the magnitude of density-effects on growth and survival varies with macroalgal composition, while controlling for individual variation in larval history. I first quantify key demographic rates of settlement intensity, mortality and growth among patches varying in macroalgal composition. Using these estimated functions, I then statistically estimate nursery value (i.e., the number of individuals entering the adult population per unit area of habitat) as a function of both conspecific density and macroalgal composition. 
Finally, in Chapter 5 I document and explore a previously unreported relationship between larval history and morphological variation for two spatially discrete local populations. I quantify differences in juvenile morphology between two local populations in contrasting environments, and then explore patterns of morphological variation in relation to larval history. I evaluate possible evidence for constraints on morphological divergence arising from variation in the larval history of settlers arriving to each population. 


\section{Chapter 2}

\section{Early post-settlement growth and survival of a reef fish: interactive effects of larval history and settlement habitat}

\subsection{Abstract}

Assessments of nursery habitat quality often rely upon measures of individual fitness estimated from growth rates or individual condition indices. Such methods assume that fitness is determined by features of the nursery habitat, as opposed to intrinsic differences among individuals that may populate different areas. However, fitness measurements may differ between individuals as a result of variation in their larval and/or parental history, which can also influence subsequent juvenile growth and/or survival rates. In this study I attempt to disentangle the effects of prior history and present attributes of a temperate reef habitat on juvenile growth and condition. In a field experiment I estimate juvenile performance of the common triplefin (Forsterygion lapillum) in relation to larval traits (larval growth, larval duration and size-at-settlement) and macroalgae composition of settlement habitat. I found that larval history traits, specifically late larval growth, was correlated with higher early juvenile growth rate and persistence on the reef. Furthermore, fish settling into mixed stands of macroalgae (containing both Carpophyllum maschalocarpum and Cystophora retrofexa) and into monocultures of Carpophyllum maschalocarpum had significantly higher juvenile growth rates than fish settling to monocultures of Cystophora retrofexa. These results indicate species composition of macroalgal habitat may have the potential to mediate the strength of carry-over effects. 


\subsection{Introduction}

Many animals have a complex life cycle with a discrete larval and adult stage (Moran 1994), and the transition between stages is often associated with a change in environment and/or habitat (Werner and Gilliam 1984). Because entry into a new environment is often associated with a period of high mortality risk (Wilbur 1980, Caley et al. 1996, Pechenik et al. 1998, Hixon et al. 2002), any growth- or condition-related advantages that promote survival during such periods may have substantial effects on future population size (Caley et al. 1996, McCormick 1998, Pechenik et al. 1998). Variation among settlement habitats in the quality and/or quantity of resources (Cocheret de la Moriniere et al. 2003) and differences in predator abundances and/or the frequency of their visits (Shulman 1985, Parrish 1989, Holbrook and Schmitt 2003, Adams et al. 2004) will result in variation in the magnitude of factors such as competition and predation. This can result in habitat-specific variation in early juvenile growth, condition and survival (Shima and Osenberg 2003, Arlt et al. 2008, Shima et al. 2008). For example, increased habitat complexity may reduce competition and predation by providing a greater spectrum of resources (e.g., structural refuge), resulting in higher rates of growth and/or survival (Anderson 1984, Main 1987, Persson and Eklov 1995, Lindholm et al. 1999).

In marine systems, habitats that increase growth and survival of juveniles and ultimately supply a higher number of individuals to the adult population are often described as "nursery habitats" (Beck et al. 2001, Dahlgreen et al. 2006). One approach to assessing nursery function has been to compare the habitat-specific growth and/or mortality rates of selected species among habitats differing in complexity (e.g., Connell and Jones 1991, Sogard 1992, Hayse and Wissing 1996, Able 1999). Assessments of nursery habitat that rely upon measures of individual fitness assume that fitness is 
determined by features of the habitat, as opposed to intrinsic differences among individuals that may populate different areas. However, fitness, as measured by growth rates or individual condition, may also be shaped by variation among individuals (Shima and Osenberg 2003, Shima et al. 2008). Evidence, particularly from the marine literature, indicates that consequences of variation in performance at one life-history stage can "carry over" into important effects on later stages (e.g., Berven 1990, Pechenik et al. 1998, Searcy and Sponguale 2001, Wacker et al. 2002, McCormick and Hoey 2004). The traits of individuals at settlement (e.g. age, body size and energetic reserves; McCormick and Moloney 1993, Philips 2002) may be a result of parental effects (e.g. maternal condition, genetics; e.g., McCormick 2003) and/or pelagic conditions (McCormick and Moloney 1995). These traits may, for example, affect feeding ability and/or predator avoidance, and influence subsequent per capita rates of growth and/or survival (Qian and Pechenik 1998, Pechenik and Rice 2001, Shima and Findlay 2002, Gimenez et al. 2004, Hoey and McCormick 2004, McCormick and Hoey 2004, Gagliano et al. 2007, Vigliola et al. 2007, Hamilton et al. 2008). The potential role of prior history is rarely considered in assessments of juvenile (or nursery) habitat (but see Searcy et al. 2007). Consideration of the role of larval history, and its interaction with habitat attributes, may provide improve knowledge into the mechanisms underlying variation in the recruitment of juveniles to the adult population. In this study, I manipulated the subtidal macroalgal habitat to create a series of replicated habitat patches varying in macroalgal species identity, composition, and density. I sampled recently settled $F$. lapillum from these macroalgal patches and used otolith microstructure analysis to reconstruct growth histories of individuals during their larval (pre-settlement) stage and the juvenile (post-settlement) stage. Given the strong effects of the habitat on post-settlement performance for juvenile reef fish, I expected to 
find that fish settling to 'higher quality' macroalgal patches (i.e., those that support higher rates of growth and survival) would also have larval traits that are associated with higher individual quality such as faster larval growth rates (i.e., the silver spoon effect, sensu Stamps et al. 2006). I expected that the relationship between postsettlement performance and larval traits may differ among macroalgal patches, with fish entering habitat patches that support on average higher growth rates, being subject to a lower strength of carry-over effects (i.e., in higher quality habitats, there would be reduced variation in growth rate among individuals varying in larval traits at settlement).

\subsection{Methods}

\section{Study species and locality}

Forsterygion lapillum (the common triplefin) is an abundant reef fish endemic to New Zealand. Pelagic larvae emerge from benthic eggs after $20 \mathrm{~d}$ (Francis 2001) and spend $~ 55$ days developing in the pelagic environment ( $\mathrm{SD}=5.3$, A. Smith, unpubl. data). In the Wellington region, young $F$. lapillum then settle onto the fronds of macroalgae in rocky reef habitats at standard length $\sim 22.4 \mathrm{~mm}(\mathrm{SD}=1.1)$ between December and April (McDermott and Shima 2001). Juveniles migrate to smooth rock and cobbles (often encrusted with corraline algae) adjacent to the settlement habitat, where they then spawn benthic egg masses (Francis 2001, McDermott and Shima 2001). F. lapillum become sexually mature at $\sim 5 \mathrm{~cm}$ (Francis 2001), and fish do not usually survive more than 2 breeding seasons (Doak 2003). Tagging studies have shown that recently settled juveniles (standard length $<30 \mathrm{~mm}$ ) do not tend to move from a $1.5 \mathrm{~m}^{2}$ patch of macroalgae habitat until they undergo ontogenetic habitat shifts $\sim 40$ days after settlement (A. Smith, unpublished data). Likewise, adult triplefins generally remain site 
attached, rarely moving more than a few meters (Thompson 1983, Clements 2003, Subedar 2009).

This study was conducted at Kau Bay, within Wellington Harbour, New Zealand $\left(41^{\circ} 17^{\prime} \mathrm{S}, 174^{\circ} 50 \mathrm{E}\right)$. Rocky reef habitat in this area is spatially discrete and relatively shallow (comprised of cobbles, boulders, and/or rock outcrops persisting to a depth of up to $\sim 12 \mathrm{~m}$ ): discrete reefs are often separated by sandy embayments (A.C.Smith pers. obs., McDermott and Shima 2006). Two species of brown algae, Carpophyllum maschalocarpum and Cystophora torulosa (from here on referred to as Carpophyllum and Cystophora), dominate these reefs. Mixed stands of Carpophyllum and Cystophora are found from $\sim 0.5 \mathrm{~m}$ depth, and stands become increasingly dominated by Carpophyllum with increasing depth (up to $\sim 8 \mathrm{~m}$ depth). F. lapillum settles at high densities to the reef at Kau Bay to depths of 8 m (McDermott and Shima 2001).

\section{Experimental manipulation of the study site}

In order to assess the effect of macroalgal species composition on growth of juvenile $F$. lapillum, I constructed a series of habitat patches, $2 \mathrm{~m}$ by $2 \mathrm{~m}$ square, each containing one of 4 experimental treatments of different macroalgal composition. Patches were arranged in a grid with one replicate of each treatment represented in each row of the grid to follow a randomised block design. Each treatment was replicated 4 times. The experimental grid ranged in depth from 4.5 to $5.5 \mathrm{~m}$ with each row following a depth contour. Patches were $1.5 \mathrm{~m}$ apart, and all macroalgae was removed from a $1.5 \mathrm{~m}$ border surrounding each patch.

The 4 habitat treatments were (1) A mixed species treatment containing six Carpophyllum and six Cystophora plants; (2) a monospecific treatment containing six Carpophyllum plants; (3) a monospecific treatment containing six Cystophora plants; 
and (4) a monospecific treatment containing 12 Cystophora plants. Treatment 4 was included to assess the affects of macroalgal plant number, independent of species identity. Within each habitat patch all other macroalgae were removed, except those required by the treatment type. All treatment plants were $\sim 1 \mathrm{~m}$ tall and were of similar biomass. Where required, additional suitable plants (with holdfast naturally attached to small boulders $0.2-0.3 \mathrm{~m}$ wide) were transplanted to reefs to experimental treatments patches.

The patches were actively maintained by divers from January to April 2007. Fish were allowed to settle naturally onto the habitat patches and juvenile F. lapillum were sampled from each patch on five dates within this period (sampling dates; $18^{\text {th }}$ January; $2^{\text {nd }}, 15^{\text {th }}$ and $27^{\text {th }}$ February and $26^{\text {th }}$ March).

\section{Fish collections and otolith analysis}

On each sampling date juvenile $F$. lapillum $(<35 \mathrm{~mm}$ total length) were sampled from all patches by divers using SCUBA and hand nets. On each date two dives were made, each approximately 70 minutes long. F. lapillum were collected by systematical searches of each plant within a patch from the top down to the holdfast. Collection times were distributed roughly equally among plants. In order to minimise disturbance, cobbles at the base of each plant were not moved. Hence, patches were not exhaustively searched and only a sub-sample of fish was collected and subsequently frozen prior to processing. Any bias associated with this method of sub-sample collection will be random with respect to habitat treatment as all habitats were searched using the same methodology, allowing me to accurately compare habitats in my analyses. 


\section{Quantifying body condition}

All $F$. lapillum collected were lightly blotted dry and weighed to the nearest 1 mg (wet weight) using a mass balance. Using electronic calipers, I measured the standard and total lengths of each fish to the nearest mm. A measure of overall body condition was obtained using ordinary least squares (OLS) regression residual analysis (Koops et al. 2004). This method uses the residuals from a least squares regression of $\log$ mass on log length as an index of relative body condition. As the relationship between mass and length is allometric, variables need to be log-transformed in order to linearise the relationship. The slopes of the regression lines were found to not be statistically significantly different between habitat treatments and therefore I assumed that body condition (i.e., residuals averaged across individual fish) could be accurately compared among treatments.

\section{Quantifying larval history and juvenile growth}

To obtain a measure of larval traits at settlement and subsequent juvenile growth, I analyzed the otolith microstructure of all sampled juvenile F. lapillum. A conspicuous settlement mark is formed in this species (Kohn 2007), and was used as a reference point for the division between larval and post-settlement increments. A previous study validated the presence of daily growth increments (i.e. rings) for this species (Kohn 2007).

Sagittal otoliths were removed and mounted medial side down on glass slides using cyanoacrylate (Superglue $\left.{ }^{\circledR}\right)$ medium, and polished along the sagittal plane with 3 $\mu \mathrm{m}$ diamond lapping film (3M, St. Paul, Minnesota, USA) to expose daily growth 
increments across the postrostral axis. Polished samples were clarified in immersion oil for $24 \mathrm{~h}$ prior to image acquisition. A set of digital images was collected for each sample, using an image analysis system comprised of a Leica compound microscope (Leica Microsystems, Wetzlar, Germany) fitted with a Nikon CoolPix (Nikon, Chiyodaku, Tokyo, Japan) digital camera and connected to a PC operating ImagePro Plus v5.0 (MediaCybernetics, Bethesda, Maryland, USA). Images for increment analysis were typically acquired with 400x magnification (though occasionally, larger otoliths were acquired at 200x). Growth increments along the postrostral axis were tagged using the Caliper Tool package of ImagePro Plus; individual increment widths and an estimate of radius (measured from the otolith's core to the outer edge of each ring) were recorded to the nearest $0.1 \mu \mathrm{m}$ for each tagged increment. The hatch check was identified by a marked increase (approx. 2 fold) in increment widths, indicating entry into the pelagic larval phase. Settlement checks were identified by a change in optical density of the otolith, as well as a sudden decrease (approx. 2 fold) in increment widths (see Kohn 2007 for more detail), indicating entry to the post-settlement stage. Samples were read once, by a single observer (A. C. Smith), and the reader was 'blind' to sample source, i.e. with samples being mixed and no information about the fish accompanying the otoliths. All unclear, abnormally shaped (nonlinear growth axis) sagittae were discarded. Out the 123 fish sampled, otoliths from 110 were included in the analysis. The 13 fish not included were distributed evenly across the treatment groups.

Daily increments from the pelagic larval stage of sampled otoliths provided estimates of four larval traits of young F. lapillum: (1) "Pelagic larval duration (PLD)", is an estimate of larval development time in days, and was estimated by the number of daily otolith increments counted in the larval stage of each sample (i.e., the interval between hatch check and settlement check). (2) "Early larval growth"' was estimated as 
the mean increment width across the first 7 days of larval growth following hatching. (3) "Late larval growth" was estimated as the mean increment width across the final 7 days of larval growth prior to settlement. (4) "Size-at-settlement" was estimated as the postrostral radius between otolith core and settlement check.

Juvenile growth rate was calculated as the mean daily increment width of (i) 010 days post-settlement and (ii) 11-20 days post-settlement, $\mu \mathrm{m} \mathrm{d}^{-1}$. Settlement date was calculated by subtracting age (i.e. the number of rings between settlement mark and outer edge of otolith) from the sample collection date.

\section{Quantifying variation in growth rates}

To investigate whether post-settlement growth rates showed a similar amount of variation within each habitat treatment, I calculated the co-efficient of variance $(\mathrm{CV})$ for each set of growth increments (0-10 days and 11-20 days post-settlement). Variation of a particular trait (e.g., growth) within a population can be quantified by calculating the $\mathrm{CV}$, given by the standard deviation / mean. I calculated the $\mathrm{CV}$ of juvenile $F$. lapillum (>10 days post-settlement) for fish collected from each replicate habitat patch $(\mathrm{n}=4)$ for each treament.

\section{Statistical analysis}

The use of otolith increments as a proxy for fish growth is based on the assumption that there is a strong relationship between somatic and otolith size. I verified this assumption by calculating a regression relationship between fish total length and otolith radius of newly settled and juvenile $F$. lapillum $\left(\mathrm{R}^{2}=0.75, \mathrm{p}<0.001\right.$, $\mathrm{n}=110)$. 
In order to assess whether measurements of otolith growth could be accurately compared among individual fish settling at different times during the samping period, I compared the regression lines slopes of fish total length and otolith longest axis (the postrostral radius between otolith core to otolith edge) of fish divided into settlement pulses depending on settlement date (estimated from otolith analysis) using the program SMATR (Warton et al. 2006). SMATR allows the comparison of regression slopes fitted using standardised major axis (SMA), major axis (MA) or ordinary least squares regression (OLS) techniques. No significant difference in slopes was observed (using SMA, MA or OLS methods) and therefore accurate comparisons of growth were applicable.

Larval growth, pelagic larval duration and size-at-settlement

To evaluate the potential influence of larval traits on one another, I explored the relationship between each larval trait. Because these attributes (early and late larval growth, pelagic larval duration and size-at-settlement) could be directly estimated for individuals regardless of their post-settlement age, all collected fish were used for this regression analysis.

\section{Distribution of larval traits of settling fish among habitat treatments}

The distribution of larval traits among juvenile fish inhabiting each habitat patch was initially explored to examine whether any habitat treatment(s) received a disproportionate number of high or low quality larvae than other habitats. I used an Mixed Analysis of Covariance (ANCOVA) model to evaluate covariance between habitat and each larval trait (early larval growth, late larval growth, PLD and size-atsettlement). Each larval trait was used as a dependent variable, habitat was included as 
a fixed factor and settlement date was included as a random factor. I was interested in patterns present at settlement, prior to any selective mortality, thus I only include fish that settled within the 24 hours prior to collection (i.e. aged as day 0 ) in this analysis.

\section{Relationships between juvenile growth, body condition and larval history}

I used stepwise backward multiple regressions to assess the presence of a relationship between each dependent variable (average growth rate 0-10 days, average growth rate 11-20 days and body condition index) and each larval trait (PLD, early larval growth rate, late larval growth rate, size-at-settlement). As samples were collected across a range of dates, temporal variation in each larval trait and/or temporal variation in the dependent variable may confound any correlation observed. Therefore I included settlement date as a random variable in the analysis. For each dependent variable, models were initiated with all four larval traits and settlement date. This analysis was done using the 'step' function in R (R Development Core Team 2006) which utilizes Akaike's information criterion (AIC), penalising any redundant model parameters, and removing the redundant parameters from the model (Crawley 2007). AIC can be used to calculate the relative weights of evidence for individual models within a set of competing models while accounting for differences in the number of model parameters.

\section{Effects of larval history and present habitat on growth}

I selected the variables which exhibited the strongest patterns of correlation; late larval growth and growth rate 0-10 days post-settlement, to investigate further. I used Analysis of Covariance (ANCOVA), to evaluate variation in post-settlement growth as a function of both late larval growth (i.e., prior history) and habitat treatment. In the full ANCOVA model I also included settlement date as a random factor to account for 
additional temporal variation in juvenile growth, and spatial block (i.e., row of grid) as a random factor also. Therefore the initial full ANCOVA model for juvenile growth rate (dependent variable) included; larval growth rate (as a covariate), habitat treatment (as an independent variable), the interaction of these variables (habitat x larval quality), plus spatial block and settlement date as random factors. Alternative reduced models were created by removing variables in a backwards step fashion using the 'step' function in R (R Development Core Team 2006) which utilizes Akaike's information criterion (AIC) to select the most parsimonious model.

\section{Selective mortality on larval history traits}

To evaluate whether mortality of juvenile $F$. lapillum might be selective on larval traits, I compared the distributions of measured larval traits (PLD, size-atsettlement, early larval growth and late larval growth) between recently settled fish ("settlers"; 0 days post-settlement) and older fish ("survivors"; 1-40 days postsettlement). Due to a low sample sizes, fish collected from all habitat treatments were pooled for this analysis. Settlers and survivors had showed a similar distribution of settlement dates (see Appendix 2). Distributions of larval traits (survivors versus settler) were compared using the non parametric Kolmogorov-Smirnov two-sample test (Sokal and Rohlf 2001, see also Gagliano et al. 2007 for a related example).

\section{Comparing growth trajectories among habitat treatments}

I used repeated measures Multivariate Analysis of Variance (MANOVA) and ANOVA to compare how the mean otolith growth rate $\left(\mu \mathrm{m} \mathrm{d}^{-1}\right)$ and mean otolith radius $(\mu \mathrm{m})$ of juvenile $F$. lapillum varied among habitat treatments through time (divided into 0-10 days and 11-20 days post-settlement). MANOVA and ANOVA models included 
habitat treatment as an independent variable, spatial block (i.e., row of grid) and settlement day as random factors.

As CV of juvenile growth were calculated for individual habitat patches (rather than individual fish as for growth trajectories), I performed a separate MANOVA and ANOVA analysis to compare CV of juvenile growth among habitat treatments. This model only contained a single independent variable (habitat treatment).

\section{Comparing body condition among habitat treatments}

I used an ANOVA to compare fish body condition residuals among habitat treatments. The ANOVA included habitat treatment as an independent variable, spatial block (i.e., row of grid) and settlement day as random factors.

\subsection{Results}

Larval growth, pelagic larval duration and size-at-settlement

A significant positive correlation existed between PLD and size-at-settlement $\left(\mathrm{R}^{2}=0.21\right.$, $\mathrm{P}=0.02)$, and also between early larval growth and size-at-settlement $\left(\mathrm{R}^{2}=0.11, \mathrm{P}=0.04\right)$. Fish that grew faster during the initial phase after hatching and/or fish that spent a longer time in the pelagic larval phase, had larger otoliths at settlement. No other significant correlations were observed among larval traits $(\mathrm{P}>0.05)$.

\section{Distribution of larval traits of settling fish among habitat treatments}

Macroalgal treatment (mixed macroalgal patches, monospecific Carpophyllum, single or double density monospecific Cystophora) had no significant effect on the larval traits exhibited by fish that had settled into the habitat within the prior 24 hours (Mixed ANCOVA; Early larval growth: $\mathrm{F}_{30,3}=1.13, \mathrm{P}=0.36$; Late larval growth: $\mathrm{F}_{30,3-}$ $=0.52, \mathrm{P}=0.66$; PLD: $\mathrm{F}_{30,3}=0.28, \mathrm{P}=0.83$; Size-at-settlement: $\left.\mathrm{F}_{30,3}=0.31, \mathrm{P}=0.82\right)($ Table 2.1). 
Table 2.1. The distribution of larval traits of fish that had recently settled into different habitat types (Mixed $=$ Carpophyllum and Cystophora, $\mathrm{Ca}=$ monospecific Carpophyllum, $\mathrm{Cy}=$ monospecific Cystophora, $2 \mathrm{x} \mathrm{Cy}=$ double density monospecific Cystophora). All fish had settled into the algae in the previous 24 hours.

\begin{tabular}{|lcccc|}
\hline Habitat & $\begin{array}{c}\text { Early larval growth } \\
\left(\mu \text { day }^{-1} \pm \text { SD }\right)\end{array}$ & $\begin{array}{c}\text { Late larval growth } \\
\left(\mu \text { day }^{-1} \pm \text { SD }\right)\end{array}$ & $\begin{array}{c}\text { PLD } \\
(\text { days } \pm S D)\end{array}$ & $\begin{array}{c}\text { Size-at-settlement } \\
(\mu \mathrm{m} \pm S D)\end{array}$ \\
\hline Mixed & $7.19 \pm 1.81$ & $8.29 \pm 2.20$ & $57.71 \pm 1.61$ & $29.16 \pm 1.95$ \\
Ca & $6.88 \pm 0.94$ & $7.39 \pm 0.87$ & $54.67 \pm 1.15$ & $28.52 \pm 2.44$ \\
Cy & $7.08 \pm 1.16$ & $8.52 \pm 1.50$ & $56.16 \pm 3.86$ & $28.16 \pm 3.70$ \\
2 x Cy & $6.39 \pm 1.61$ & $7.46 \pm 1.75$ & $56.35 \pm 5.32$ & $29.24 \pm 1.89$ \\
\hline
\end{tabular}

Relationships between juvenile growth, body condition and larval history traits

A summary table is given that provides mean values $( \pm \mathrm{SD})$ of phenotypic traits of juveniles used in this analysis (Table 2.2). The model that provided most parsimonious preditictive fit for growth rates in the first 10 days post-settlement contained only a single variable; late larval growth (AICc weight $=0.42$, Adj. $\mathrm{R}^{2}=$ 0.20). See Appendix 1 for details of AIC values for models tested. None of the models were found to be a significant predictor of growth rate 11-20 days after settlement, or of body condition (All models adj. $\mathrm{R}^{2}<0.1$ ).

\section{Effects of larval history and present habitat on post-settlement growth}

The most parsimonious ANCOVA model for growth rate 0-10 days after settlement only included the independent variables: habitat and late larval growth rate, with no interaction between them $\left(\right.$ AIC weight $=0.47$, Adj. $\left.\mathrm{R}^{2}=0.42\right)($ See appendix 1$)$. This indicates that none of the other larval traits in the model (early larval growth rate, PLD and size-at-settlement) appear to be important in predicting early juvenile growth of $F$. lapillum. The ANCOVA revealed a positive linear relationship between juvenile growth and late larval growth within all habitat treatments (Table 2.3, Figure 2.1). There 
was also a significant overall effect of habitat treatment on post-settlement growth, independent of larval growth (Table 1.1, Figure 1.1). Least squared means of postsettlement growth rate were higher in Mixed and Carpophyllum habitats compared to both Cystophora habitats (Tukey HSD, $\mathrm{p}<0.05$ ). This indicates that fish that have experienced any given larval growth rate, exhibit higher post-settlement growth rates when they settle to Mixed and Carpophyllum macroalgal patches compared to patches comprised of Cystophora.

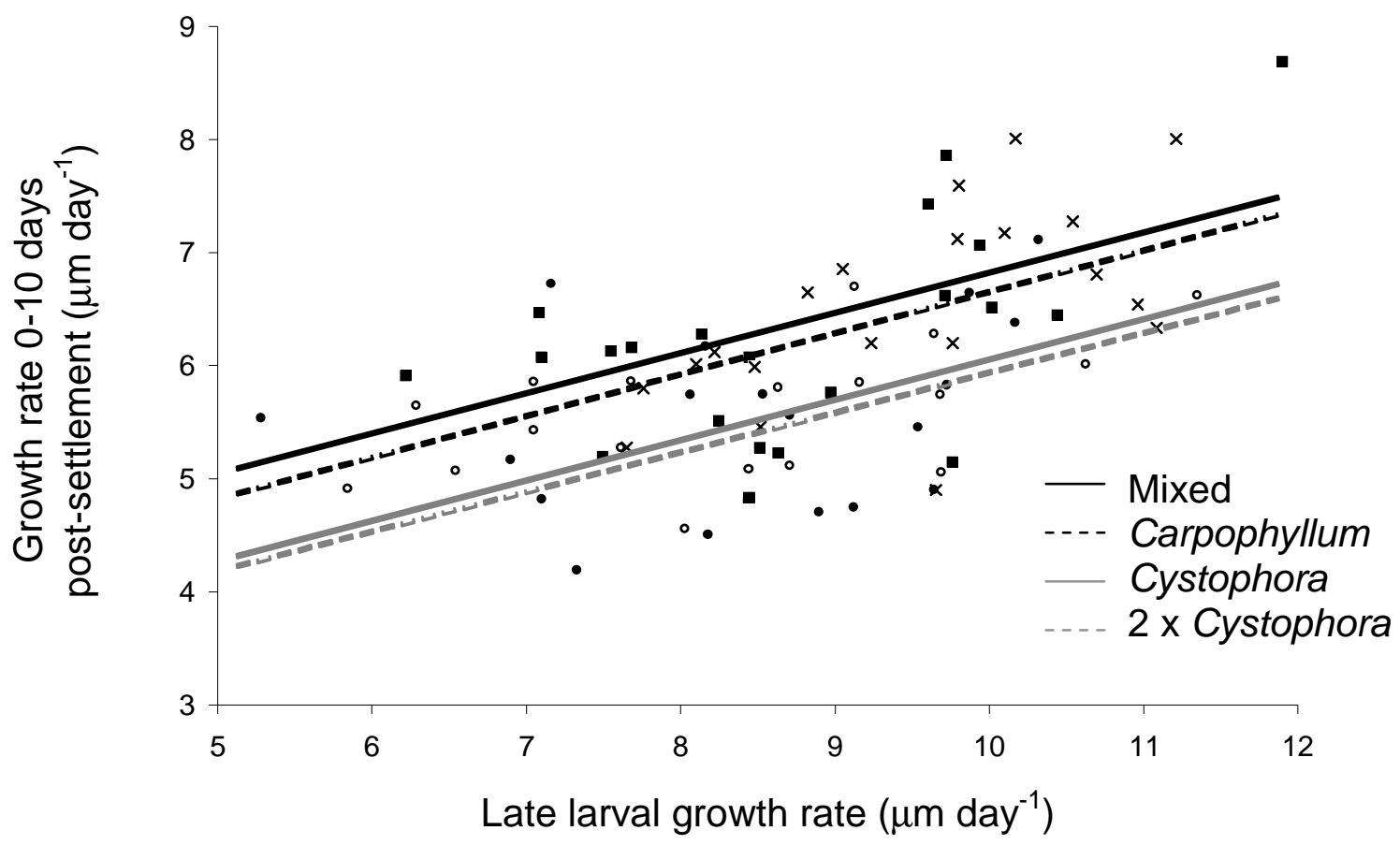

Figure 1.1 Effects of macroalgal habitat (experimental treatments) and prior history (larval growth rate, covariate) on growth performance of juvenile Forsterygion lapillum. Given are fitted lines from an ANCOVA (N; Mixed = 17 [cross symbol, black line], Carpophyllum $=15$ [open symbol, black dotted line], Cystophora $=16$ [square symbol, grey dotted line], double density Cystophora $=17$ [circle symbol, grey line]; Adjusted $\left.\mathrm{R}^{2}=0.42 ; \mathrm{p}<0.001\right)$. 
Table 2.2. Summary table of mean \pm SD values for the different variables examined for juvenile fish that were collected from different habitat types (Mixed= Carpophyllum and Cystophora, $\mathrm{Ca}=$ monospecific Carpophyllum, $\mathrm{Cy}=$ monospecific Cystophora, 2x Cy=double density monospecific Cystophora). All fish were older than 24 hours post-settlement (PS).

\begin{tabular}{|c|c|c|c|c|c|c|c|c|c|}
\hline Habitat & $\begin{array}{c}\text { Early larval } \\
\text { growth }(\mu \mathrm{m} \\
\left.\text { day }^{-1} \pm \mathrm{SD}\right)\end{array}$ & $\begin{array}{c}\text { Late larval } \\
\text { growth } \\
\left(\mu \text { day }^{-1} \pm \mathrm{SD}\right)\end{array}$ & $\begin{array}{c}\text { PLD } \\
\text { (days } \pm S D)\end{array}$ & $\begin{array}{c}\text { Size-at- } \\
\text { settlement } \\
(\mu \mathrm{m} \pm \mathrm{SD})\end{array}$ & $\begin{array}{l}\text { PS Age } \\
\text { (days) }\end{array}$ & $\begin{array}{l}\text { Standard } \\
\text { length } \\
(\mathrm{mm})\end{array}$ & $\begin{array}{c}\text { Growth } \\
\text { 0-10 days PS }(\mu \mathrm{m} \\
\left.\text { day }^{-1} \pm \mathrm{SD}\right)\end{array}$ & $\begin{array}{c}\text { Growth } \\
\text { 11-20 days PS } \\
\left(\mu \text { day }^{-1} \pm \text { SD }\right)\end{array}$ & $\begin{array}{l}\text { Juvenile body } \\
\text { condition index }\end{array}$ \\
\hline Mixed & $7.19 \pm 1.81$ & $9.48 \pm 1.12$ & $57.71 \pm 1.61$ & $29.16 \pm 1.95$ & $22.63 \pm 16.28$ & $24.89 \pm 2.32$ & $6.52 \pm 0.67$ & $6.06 \pm 0.67$ & $0.08 \pm 0.14$ \\
\hline $\mathrm{Ca}$ & $6.88 \pm 0.94$ & $8.47 \pm 1.54$ & $54.67 \pm 1.15$ & $28.52 \pm 2.44$ & $19.00 \pm 10.32$ & $24.91 \pm 2.31$ & $6.44 \pm 0.79$ & $6.48 \pm 0.84$ & $-0.02 \pm 0.16$ \\
\hline $\mathrm{Cy}$ & $7.08 \pm 1.16$ & $8.57 \pm 1.89$ & $56.16 \pm 3.86$ & $28.16 \pm 3.70$ & $24.96 \pm 17.28$ & $24.71 \pm 2.32$ & $5.79 \pm 0.70$ & $5.27 \pm 0.74$ & $-0.03 \pm 0.15$ \\
\hline $2 \mathrm{x}$ Cy & $6.39 \pm 1.61$ & $8.74 \pm 1.59$ & $56.35 \pm 5.32$ & $29.24 \pm 1.89$ & $23.65 \pm 14.49$ & $24.93 \pm 1.94$ & $5.80 \pm 0.94$ & $5.82 \pm 0.97$ & $-0.01 \pm 0.09$ \\
\hline
\end{tabular}


For each habitat treatment, the slopes appear to be statistically similar (slope \pm

S.E $;$ mixed $=0.37 \pm 0.15$, Carpophyllum $=0.24 \pm 0.11$, Cystophora $=0.33 \pm 0.12$, double density Cystophora $=0.26 \pm 0.10$ ). This indicates that approximately the same strength of growth advantage conferred by pre-settlement growth rate across all habitats (Fig. 2.1).

Table 2.3. ANCOVA results showing the effect of late larval growth rate and habitat treatment (Mixed, Carpophyllum, Cystophora or double density Cystophora) on otolith growth rate in the first 10 days following settlement. The interaction (larval growth rate $\mathrm{x}$ habitat), plus the individual terms, settlement date and spatial block, were all removed from the analysis (using AICc criteria, see Methods for full description) to give the reduced model shown here.

\begin{tabular}{|llrrc|}
\hline Source & DF & SS & $F$ & $P$ \\
\hline Late larval growth & 1,65 & 10.51 & 22.35 & $<\mathbf{0 . 0 0 0 1} *$ \\
Habitat & 3,65 & 4.42 & 3.13 & $\mathbf{0 . 0 3 1}^{*}$ \\
Error & 1,65 & 44.12 & & \\
\hline
\end{tabular}

\section{Selective mortality on larval history traits}

The distribution of late larval growth rates between survivors and settlers differed significantly (Two-sample Kolmogorov-Smirnov test; $\mathrm{D}=0.3944, \mathrm{p}=0.009$ ). The survivor group had a higher mean larval growth rate and a lower amount of variation in larval growth rate (Figure 2.2). No significant differences between survivors and settlers in the distributions in PLD, early larval growth or size-atsettlement were observed (PLD: $\mathrm{D}=0.2007, \mathrm{p}=0.61$, early larval growth: $\mathrm{D}=0.1950$, $\mathrm{p}=0.54$, size at settlement: $\mathrm{D}=0.0872, \mathrm{p}=0.97)$.

\section{Comparing growth trajectories among habitat treatments}

Otolith growth profiles differed significantly among fish from different habitat treatments (Table 2.4). During the first 10d following settlement, fish that settled 
within the mixed macroalgal treatment grew $10 \%$ faster than fish settling to patches of Cystophora at either low or high density. Similarly, fish collected from patches comprised of Carpophyllum grew 11\% faster than both Cystophora treatments (Table 2.4, Fig. 2.3a). There was no significant difference between growth rates in the first 10 days of fish sampled from Carpophyllum and mixed macroalgal patches.

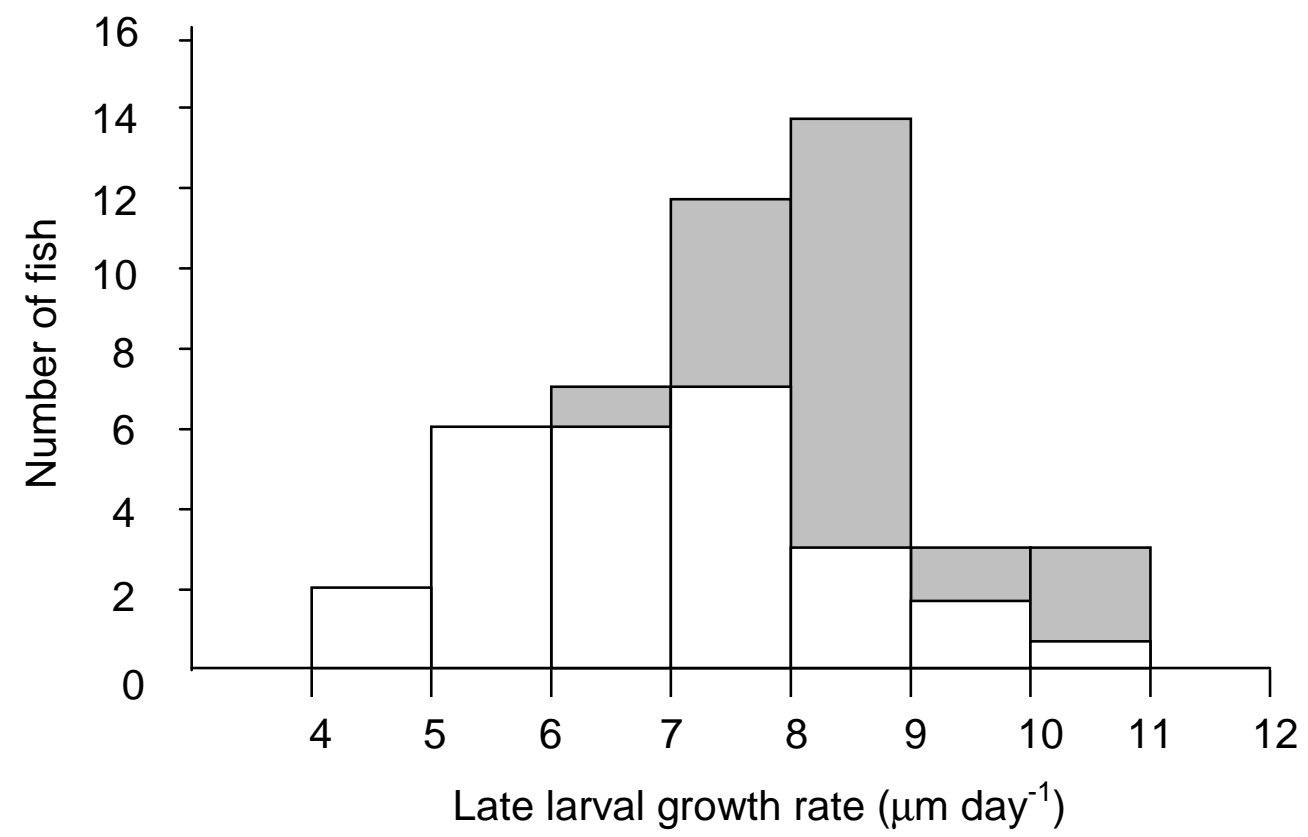

Figure 1.2. Histograms showing the distribution of larval growth rates for younger (settler group; 0 days old; mean larval growth rate $\pm \mathrm{SD}=8.01 \pm 1.69 ; \mathrm{CV}=21.14$ [unshaded bars]) and older juveniles (survivor group; 1-40 days old; mean larval growth rate $\pm \mathrm{SD}=8.91 \pm 1.47 ; \mathrm{CV}=16.49$ [shaded bars]) of Forsterygion lapillum.

During the first 10d following settlement, fish within mixed macroalgal treatments exhibited $65 \%$ less variable than those of fish collected from Carpophyllum and Cystophora treatments, and $80 \%$ less variable than those from double density Cystophora treatment (Fig. 2.3c). After 10d fish within all treatments, except fish within double density Cystophora, exhibited a decrease in growth rates. Different patterns in growth trajectories resulted in a difference in growth rates among habitats decreasing from 11-20d. Differences in the level of variation among the habitat 
treatments declined from 11-20 d. Despite differences in growth rates decreasing, by day 20, fish within mixed macroalgal habitats were of significantly larger size than any other habitat (Fig. 2.3a).
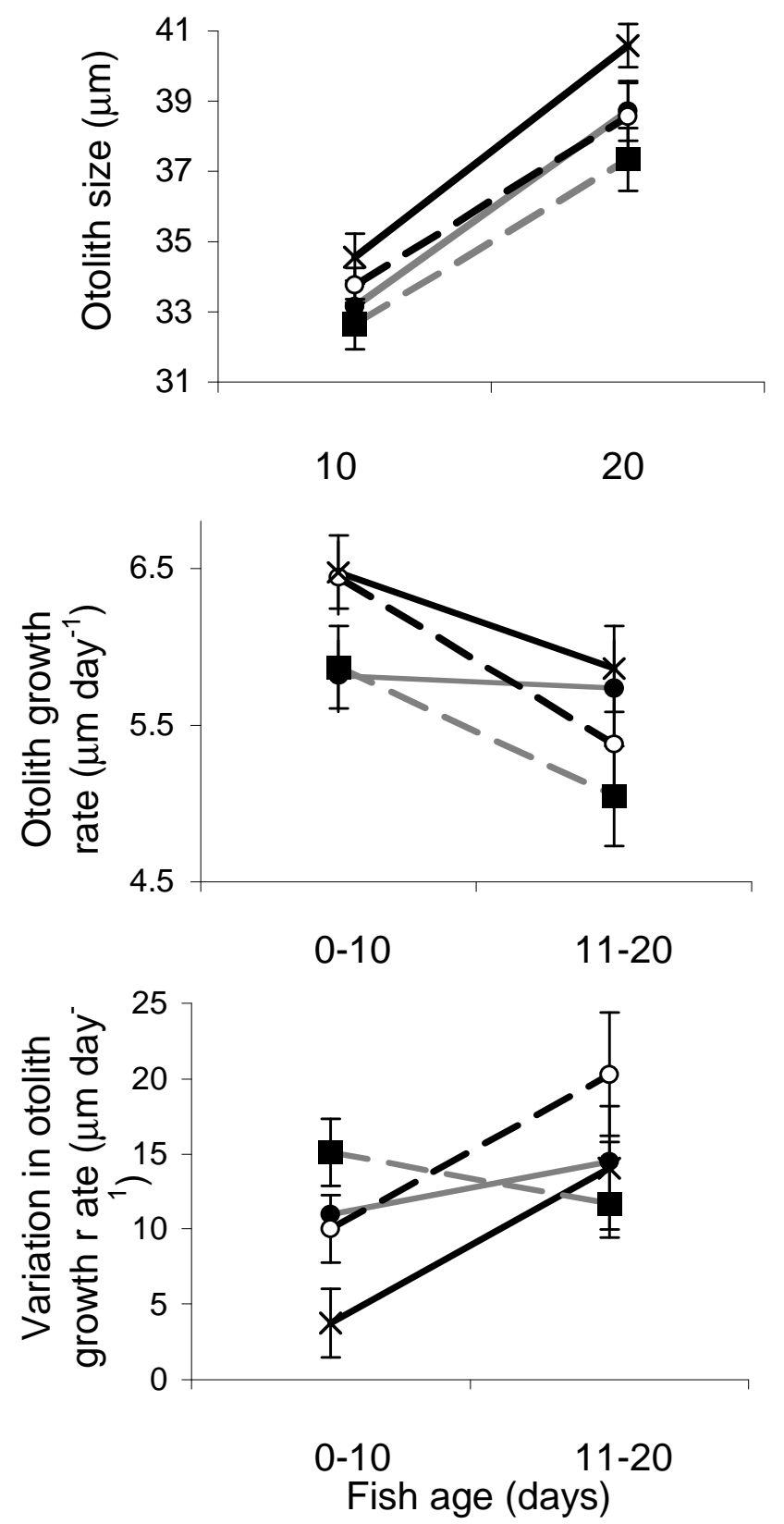

Figure 2.3 Effect of macroalgal treatment on a) otolith growth rate and (b) otolith radius at age of juvenile Forsterygion lapillum. Given are means $\pm 1 \mathrm{SE}(\mathrm{N}$; Mixed $=16$, Carpophyllum $=14$, Cystophora $=13$, double density Cystophora $=13$ ). 
Table 2.4 Results of repeated-measures MANOVA a, within-subject effects and b, between subject effects that compared (i) otolith radius (mm) at age, (ii) daily otolith growth rate $\left(\mathrm{mm} \mathrm{d}^{-1}\right)$ and (iii) $\mathrm{CV}$ of daily growth of fish from four different habitat treatments (Mixed, Carpophyllum,

Cystophora and double density Cystophora). Significant results are in bold.

\begin{tabular}{|c|c|c|c|c|c|c|c|}
\hline a. Factor & $d f$ & $F$ & $P$ & b. Factor & $d f$ & $F$ & $P$ \\
\hline (i) Radius at age & & & & (i) Time & 1,53 & 1888.38 & $<0.001$ \\
\hline Habitat & 3 & 0.88 & 0.456 & Time*Habitat & 3,53 & 3.19 & 0.032 \\
\hline Block & 3 & 0.34 & 0.796 & Time*Block & 3,53 & 1.52 & 0.22 \\
\hline (ii) Daily growth & & & & (ii) Time & 1,53 & 13.21 & $<0.001$ \\
\hline Habitat & 3 & 4.05 & 0.012 & Time*Habitat & 3,53 & 3.08 & 0.036 \\
\hline Block & 3 & 1.86 & 0.149 & Time*Block & 3,53 & 0.30 & 0.819 \\
\hline (iii) $\mathrm{CV}$ of daily growth & & & & (iii) Time & 1,12 & 1.38 & 0.262 \\
\hline Habitat & 3 & 4.68 & 0.022 & Time*Habitat & 3,12 & 0.69 & 0.574 \\
\hline
\end{tabular}




\section{Comparing body condition among habitat treatments}

Fish from mixed macroalgal patches had higher body condition than those sampled from all other habitats, with body condition being 7\%, 8\% and $10 \%$ higher in mixed macroalgal patches relative to Carpophyllum, single density Cystophora and double density Cystophora treatments respectively $\left(\mathrm{F}_{3,127}=4.27, \mathrm{p}<0.01\right)$ (Fig. 2.4).

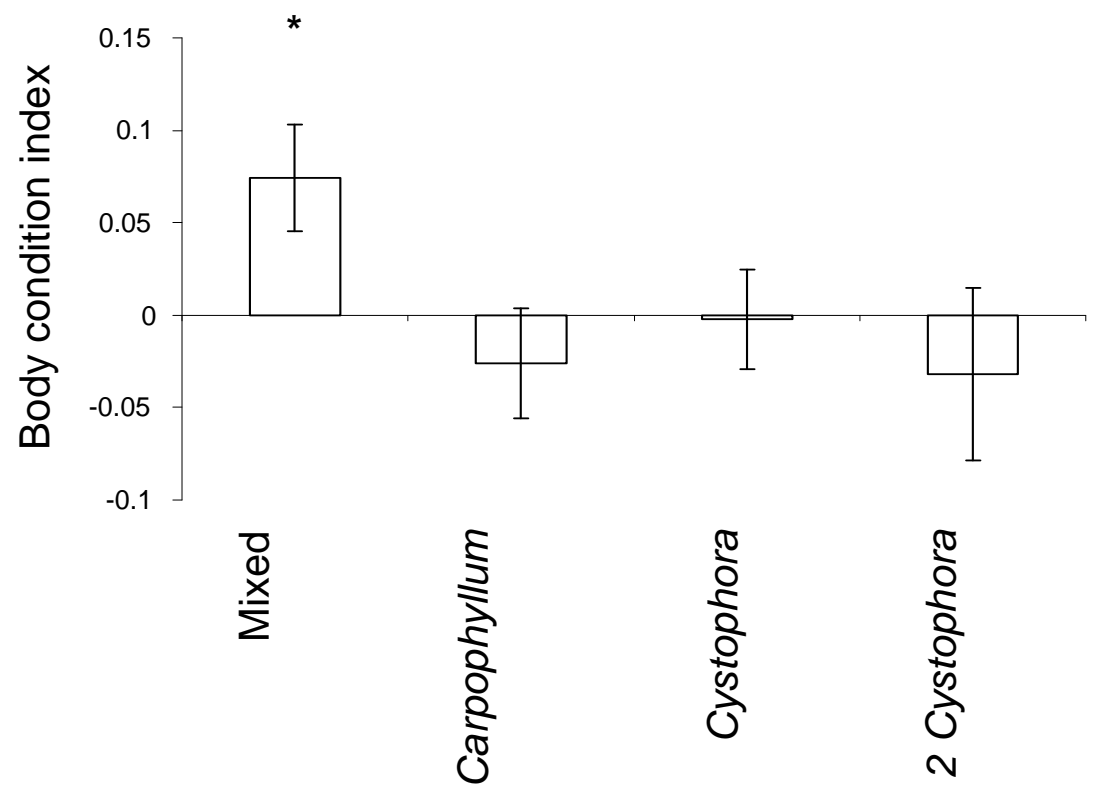

Figure 2.4 Effect of macroalgal treatment on body condition index of juvenile Forsterygion lapillum. Given are means $\pm 1 \mathrm{SE}(\mathrm{N}$; Mixed $=17$, Carpophyllum $=15$, Cystophora $=17$, double density Cystophora $=17$ ). Treatments that differ in their associated symbol (either absent or *) are statistically different as revealed by a poststatistical test (Tukey HSD, $\mathrm{p}<0.05$ )

\subsection{Discussion}

Nursery habitats have been the focus of much research, but only a handful of studies have incorporated the role of preceding life history into understanding habitat effects on juvenile stages. Larval growth history is an important determinant of growth 
and survival immediately after settlement (Searcy and Sponaugle 2001, Shima and Findlay 2002, McCormick and Hoey 2004, Johnson 2008). Rapid larval growth rates may be indicative of favorable parental effects (e.g. maternal condition, genetics) and/or pelagic conditions. Previous studies have demonstrated that late larval growth can be positively correlated with higher physiological condition at settlement in reef fish, e.g. as measured by lipid concentrations (Hovenkamp and Witte 1991, McCormick and Molony 1992, Suthers et al. 1992, Green and McCormick 1999). I found that late larval growth, was positively correlated with initial post-settlement growth and persistence on the reef. This supports the findings of other studies on reef fish that have found larval growth can influence post-settlement performance (Searcy and Sponaugle 2001, Bergenius et al. 2002, Shima and Findlay 2002, Wilson and Meekan 2002, McCormick and Hoey 2004, Johnson 2008). Furthermore, my results indicate that initial postsettlement growth is also dependent on macroalgal species composition. For any given larval growth rate, subsequent growth will vary depending on the macroalgal habitat to which the individual settles (i.e. the intercept of the linear relationship between postsettlement and larval growth varies with habitat, but it appears the slope may not vary). In rocky reef systems, macroalgae are likely to increase juvenile fish performance by providing refuge against predation and/or by increasing food resources that are accessible to juveniles, such as a range of small epibiota (Edgar and Moore 1986, Carr 1989, Dahlgren and Eggleston 2000, Ryer et al. 2004). Although Carpophyllum maschalocarpum and Cystophora torulosa are structurally similar, they do vary in complexity on a fine-scale. Carpophyllum maschalocarpum has been reported as being more coarsely structured, with a higher mean thallus width than Cystophora torulosa (Taylor and Cole 1994). Greater structural complexity may reduce competitive interactions and rates of predation on juvenile fish (Almany 2004, Johnson 
2007), however in this study fish inhabiting Carpophyllum stands appear to perform better despite this seaweed being less structurally complex. These seaweed species have also been shown to support distinctly different epifauna (i.e. potential prey for fish; Feary et al. 2009) (Taylor and Cole 1994, Tuya et al. 2008). Food availability can strongly influence growth rate, and this may explain the differences observed in growth of fish among macroalgal treatments. Furthermore, I found no positive effects of increased plant density in monospecific Cystophora patches on fish density, growth rate or body condition. A positive affect of plant density on fish performance would be expected if a resource such as refuge availability was responsible for driving variation in fish density and growth rate (e.g., Holbrook and Schmitt 2002). However if the abundance of prey species, which are more commonly associated with algae such as Carpophyllum rather than Cystophora, are a limiting factor, then an increase in Cystophora plant density may not be expected to increase prey availability. As mixed macroalgal patches contain both forms of macroalgal structure, this may have increased overall fine-scale structural complexity within patches, relative to monospecific habitat patches. This may have increased the diversity and abundance of associated epifauna (Taylor and Cole 1994, Kraufvelin and Salovius 2004), as well as providing refuge from predation, resulting in increased feeding rates, leading to higher body condition as observed in this study.

I found no relationship between size-at-settlement, early larval growth and PLD with fish growth and/or body condition. This result fits with several other studies that have found no affect of PLD on growth and survival on reef fish while larval growth had a positive effect (e.g., Shima and Findlay 2004, Nemeth 2005, Raventos and Macpherson 2005, Gagliano et al. 2007). There are more frequent reports of size-atsettlement being indicative of faster growth following settlement and a higher juvenile 
survival rate (e.g., Vigiola and Meekan 2002). However other studies have questioned the generality of the 'bigger is better concept' (Litvak and Leggett 1992, Pepin et al. 1992) and the intensity of size-selective mortality may vary year to year (Meekan and Fortier 1996). In this study, size-at-settlement was positively correlated to pelagic larval duration, and detrimental consequences of a longer developmental time may be outweighing potential advantages of being of a larger size-at-settlement.

Growth advantages from faster growth during the late larval period are not maintained long into benthic life, with no correlation being between post-settlement growth and larval growth being observed after 10 days. This emphasizes that strong directional mortality may be acting in relatively narrow temporal window (Sogard 1997, Searcy and Sponaugle 2001). Due to being highly vulnerable to predation, juvenile fish will face a strong trade-off between eating (i.e. growth) and being eaten (i.e. mortality) (Martel 1996). Several predatory fish species were observed within the experimental area during the study, such as Parapercis colias and Notoclinus compressus. Given that potentially important predators such as the highly cryptic $N$. compressus show high levels of habitat specificity, occurring only within foliose algae (Clements 2003), such predatory species may vary in abundance among patches varying in macroalgal composition (for example $N$. compressus has been reported to occur in higher densities within Cystophora species compared to Carpophyllum maschalocarpum; K. D. Clements, personal communication). If predation risk was perceived to be higher in Cystophora habitats this may explain the initial period of reduced growth observed for fish in both these habitats. After 10 days, fish within double density Cystophora habitat patches appeared to show some growth compensation for an initial period of reduced growth. Compensatory growth is a well documented in fishes (reviewed in Ali et al 2003), and a similar observation of flexible growth trajectories during early benthic life 
has been reported for a tropical damselfish (Gagliano and McCormick 2007). This change in growth trajectory may represent a change in the relative trade-off between growth and predation risk as fish increase in size. Alternatively it may be due to changes in conspecific density through time within each habitat type. Fish within Cystophora habitats may have been subject to higher mortality rates in the first few days following settlement, and after this initial period, densities of fish may have been reduced. Surviving fish may then be able to maximise growth, due to reduced competition for food or refuges. Rates of competition may also explain the difference in growth trajectories between single density and double density habitats, with fish in double density habitats experiencing reduced competition for resources. Further experimentation is needed to unravel the mechanisms that result in juvenile $F$. lapillum inhabiting mixed habitats having higher growth and body condition.

Overall, the implications of this study suggest that it is important to consider larval growth rates, especially if juvenile mortality is size- or growth-dependent, as well as if juvenile traits are used to infer quality of the juvenile environment. Future work should recognize the role dynamic environments play in the ability to detect dependence of traits between earlier and later ontogenetic stages. 


\title{
Chapter 3
}

\section{Variation in the effects of larval history on juvenile performance}

\author{
of a temperate reef fish
}

\subsection{Abstract}

Many organisms develop and grow through a succession of discrete life-history stages that often have unique physiological requirements and ecological challenges. Phenotypic and/or physiological traits acquired in one stage (e.g., larvae) can propagate to future stages (e.g., juveniles or adults), and such "carry-over effects" can shape fitness and phenotypic distributions within a population. However, variation in the strength of carry-over effects, and how these might be mediated by environmental variability in the wild, is poorly known. Here, I evaluate variation in the strength of carry-over effects that link larval growth histories to juvenile performance (growth and survival), for a reef fish (Forsterygion lapillum) common to rocky reefs of New

Zealand. I used otoliths to reconstruct demographic histories of recently settled fish that were sampled across cohorts, sites and microhabitats. I quantified sources of variation in the strength of carry-over effects and selective mortality that operate on larval growth histories. I found overall evidence for carry-over effects: individuals that grew fast as larvae tended to experience proportional growth advantages as juveniles. However, the strength of these carry-over effects also varied among cohorts, sites and microhabitats. Specifically, carry-over effects conveyed a stronger growth advantage on some microhabitats (e.g., mixed stands of macroalgae) relative to others (e.g., monocultures of Carpophyllum maschalocarpum) for some cohorts and sites only. For other cohorts and sites, carry-over effects were either indistinguishable between microhabitats or else 
not evident. Similarly, the intensity of selective mortality varied among cohorts, sites and microhabitats: for the cohort and site where carry-over effects differed between microhabitats, I also observed a 3-fold increase in selective intensity on Carpophyllum relative to mixed algal stands. Overall, our results highlight the potential for carry-over effects, selective intensity, and the ecological and evolutionary consequences of these to vary through space and time in a context-dependent manner.

\subsection{Introduction}

Many organisms undergo discrete stages of development, punctuated by major life-history transformations (e.g. tadpoles to frogs, caterpillars to butterflies). Often, physiological requirements and ecological challenges differ markedly between these stages, and this may lead some researchers to focus on particular life-history stages in relative isolation. Nonetheless, successive developmental stages are connected across the life-history of individuals, metamorphosis is generally not a "new beginning" (reviewed in Pechenik 2006), and the physiological experiences and resultant phenotypes from one stage can "carry-over" to affect fitness of subsequent developmental stages (Madsen and Shine 2000, Phillips 2002, 2004, Marshall et al. 2003, Marshall and Keough 2004, Hoey and McCormick 2004, Scott et al. 2007).

Carry-over effects have been documented for a wide variety of organisms. Developmental histories have been shown to influence subsequent growth rates of fishes (e.g. McCormick and Hoey 2004), amphibians (e.g. Altwegg and Reyer 2003), terrestrial invertebrates (e.g. Jannot 2009), and aquatic invertebrates (e.g. Wacker and von Elert 2002). Carry-over effects on growth can increase variation in size structure, because individuals with unfavourable traits (e.g. arising from earlier developmental experiences) may tend to grow more slowly while individuals with more favourable 
traits may grow rapidly. Resulting variation in organism sizes can lead to concomitant variation in fitness (e.g. survival and/or future reproductive potential, Crowder et al. 1992, Ohgushi 2008).

The ecological implications of growth-related carry-over effects are not straightforward, and these will likely depend upon (1) the underlying patterns of initial phenotypic or physiological variation, (2) the strength of the carry-over effect (i.e., the degree of coupling across life-history stages and relative advantages that can be propagated to subsequent stages), and (3) the ecological context within which these effects ultimately play out. Importantly, all of these factors can vary in natural systems: within and among local populations, and through time-yielding a number of potential outcomes. For example, if (i) variation in early developmental histories is prevalent among individuals within a local population, and (ii) carry-over effects are strong, and (iii) the local ecological context (e.g. predator density) affects fitness, then growthrelated carry-over effects may strongly promote selective mortality and affect the fitness and phenotypic distributions of survivors within the local population. Very different outcomes may be expected under alternative scenarios (e.g. where variability in developmental histories is minimal or occurs primarily among- rather than within local populations; or, where carry-over effects are weak; or, where fitness is not strongly influenced by ecological context).

Carry-over effects operate on- and potential accentuate the intrinsic variation among individuals. This variation can facilitate natural selection (i.e., selective mortality) on phenotypes and/or physiological traits that were established earlier in the developmental history of an individual (e.g. in a prior developmental stage, irrespective of present conditions). While these effects appear to be important for many species, extrinsic factors (e.g. environmental variation, habitat quality, local community 
structure experienced by the present life-history stage) provide an additional set of proximate mechanisms that can strongly affect variation in growth and survival of individuals (Tupper and Boutilier 1997, Relyea and Hoverman 2003). Little is known about the potential for extrinsic variability to interact with (and potentially mediate) the strength and importance of carry-over effects (i.e., intrinsic variation) on growth and survival.

Here, I evaluate variation in carry-over effects, and potential interactions between intrinsic (individual) and extrinsic (environmental) variation on patterns of growth and survival of a temperate reef fish. Our focal study species has a life-history that is common to many marine reef organisms: larvae develop for an extended period of time in offshore waters before settling to reef habitats. A substantial body of literature suggests that this life-history pattern is conducive to carry-over effects (e.g., Searcy and Sponaugle 2001, Shima and Findlay 2002, Vigliola and Meekan 2002, Phillips 2002, 2004, McCormick and Hoey 2004, Giménez 2004, 2006). Environmental variability operates over a range of temporal and spatial scales. At large spatial scales, local populations can be subject to different wave exposure, temperature and predation pressure. Over small scales variation in microhabitat composition may influence habitat complexity resulting in microhabitat-specific variation in juvenile performance. I sampled cohorts of recently settled reef fish from different sites and microhabitats, and I reconstructed growth histories of individuals during their larval (pre-settlement) stage and the juvenile (post-settlement) stage. I expect to find patterns of variation in the strength of carry-over effects on growth and in the intensity of selective mortality between microhabitats and across cohorts and sites. 


\subsection{Methods}

Study system and sampling regime

I quantified life-history traits and demographic performance of the common triplefin, Forsterygion lapillum near Wellington, New Zealand. A full description of the species biology is included in Chapter 1 . Briefly, F. lapillum larvae spend $\sim 55$ days in the pelagic phase before settling back to the shallow subtidal reef. Larval phenotypes (e.g., growth, PLD) are variable among individuals, and these traits appear to be shaped by larval developmental environments (Shima and Swearer 2009). Specifically, larvae with environmental signatures consistent with development in a semi-enclosed embayment (Wellington harbour) grow faster and settle sooner than larvae that putatively develop along the Wellington south coast, irrespective of natal origin (Shima and Swearer 2009). (e.g., temperature, turbidity, densities of potential predators and competitors (A. Smith and J. Shima, unpublished data).

I sampled recently settled F. lapillum in January and February 2008 at a site within Wellington harbour (Kau Bay, $41^{\circ} 17^{\prime} \mathrm{S}, 174^{\circ} 50 \mathrm{E}$ ) and a site on the adjacent Wellington south coast (Island Bay, $41^{\circ} 20^{\prime}$ S, $174^{\circ} 46^{\prime}$ E). These sites were chosen because they are known to be replenished by larvae with different phenotypes (e.g., Shima and Swearer 2009, in press), and because they differ in local environmental conditions such as wave exposure, temperature and the abundance of predator and competitor species. Kau Bay, located within the comparatively sheltered Wellington Harbour, is exposed to northerly winds and protected from southerly swells, with recorded sea temperatures of $16.8{ }^{\circ} \mathrm{C}( \pm 1.0 \mathrm{SD})$ during the study period. Island Bay, is partially protected from periodic large southerly swells by a small offshore island (Taputeranga Island), and during the study period had average sea temperatures of 15.0 ${ }^{\circ} \mathrm{C}( \pm 1.4 \mathrm{SD})$. The overall abundance of fish species is higher at Kau Bay compared to 
Island Bay, adult $F$. lapillum were found to be approximately 3 times more abundant in Kau Bay and predators of F. lapillum, such as Parapercis colias, appear to also be more abundant within Kau Bay (A. Smith and A. Perez-Matus, unpublished data) Macroalgal canopy (i.e., the settlement habitat for $F$. lapillum) is patchily distributed within both sites, and is predominately comprised of two species of fucalean brown algae, Carpophyllum maschalocarpum and Cystophora torulosa (A. Smith, personal observations). At each site I identified a representative area of reef $\sim 10 \mathrm{~m}$ long (parallel to the shore), $5 \mathrm{~m}$ wide, and at a depth of $\sim 6 \mathrm{~m}$; from within these areas I collected recently settled $F$. lapillum (individuals $<40 \mathrm{~mm} \mathrm{SL}$ ) with hand nets (and aided by the use of SCUBA). Because I were interested in the potential effect of microhabitat on life-history traits and demographic performance of $F$. lapillum, I further stratified our sampling within two distinct types of settlement habitat: (1) monocultures of Carpophyllum, or (2) mixed algal stands (generally comprised of Carpophyllum and Cystophora). During each sampling event, I collected fish from 4 separate $1 \mathrm{~m}^{2}$ quadrats, placed haphazardly within of each of these two microhabitats. Quadrats delineated the holdfasts and an overstory of stipes and fronds (i.e., the canopy), and these components of the microhabitat were all thoroughly sampled. I collected fish on three dates, paired (as closely in time as weather and sea conditions would permit) between locations (Harbour: 16-Jan, 15-Feb, 29-Feb; South coast: 21-Jan, 13-Feb, 22Feb).

Quantifying age and growth histories before and after settlement

To quantify age and growth histories of individuals, I extracted and analyzed sagittal otoliths ('ear stones') of recently settled F. lapillum. Otoliths of many fishes 
(including $F$. lapillum) form in daily growth increments that can be used to infer stagespecific age and growth patterns of individuals (e.g., Campana and Thorrold 2001, Hare and Cowen 1995, Shima and Findlay 2002, Sponaugle et al. 2006). Otoliths were prepared following the methods of Shima and Swearer (2009). I used an image analysis system consisting of a compound microscope, a digital camera, and computer-based image analysis software (Image Pro Plus v5.0), to measure sequences of daily otolith increment widths from different stages of the life history of each sampled fish. I estimated 'late larval growth rate' as the average increment width $\left(\mu \mathrm{m} \mathrm{d}^{-1}\right)$ across the final $7 \mathrm{~d}$ of larval growth prior to the distinct settlement mark that was visible on each otolith (Kohn 2007). I estimated 'post-settlement age' from the number of daily growth increments following the settlement mark, and this facilitated a back-calculation of 'settlement date' from the known date of collection. I estimated 'average juvenile growth rate' as the average increment width $\left(\mu \mathrm{m} \mathrm{d}^{-1}\right)$ across the entire juvenile period (i.e., from settlement to capture; mean post-settlement age of sampled fish $=10.74 \mathrm{~d}$, $\mathrm{SD}=10.68$ ), and I identified two discrete settlement cohorts in our sample (see Results).

\section{Quantifying density}

I calculated density as the number of fish collected from each quadrat. I used a one-way ANOVA to compare mean density across each site, cohort and microhabitat. The ANOVA model included site, cohort and microhabitat, plus all interactions (site $\mathrm{x}$ cohort, site x microhabitat, cohort x microhabitat, site x cohort x microhabitat).

\section{Variation in carry-over effects on growth}

Demographic performance in the post-settlement stage of many marine organisms is not decoupled from prior life history. However, the strength of carry-over 
effects may vary through time (e.g., among cohorts that experience different environmental conditions during their larval development), and/or these may be mediated by local environmental conditions (e.g., habitat quality; Searcy et al. 2007) in the post-settlement stage. I expected a priori that fish sampled from different cohorts and sites would differ in their growth histories (particularly given our prior observations of variation among sites within the harbour versus the open coast; Shima and Swearer 2009 , in press). Furthermore, I hypothesized that microhabitats might play a role in mediating the pattern and strength of carry-over effects (i.e., the degree of coupling between growth in the larval and post-settlement stages). Separately for each cohort and site, I evaluated variation in the relationship between juvenile growth and larval growth across the two sampled microhabitats (Carpophyllum monoculture versus mixed algal stands) using ANCOVA (PROC GLM, SAS v9.2).

\section{Variation in intensity of selective mortality}

Variation in individual phenotypes (e.g., larval growth histories) can facilitate selective mortality in subsequent life history stages (e.g., Searcy and Sponaugle 2001). I hypothesized that the strength of selection on individual phenotypes related to late larval growth varies among cohorts, sites and microhabitats. I used z-scores (Zar 1984) to estimate the pattern and magnitude of post-settlement selective mortality operating on late larval growth rate. I calculated the z-score (i.e., normal deviate) for each individual relative to late larval growth rates recorded from new settlers (Figueira et al. 2008), as: $\mathrm{Z}=(\mathrm{X}-\mu) / \sigma$, where $\mathrm{X}$ is the late larval growth rate of an individual fish, $\mu$ is the sample mean (i.e., mean late larval growth rate of all 'settlers', defined as individuals with a post-settlement age $=0$ sampled from a given site and cohort), and $\sigma$ is the sample standard deviation. I evaluated variation in selective intensity (z-score) between 
microhabitats (Carpophyllum monoculture versus mixed algal stands), separately for each cohort and site. Because individuals varied in post-settlement age (and hence, time for selection to operate), I analyzed variation between microhabitats using ANCOVA (PROC GLM, SAS v9.2), with post-settlement age as a covariate. Least-square means from this model were used as our estimate selective intensity, and I tested the null hypotheses that (1) selective intensity was not different between the two microhabitats and (2) that selective intensity was $=0$ for each microhabitat.

\subsection{Results}

I identified two discrete settlement cohorts in our sample: fish identified as cohort 1 settled between 10 Jan 2008 and 22 Jan 2008, and fish identified as cohort 2 settled between 8 Feb 2008 and 20 Feb 2008 (Fig 3.1A). The distributions of settlement dates for the two cohorts were similar for each site and microhabitat. Larval growth rates were variable (Fig 3.1B) and motivated our exploration of the consequences of this variation on juvenile growth (via carry-over effects) and survival (via selective intensity). Density of fish sampled from within each quadrat did not significantly vary among sites, cohorts and/or microhabitats $\left(\mathrm{F}_{7,31}=0.80, \mathrm{P}=0.59\right.$; Table 3.1).

Table 3.1 The density of fish $\left(\mathrm{m}^{-2}\right)$ collected from each site (Island bay or Kau bay), cohort (1 or 2) and microhabitat (Carpophyllum monoculture or mixed algal stands).

\begin{tabular}{|ll|cc|}
\hline \multirow{2}{*}{ Site } & Microhabitat & 1 & \multicolumn{2}{|c|}{ Cohort } \\
\hline Island Bay & Carpophyllum & $3.0 \pm 1.8$ & $5.5 \pm 3.7$ \\
& Mixed & $3.5 \pm 1.7$ & $3.3 \pm 0.6$ \\
Kau Bay & Carpophyllum & $5.3 \pm 3.3$ & $7.0 \pm 2.7$ \\
& Mixed & $3.8 \pm 0.9$ & $5.0 \pm 6.1$ \\
\hline
\end{tabular}




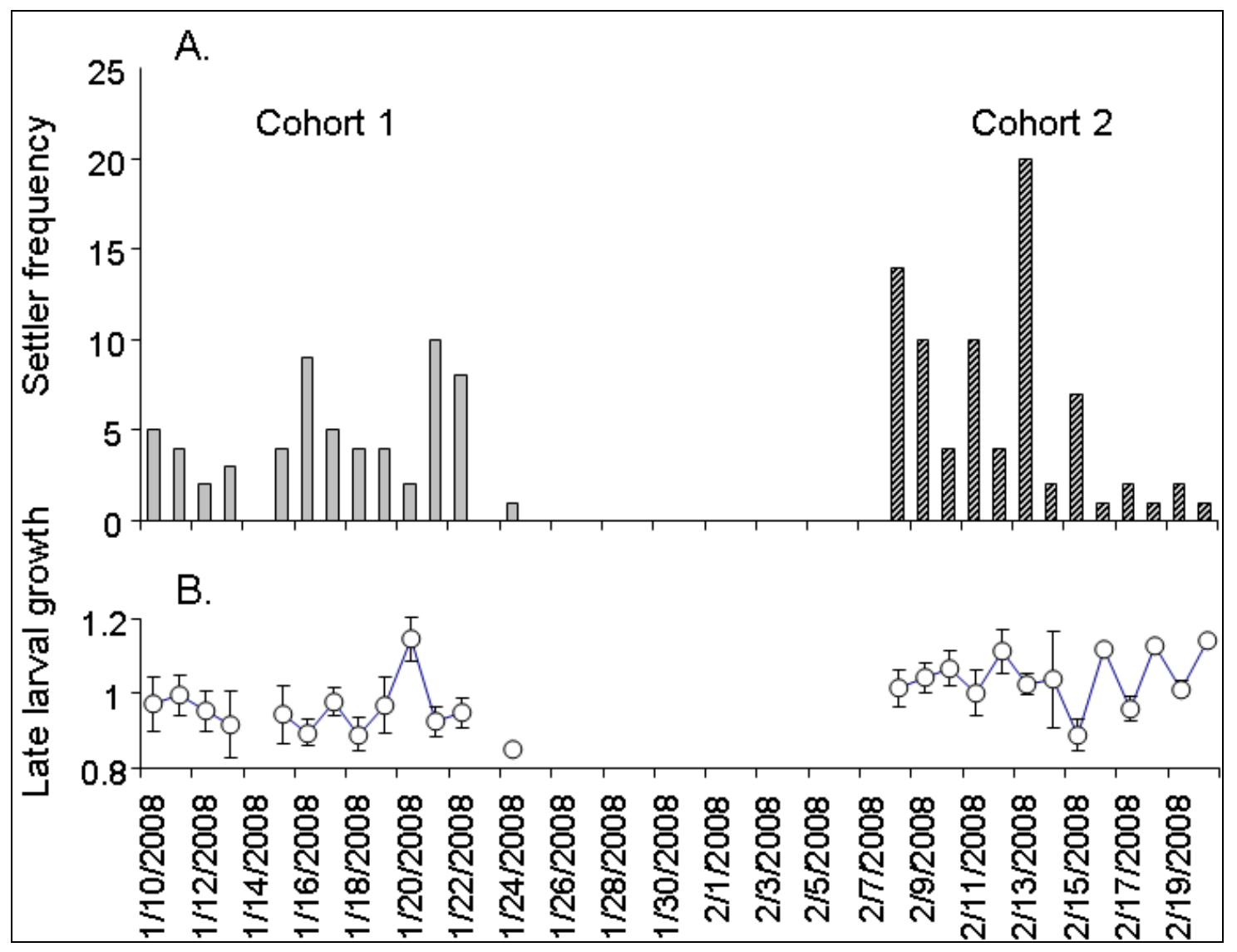

Figure 3.1. Between cohort variation in (A) daily settler frequency and (B) daily mean late larval growth $\left(\mu \mathrm{m}\right.$ day $\left.^{-1} \pm 1 \mathrm{SE}\right)$ for 16 quadrats sampled across all sites and microhabitats.

relationship between post-settlement growth and late larval growth differed between microhabitats (Fig 3.2A, Table 3.2). Carry-over effects observed for cohort 1 settling to the south coast were accentuated on mixed algal stands, where individuals with higher growth rates as larvae grew increasingly more as juveniles, relative to individuals that settled to Carpophyllum monocultures (Fig 3.2A). For cohort 2 settling to the south coast, I observed a significant carry-over effect (Fig 3.2B, Table 3.3) that did differ between microhabitats (Table 3.3). Similarly, for cohort 1 settling to the harbour, I observed a significant carry-over effect that did not differ between microhabitats (Fig 3.2C, Table 3.4). In contrast, for cohort 2 settling to the harbour I observed no 
significant carry-over effect (Fig 3.2D, Table 3.5) or variation between microhabitats (Fig 3.2D, Table 3.5).

\section{Variation in intensity of selective mortality}

Selective intensity varied among sites, cohorts and microhabitats (Fig 3.3). Values for z-scores were consistently positive, indicating that the predominant trend was for the distribution of late larval growth rates among survivors to be positively skewed relative to settlers. This is consistent with selection that favours individuals that were growing rapidly as larvae (Fig 3.3). The intensity of selection on fish from cohort 1 settling to the south coast differed between microhabitats; selective intensity was greater (and significantly different from 0) on Carpophyllum monocultures, and was comparatively weak (and not different from 0) on mixed algal stands (Fig 3.3A).

Selective intensity on fish from cohort 2 settling to the south coast was statistically indistinguishable between microhabitats, and was moderately strong (and different from 0) for both (Fig 3.3B). Selective intensity on fish from cohort 1 settling to the harbour was qualitatively similar to that observed for fish of the same age class settling to the south coast, though the difference between microhabitats was not statistically significant (Fig 3.3C). No evidence of selective mortality was observed for fish from cohort 2 settling to the harbour (Fig 3.3D). 


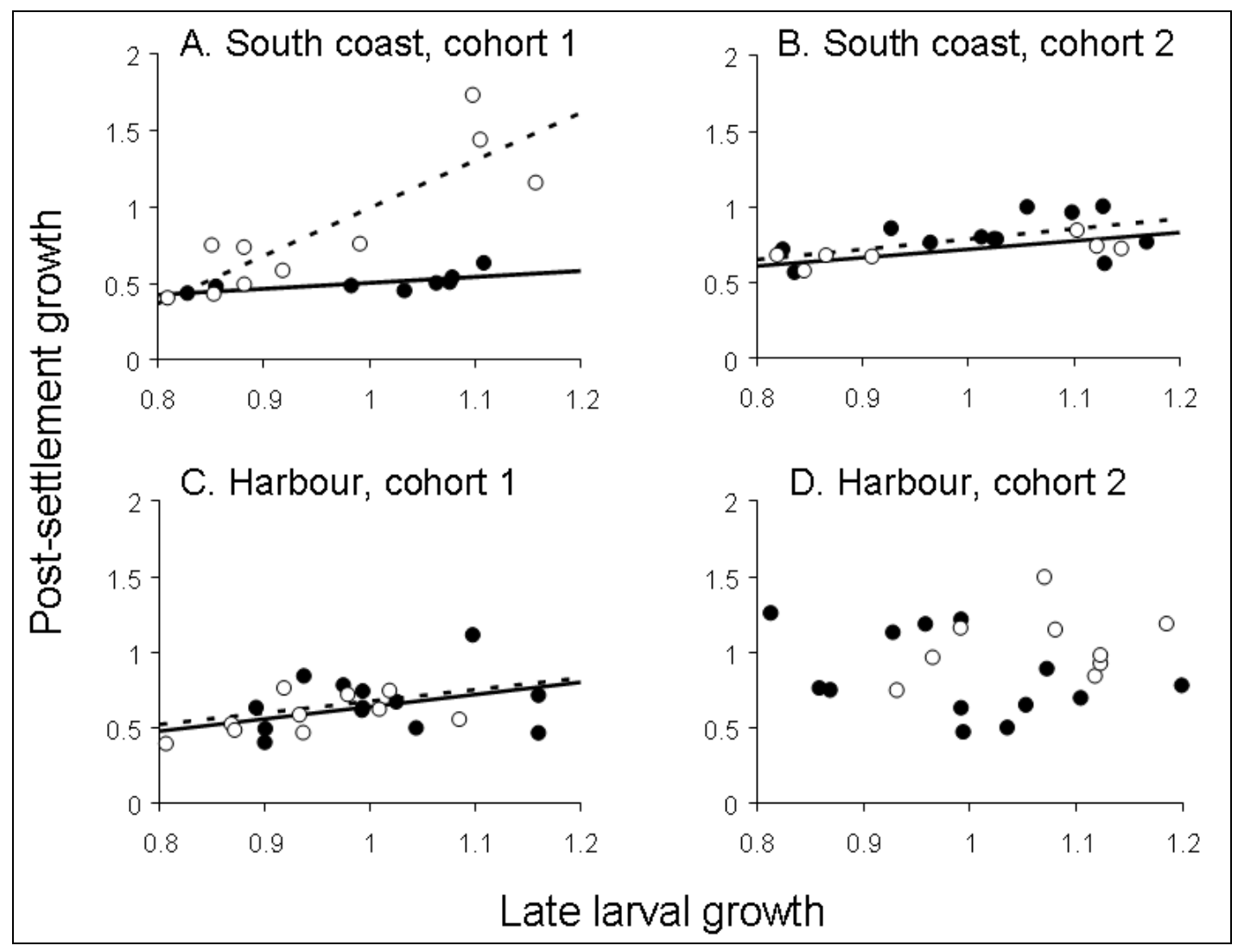

Figure 3.2. of the relationships between late larval growth $\left(\mu \mathrm{m}\right.$ day $\left.^{-1}\right)$ and postsettlement growth $\left(\mu \mathrm{m}\right.$ day $\left.^{-1}\right)$ of fish from 2 different microhabitats; mixed stands of macroalgae (open circles/dotted lines) and Carpophyllum monocultures (closed circles/black lines), for each of the 4 different sampling events (A-D). Sampling events varied in location (harbour or south coast) and/or timing of settlement (cohort 1 or 2). 
Table 3.2. ANCOVA results for effects of larval quality and habitat on juvenile growth for South coast, cohort 1. Significant p-values are displayed in bold.

\begin{tabular}{|lllrl|}
\hline Source & DF & SS & \multicolumn{1}{l|}{$F$} & \multicolumn{1}{l|}{$P$} \\
\hline Larval quality & 1 & 0.5467 & 12.5932 & $\mathbf{0 . 0 0 2 7} *$ \\
Habitat & 1 & 0.5039 & 11.6060 & $\mathbf{0 . 0 0 3 6}$ \\
Larval quality x Habitat & 1 & 0.1429 & 3.2914 & $\mathbf{0 . 0 0 8 8 *}$ \\
Error & 16 & 0.6946 & & \\
\hline
\end{tabular}

Table 3.3. ANCOVA results for effects of larval quality and habitat on juvenile growth for South coast, cohort 2.

\begin{tabular}{|lllll|}
\hline Source & DF & SS & $F$ & $P$ \\
\hline Larval quality & 1 & 0.3402 & 8.7718 & $\mathbf{0 . 0 0 7 4 *}$ \\
Habitat & 1 & 0.0167 & 0.4315 & 0.5184 \\
Larval quality x Habitat & 1 & 0.0174 & 0.4506 & 0.5094 \\
Error & 21 & 0.8143 & & \\
\hline
\end{tabular}

Table 3.4. ANCOVA results for effects of larval quality and habitat on juvenile growth for Harbour, cohort 1.

\begin{tabular}{|lllrl|}
\hline Source & DF & SS & $F$ & $P$ \\
\hline Larval quality & 1 & 0.6842 & 16.7663 & $\mathbf{0 . 0 0 0 3 *}$ \\
Habitat & 1 & 0.1012 & 2.4800 & 0.1261 \\
Larval quality x Habitat & 1 & 0.0265 & 0.6481 & 0.4273 \\
Error & 19 & 1.1834 & & \\
\hline
\end{tabular}

Table 3.5. ANCOVA results for effects of larval quality and habitat on juvenile growth for Harbour, cohort 2.

\begin{tabular}{|lllll|}
\hline Source & DF & SS & $F$ & $P$ \\
\hline Larval quality & 1 & 0.1122 & 0.9392 & 0.3418 \\
Habitat & 1 & 0.0001 & 0.0011 & 0.9732 \\
Larval quality x Habitat & 1 & 0.0174 & 0.1457 & 0.7059 \\
Error & 25 & 2.9866 & & \\
\hline
\end{tabular}




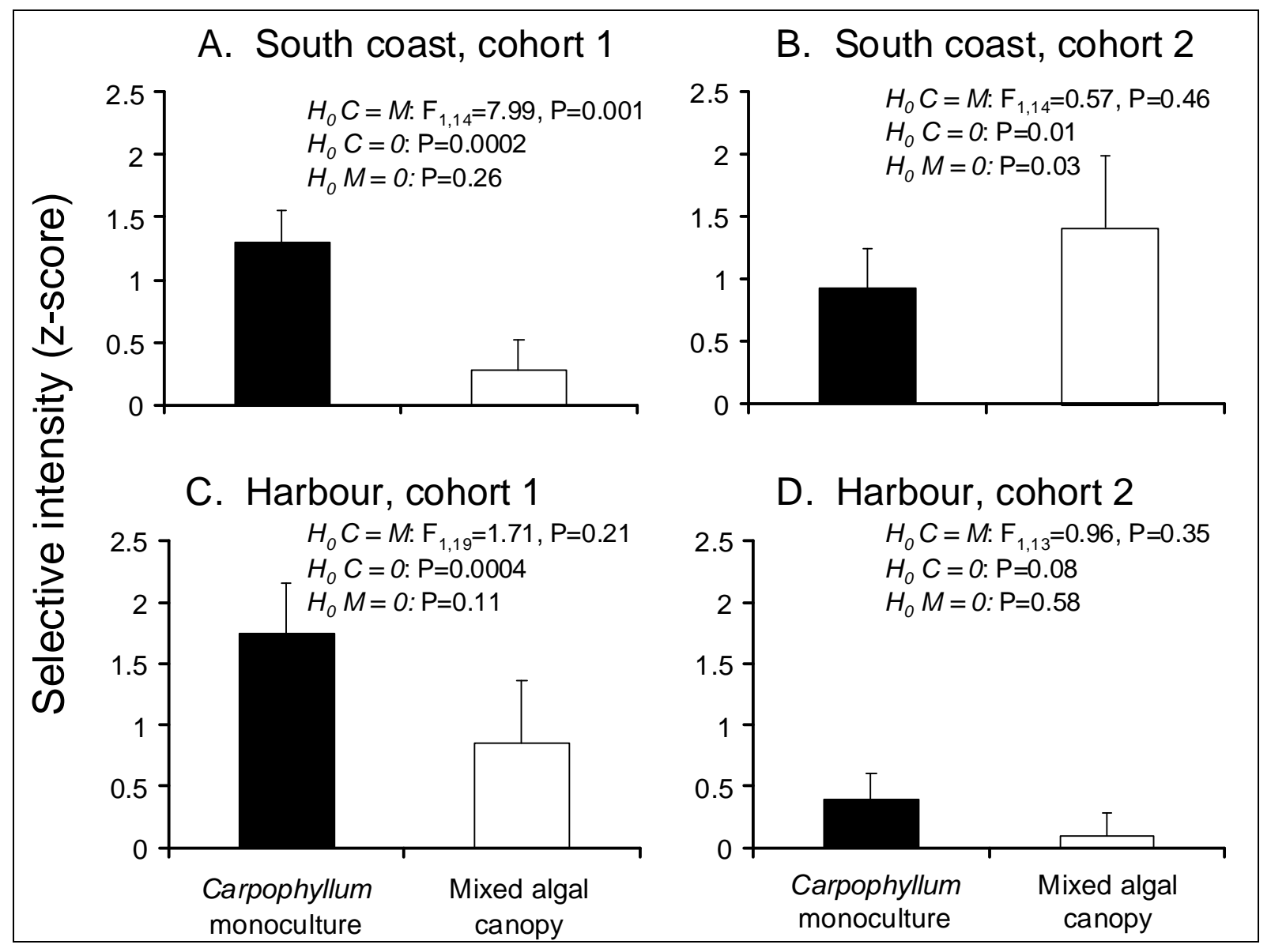

Figure 3.3. Comparison of selective intensity (z score $\pm 1 \mathrm{SE}$ ) for fish from different microhabitats; mixed stands of macroalgae (M; black bars) and Carpophyllum monocultures ( $C$; open bars), for each of the 4 different sampling events (A-D). For each sampling event the probabilities of 3 null hypotheses being met are given; that selective intensity does not differ between microhabitats $\left(\mathrm{H}_{0} \mathrm{C}=\mathrm{M}\right)$ and that for each microhabitat selective intensity does not differ from zero $\left(\mathrm{H}_{0} \mathrm{C}=0\right.$ and $\left.\mathrm{H}_{0} \mathrm{M}=0\right)$.

Table 3.6

Results from a 3-way ANOVA comparing selective intensity among locations (south coast or harbour), macroaglal habitats within locations (Carpophyllum or mixed) and cohorts. $\mathrm{N}=79$

\begin{tabular}{|llccl|}
\hline Source & DF & SS & F & P \\
\hline Location & 1 & 0.981 & 0.444 & 0.444 \\
Habitat & 1 & 0.813 & 0.494 & 0.485 \\
Cohort & 1 & 7.200 & 4.377 & $\mathbf{0 . 0 4 1}$ \\
Location*Habitat & 1 & 1.172 & 0.712 & 0.403 \\
Location*Cohort & 1 & 8.717 & 5.298 & $\mathbf{0 . 0 2 5} *$ \\
Habitat*Cohort & 1 & 3.288 & 1.999 & 0.163 \\
Location*Habitat*Cohort & 1 & 10.201 & 4.948 & $\mathbf{0 . 0 4 8}$ \\
\hline
\end{tabular}




\subsection{Discussion}

Physiological coupling across the larval-juvenile stage transition for $F$. lapillum varies in space and time. Larval growth rate was positively correlated with post-settlement growth rate in 3 of 4 samples, suggesting that carry-over effects on growth are common, but context-dependent. Although previous studies of reef fishes have demonstrated that variation in developmental history can affect individual growth and survival (Searcy and Sponaugle 2001, Shima and Findlay 2002, McCormick and Hoey 2004, Raventos and Macpherson 2005, Chapter 2), at the population level it is less clear how individual variation interacts with extrinsic variability through space and time. Extrinsic factors may potentially affect both the level of phenotypic expression (e.g. Schoeppner and Relyea 2008) and the relationship between phenotype and fitness (e.g. Kingsolver and Gomulkiewicz 2003). I observed variation in the strength of the growth advantage conveyed by carry-over effects, and concomitant variation in selective intensity across cohorts, sites and microhabitats.

Late larval growth rate may be correlated with a range of physiological and phenotypic traits that can contribute to variation in post-settlement growth, size, and/or performance (Searcy and Sponaugle 2001, Bergenius et al. 2002, Shima and Findlay 2002, Wilson and Meekan 2002, McCormick and Hoey 2004, Johnson 2008). For example, the level of competitive dominance exhibited by fish shortly after settlement has been linked to larval condition, with high condition fish showing more aggressive behaviour towards conspecifics and having higher rates of post-settlement survival (Johnson 2008). In addition, expression of traits or behaviour patterns may be modified by extrinsic factors, for example the threat of predation can affect the expression of boldness and activity levels (McPeek et al. 2001, reviewed in Lima 1998), which can lead to a reduced level of among-individual variation in size (Peacor 
et al. 2007). These studies suggest that extrinsic factors such as elevated risk of predation may reduce the strength of carry-over effects on performance.

Alternatively, interactions such as interference competition, may contribute to increased phenotypic variation among individuals if the competitive advantage of individuals with certain traits becomes more prenounced (Ziemba and Collins 1999, Ward et al. 2006). I speculate that the effects of larval history that carry-over to subsequent stages may become more prenounced in highly competitve contexts. In this way, the local competitive environment (i.e., the "ecological context") may mediate the strength of carry-over effects on phenotypes, as well as how phenotypes then correlate to performance and fitness.

Microhabitat often shapes the local ecological context experienced by juvenile fish, e.g. predation rate (Tupper and Boutilier 1997) and intraspecific competition (Bonin et al. 2009). I found that- under some conditions (e.g. cohort 1 from south coast) - microhabitats appeared to mediate the fitness and phenotypic consequences of intrinsic variation among individuals. Fish in cohort 1 that settled on the south coast grew on average faster in mixed macroalgal stands following settlement in comparison to monospecific Carpophyllum stands and the selective intensity based on larval growth rate was also lower. Increased habitat complexity is expected to mitigate the negative effects of competition and predation by providing a greater spectrum of resources (e.g., structural refuge) or decreasing encounter rates due to reduced maneuverability and/or the ability to visually detect competitors/prey (Anderson 1984, Main 1987, Persson and Eklov 1995, Lindholm et al. 1999). Conversely, variation in macroalgal composition may drive variability in the abundance and range of predators which can counteract these positive effects (e.g., 
Shima et al. 2008). In this case, an increase in habitat heterogeneity appeared to result in fish growing faster and being subject to lower selective pressure.

In different ecological contexts, carry-over affects and selective intensity appeared to be important but unaffected by microhabitat (e.g. cohort 1 from harbour and cohort 2 from south coast). Spatio-temporal variability in the apparent effects of microhabitat may be attributable to any number of variables that likely varied among sites and through time (e.g. temperature, food availability, predator and/or conspecific density, turbidity, quality of the refuge provided by microhabitat, etc). At present, I am unable to identify the mechanisms that contribute to the observed variation in carry-over effects and selective intensity. Given that the abundance of $F$. lapillum is higher within the harbour, coupled with reports that the distribution of juvenile and adult $F$. lapillum is positively associated to low wave exposure habitats (Wellenreuther and Clements 2008), this may indicate that conditions at Kau Bay were more favourable for $F$. lapillum than at Island Bay. Other workers have hypothesised that carry-over effects may be of lesser importance when environmental conditions are more favourable (e.g. Marshall 2006, Donelson et al. 2009), as all individuals may have sufficient access to resources, and competition is minimised. Thus, the finding that carry-over effects are weaker at Kau Bay fits with this hypothesis, however further experimentation over a longer time-scale (i.e., across years) is needed. Conditions within a single location may exhibit considerable annual variation, for example, recruitment intensity of reef fish can show large differences between consecutive years (Connell and Jones, 1991). Regardless of mechanisms, our observations of variation in both carry-over effects and selective intensity have important implications for the dynamics and phenotypic structure of local populations. I can speculate that spatial variation in the strength of phenotypic links may have 
implications for the range of a phenotype present, for example the size distribution of individuals within a local population. By modifying the distribution of phenotypic traits, carry-over effects may play a substantial role in mediating the strength and direction of ecological interactions, from antagonism to mutualism (De Roos et al. 2003, Peacor et al. 2007). This has implications for a suite of evolutionary processes, including disruptive selection, niche expansion, and adaptive radiation (Bolnick 2001).

The ecological and evolutionary implications of phenotypic variation are further amplified for organisms where initial intrinsic variation is associated with dispersal history, as is the case for F. lapillum (Shima and Swearer 2009). If postsettlement fitness is associated with an individual's natal origin and/or its dispersive pathway, the identity of surviving fish could determine which sources contribute to population persistence (Hamilton et al. 2008). Variation in the strength of carry-over effects may therefore mediate patterns of connectivity among local popualtions. In such ecological contexts where larval history has a reduced effect on phenotypic expression and fitness (e.g. for F. lapillum, cohort 2 in the harbour), a wider collection of source populations may successfully contribute to replenishment of the local population. In contrast, when strong carry-over effects and intense selection occur, (e.g. for F. lapillum on the south coast), individuals that survive to successfully replenish the local population may represent only a small subset of contributing source populations. In short, patterns of metapopulation connectivity may be mediated by the local ecological context (and specifically, how this shapes the strength of carryover effects and selective mortality).

For organisms with complex life cycles, experiences throughout the larval phase or at particular 'critical periods' before metamorphosis can undoubtedly 
influence fitness at later life stages. Our study highlights context-dependent variation in the strength of carry-over effects and selection, and this spatio-temporal variation may have important implications for population dynamics and evolutionary processes. For organims with a complex life cycle, studies that consider the interaction of environmental and phenotypic variation across life stages are likely to provide a more complete picture of the ecological context of ecological and evolutionary change. 


\title{
Chapter 4
}

\section{Fine-scale variation in density-dependent survival can affect}

\author{
estimates of nursery habitat value
}

\subsection{Abstract}

Juveniles of many marine species are closely associated with structured, nearshore habitats (e.g., seagrass beds, mangrove forests), which are often patchily distributed. Spatial heterogeneity in the composition of habitat patches can influence demographic rates (e.g., growth and survival) and may alter the strength of density dependence. Here, I explore whether variation in the species composition and diversity of macroalgal patches impacts the strength of density dependent growth and survival in a temperate reef fish, Forsterygion lapillum (the common triplefin). Recently settled fish were tagged and released onto patches varying in natural densities of conspecifics. I find evidence of local density-dependent survival during the first 30 days after settlement, and that the strength of density dependence varies as a function of macroalgal composition. Results from this study demonstrate that variation in the composition of macroalgal patches can affect quantitative estimates of the value of nursery habitat.

\subsection{Introduction}

Population dynamics are driven by changes in demographic rates, and densitydependent rates are particularly important in regulating dynamics. For organisms with a complex life cycle, the magnitude of density-dependent processes occurring in a single 
life-stage can have profound implications for population-level dynamics (e.g. adult abundance) (Wilbur 1996, Hellriegel 2000). Intense post-settlement mortality is often cited as a demographic bottleneck (e.g. Almany and Webster 2006), and identifying sources of variation (e.g. the availability of settlement habitat) in density dependent mortality of juveniles is important for constructing realistic population models and effective conservation strategies.

In recent years there has been increasing interest in conserving nursery habitats for early juvenile stages (e.g. Dahlgreen and Eggleston 2000, McDermott and Shima 2001, Halpern 2004, Nislow et al. 2004, Aburto-oropeza et al. 2007). Juveniles of many marine organisms are closely associated with near-shore ecosytems that that can offer food and refuge from predation and may serve as nursery habitats (e.g., seagrass meadows and mangrove forests; Beck et al. 2001). Beck et al. (2001) provided an important framework for the empirical assessment of nursery habitat and stated that nursery habitats support a greater density, productivity (i.e. growth) or survivorship of juvenile stages than surrounding alternative habitat types, and therefore contribute disproportionately more recruits to adult populations (i.e., have a higher nursery value, sensu Beck et al. 2001). Inshore habitats often consist of a complex mosaic of patches (Dayton and Tegner 1984, Sale and Douglas 1984, Bologna and Steneck 1993, Robbins and Bell 1994, Syms and Jones 2000, Hovel and Lipcius 2001) that vary in habitat characteristics (e.g. as predator density, refugia from predators; Behrents 1987, Hixon and Beets 1989, 1993, or food resources; Nemeth 1996). Spatial and temporal variation in habitat characteristics can affect per capita growth (e.g., Steele and Forrester 2002, Srinivasan 2003), per capita survival (Caley et al. 2001), and also the strength of density dependent mortality (Wilson and Osenberg 2002, Shima and Osenberg 2003). For example, habitat patches with a higher number of refuges, can reduce levels of 
intraspecific competition, and in turn reduce the strength of density dependent mortality (Forrester and Steele 2004).

Juvenile performance (e.g., growth and/or survival) not only depends upon local patch quality (e.g. habitat composition) and conspecific density, but also the intrinsic quality of individuals (e.g., due to traits such as size and condition of individuals that populate a patch) (Shima et al. 2008). Intrinsic quality of individuals may also fluctuate through time (Jarret and Pechenik 1997, Radtke et al. 2001, Jarrett 2003, Phillips 2006) and can influence the strength of density-dependent processes (e.g. growth; Johnson 2008). Consequently, understanding the effects of heterogeneity in habitat features on nursery value may require a more sophisticated approach than simply quantifying observed variation in vital rates (Van Horne 1983, Battin 2004). The challenge then is to describe performance in relation to all three variables (habitat characteristics, individual quality, and local density), or at least, remove the effects of two variables while quantifying the effects of the third.

The objective of this study was to determine the role of fine-scale variation (i.e. differences between patches over a scale of metres) in the macroalgal composition of habitat patches on the juvenile population dynamics of a temperate reef fish, Forsterygion lapillum (the common triplefin). This study uses a combination of field experiments and otolith microstructure analysis to address the following questions: 1) Does settler density and individual quality vary among patches varying in macroalgal composition?; (2) Controlling for variation in intrinsic quality, does juvenile survival and growth vary as a function of conspecific density?; (3) Do density-dependent relationships vary with macroalgae composition?; and (4) How do quantitative estimates of nursery value vary when density-dependent processes are considered? 


\subsection{Methods}

\section{Study species and site}

In the present study I used Forsterygion lapillum (the common triplefin) as my focal species. The study was conducted at Kau Bay, within Wellington Harbour, New Zealand $\left(41^{\circ} 17^{\prime} \mathrm{S}, 174^{\circ} 50 \mathrm{E}\right)$. On the subtidal rocky reef, I constructed a series of habitat patches ( $2 \mathrm{~m} \times 2 \mathrm{~m})$, each containing one of three macroalgal treatments. (1) A mixed species treatment containing three Carpophyllum and three Cystophora plants; (2) A monospecific treatment containing six Carpophyllum plants; (3) A monospecific treatment containing six Cystophora plants. I followed the same protocol for constructing and maintaining macroalgae treatments as detailed in chapter 2 . Patches were arranged in a grid with one replicate of each treatment represented in each row of the grid, following a randomised block design. Each treatment was replicated 4 times (i.e., the grid was $3 \times 4$ ). Patches were constructed $1.5 \mathrm{~m}$ apart, and all macroalgae was removed from a $1.5 \mathrm{~m}$ border surrounding each patch. The experimental grid ranged in depth from 4.5 to $5.5 \mathrm{~m}$. Each row within the grid followed a depth contour. Tagging studies have shown that recently settled juveniles (standard length $<30 \mathrm{~mm}$ ) do not tend to move from a $1.5 \mathrm{~m}^{2}$ patch of macroalgae habitat until they undergo ontogenetic habitat shifts $\sim 40$ days after settlement (A. Smith, unpublished data). Likewise, adult triplefins generally remain site attached, rarely moving more than a few meters (Thompson 1983, Clements 2003, Subedar 2009). Therefore a gap of $1.5 \mathrm{~m}$ between habitat patches, when they are cleared of all algae $>10 \mathrm{~cm}$ high, will provide enough of a barrier to prevent movement of recently settled F. lapillum.

How does settler density and intrinsic quality of individuals vary among patches that differ in macroalgal composition? 
To quantify settlement rate, I monitored settlement of fish to each of the 12 macroalgae patches. For a ten-day period, beginning 23 Feb 2008, I collected all $F$. lapillum less than $30 \mathrm{~mm}$ in total length from each patch $(\mathrm{n}=12)$ every other day. To determine post-settlement age, I analysed the sagittal otoliths of all collected recuits (details of otolith microstructure analysis are described in Chapter 2). A conspicuous settlement mark is formed in F. lapillum (Kohn 2007), facilitating estimates of postsettlement age, which is simply the number of daily increments along the post-rostral axis between the settlement mark and the outer edge of the otolith. Settlement rate was then calculated as the number of settlers (identified as 0 or 1 days post-settlement age) present in each patch on each sampling day, divided by two, to give the density (per square meter) of fish settling to each patch per day.

I compared settlement rate among macroalgal patches using a Freidman Test based in the statistical package 'coin' (Hothorn et al. 2008). The Freidman Test is appropriate when the dependent variable (settlement rate) is non-normally distributed. The Freidman Test compares the distribution of the dependent variables against 9999 randomly generated distributions, to determine the probability of the observed pattern occurring by chance. To remove any confounding temporal variation in larval quality between sampling days, I included sampling date (labeled as 1,2,3,4 or 5) as a blocking variable in the model.

To quantify the quality of settlers among macroalgal patches, I analysed the otolith microstructure of all $F$. lapillum identified as 0 or 1 day post-settlement. Using daily increments along the post-rostral axis of sampled otoliths, I characterized larval history traits of juvenile F. lapillum using four phenotypic variables: (1) Pelagic larval duration (PLD), an estimate of duration of larval development in days, calculated as the number of daily otolith increments in the larval stage of each sample (i.e., the interval 
between hatch check and settlement check); (2) Early larval growth, estimated as the mean increment width across the first seven days of larval growth following hatching; (3) Late larval growth, estimated as the mean increment width across the final seven days of larval growth prior to settlement; and (4) size-at-settlement, estimated as the distance from the core to the settlement mark. I used an ANOVA to compare the distribution of each larval trait (PLD, early and late larval growth rate and size-atsettlement) among habitat treatments.

\section{Controlling for intrinsic variation among individuals, does survival vary with macroaglae composition?}

To test for the effects of macroalgae composition on post-settlement survival, I introduced 10 tagged F. lapillum (post-settlement age 27 days, $\mathrm{SD}=7.2$; standard length $=24.6 \mathrm{~mm}, \mathrm{SD}=2.0$ ) onto each of the 12 macroalgal patches within the grid, and calculated survival as the proportion of tagged fish remaining on each patch after 4 days.

Using hand nets, I collected recent settlers from reef $\sim 10 \mathrm{~m}$ from the experimental grid from mixed macroagal patches containing both Carpophyllum and Cystophora. In order to minimize variation in settler condition, collections were made from within the same small area of reef $\left(\sim 5 \mathrm{~m}^{2}\right)$. To further control for any systematic variation in settler condition, settlers were then haphazardly assigned to macroalgal patches. Settlers were individually tagged with different colors of Visible Implant Elastomer (VIE) (Northwest Marine Technology, Shaw Island, Washington, USA) forward of the caudal peduncle. Each group of 10 fish was given unique tag - coloured green, yellow, pink or orange, and either on the left or right hand side of the body. VIE tags do not have adverse effects on other fishes (Frederick 1997, Beukers et al. 1995, 
Simon 2007), and my own preliminary study confirmed no tag-induced mortality of a sample of 20 tagged $F$. lapillum held in aquaria for 72 hours.

I ran the experiment in two temporal blocks (beginning Feb 7 and 25 2008) yielding seven replicates (three replicates in the first temporal block, four replicates in the second temporal block). During the initial 16 hours after release each patch was covered by a mesh cage to allow fish to acclimate to their new surroundings and exclude predators. Cages ( $1.5 \mathrm{~m}$ diameter x $1.5 \mathrm{~m}$ tall) consisted of a rigid steel frame and galvanized steel mesh ( $25 \mathrm{~mm}$ hexagonal mesh). After this acclimatization period the cage was carefully removed. A total of 90 tagged fish were released in the first temporal block over three consecutive days $(n=9)$. In the second temporal block a total of 120 tagged fish were released over four consecutive days $(n=12)$. Each day fish were collected from the same area of reef, before being tagged onshore and released onto a single row of patches within the grid.

The VIE tags were not clearly visible through the skin of the fish by observers in the field, so it was necessary to recapture individuals to determine their identity. In the laboratory, I could visually identify tagged fish from the samples, aided by a UV light which caused VIE tags to fluoresce. Four days after release I collected all F. lapillum from all macroalgal patches and from cobble surrounding each patch. Thorough sampling was carried out in a series of steps. First, I systematically searched each plant within a patch from the top down to the holdfast. Second, I searched all cobbles at the base of each plant, turning and replacing them as necessary. Third, I searched surrounding cobbles in expanding circles until I reached a distance of $3 \mathrm{~m}$ from the centre of the patch. These steps were repeated on the following day, to ensure no tagged fish had been missed. 
For each macroalgal patch I calculated the percentage survival of tagged fish (i.e., the percentage of tagged fish recovered), and the density of conspecifics present within the patch. Conspecifics were split into two age classes; recently settled $(<25$ days post-settlement age) and juveniles (25 - 40 days post-settlement age). To determine if habitat treatments mediated the relationship between percentage survival and fish density I used a permutation analysis of covariance (ANCOVA). This analysis was appropriate because percent survival was not normally distributed (Good 2000). I $\log _{10^{-}}$ transformed percent survival and each density age-class in order to linearise the relationship between survival and density. I used linear regression to fit 3 parallel lines to the 3 treatment groups (Carpophyllum, Mixed and Cystophora). This represents the null hypothesis that the relationship between survival and density is the same for all macroalgal treatments. I performed a permutation ANCOVA test by using a randomization of the residuals, as fitted by the null hypothesis. If the null hypothesis is correct, then the observed slopes of the residuals regressed against the covariable (density) should be the same for all macroalgal treatments. Alternatively, if the regression slopes of the residuals differ among habitats, the relationship between survival and density differs among macroalgal treatments.

To perform the permutation test, data were arranged in three columns: (i) macroalgal treatment; (ii) regression residuals; and (iii) the covariable (density). I randomly permuted the macroalgal treatment cells and then recomputed the regressions of the residuals against density for each 'pseudo-group'. For each permutation I calculated the test statistic, which reflects the difference between treatments. I then compared the test statistic calculated for the observed residuals fitted to the null hypothesis, against the distribution of the pseudo-value test statistic generated from a series of 1000 randomisations. The p-value is the proportion of pseudo-values less than 
the data based value. A significant $p$-value $(<0.05)$ indicates the rejection of the null hypothesis that fish within all habitats exhibit the same relationship between survival and density.

\section{Does growth vary among habitat patches?}

All F. lapillum collected during the sampling (described in the previous section) were lightly blotted dry and weighed to the nearest $1 \mathrm{mg}$ (wet weight) using a mass balance. Using electronic calipers, I measured the standard and total lengths of each fish to the nearest $\mathrm{mm}$. For each juvenile $F$. lapillum $(\mathrm{n}=369)$, I used the otolith record to determine post-settlement age (see chapter 2 for details of otolith microstructure analysis).

I used all F. lapillum collected to compare juvenile growth rates among each macroalgal treatment. For this analysis I only used fish sampled from within the $2 \mathrm{~m} \mathrm{x}$ $2 \mathrm{~m}$ patch (i.e., not from the surrounding cobbles). I also only include $F$. lapillum less than 36 days old, as after this age fish may be moving between macroalgal patches. I used an ANCOVA to compare growth, settlement age (covariate), macroalgal treatment (independent variable) and the interaction between post-settlement age $\mathrm{x}$ macroalgal treatment. I $\log _{10}$ transformed wet weight to linearise its relationship with age.

I also used an ANCOVA to analyse the relationship between average growth rate and conspecific density for each macroalgal treatment separately. Fish were split into two age classes; recently settled ( $<25$ days post-settlement age) and juveniles (25 40 days post-settlement age). For each age group and replicate macroalgal patch $(\mathrm{n}=$ 42), I calculated mean fish growth and fish density. I then performed ANCOVA analyses, with mean growth rate as the dependent variable, density as the covariate and habitat as an independent variable. I performed four ANCOVA's to examine the 
relationship between average growth rate and conspecific density: (i) the relationship between settler growth with settler density; (ii) the relationship between settler growth with juvenile density; (iii) the relationship between juvenile growth with settler density; and (iv) the relationship between juvenile growth with juvenile density.

\section{Incorporating density-dependent effects into quantitative estimates of nursery habitat} value.

As an estimate of the nursery value of macroalgal patches, I use the total juvenile biomass produced 30 days after settlement. Nursery value is presented as a function of density, calculated for each macroalgal treatment separately. Therefore, as the strength of density dependent survival rates differ, so does the nursery value function. This function also incorporates habitat-dependent variation in growth rates, as the total juvenile biomass produced from each habitat will depend on the growth rate associated with it.

First, I use the simple linear function (equation 1) generated from the tagging experiment (Fig.4.2) to predict percentage survival (S) as a function of density of recently settled fish $(\mathrm{N})$ :

$\log _{10} S=a\left(\log _{10} N\right)+b$

where $a$ and $b$ are constants. This allows me to estimate juvenile density $(J)$ as a function of $N$, using percentage survival $(S)$. I assume that all juvenile migration rates are negligible (see results).

$J=S N$ 
Therefore,

$J=10^{(a * \log 10 N+b) * N}$

Finally, total juvenile biomass $(B)$ at $T$ days after settlement, is calculated as a function of $N$ :

$B_{T}=M_{T} J$

where $M$ is individual wet weight at $T$ days after settlement. This can be rewritten as:

$B_{T}=M_{T}\left(10^{\wedge}\left(a^{*} \log _{10} N+b\right) * N\right)$

I use habitat-specific estimates of $a, b$, and $M_{T}$, taken from habitat-specific linear regression functions (linear regressions shown in Fig. 4.2 and Fig. 4.3).

\subsection{Results}

How does settler density and intrinsic quality of individuals vary among patches that differ in macroalgal composition?

The permutation test revealed no significant difference in settlement rate among macroalgal treatments $\left(\chi^{2}=1.72, p=0.43\right)($ Fig.4.1). Mean settlement rates $( \pm S D)$ over the ten days for each macroalgal treatment were: Carpophyllum $=1.4$ fish $\mathrm{m}^{2} \mathrm{~d}^{-1} \pm$ 1.2, Mixed $=0.7$ fish $\mathrm{m}^{2} \mathrm{~d}^{-1} \pm 0.9$, Cystophora $=0.6$ fish $\mathrm{m}^{2} \mathrm{~d}^{-1} \pm 0.8$. Similarly, ANOVA analyses revealed no significant difference in larval traits, body size or condition, among macroalgal treatments (Table 4.1). 


\section{Accounting for intrinsic variation among individuals, does survival vary with}

\section{macroaglae composition?}

I found no tagged $F$. lapillum outside the $2 \mathrm{~m} \times 2 \mathrm{~m}$ macroalgal patches into which they were released. I therefore assume that juvenile migration rates were negligible and the loss of tagged $F$. lapillum from macroalgal patches is representative of mortality. Percent survival of tagged individuals ranged

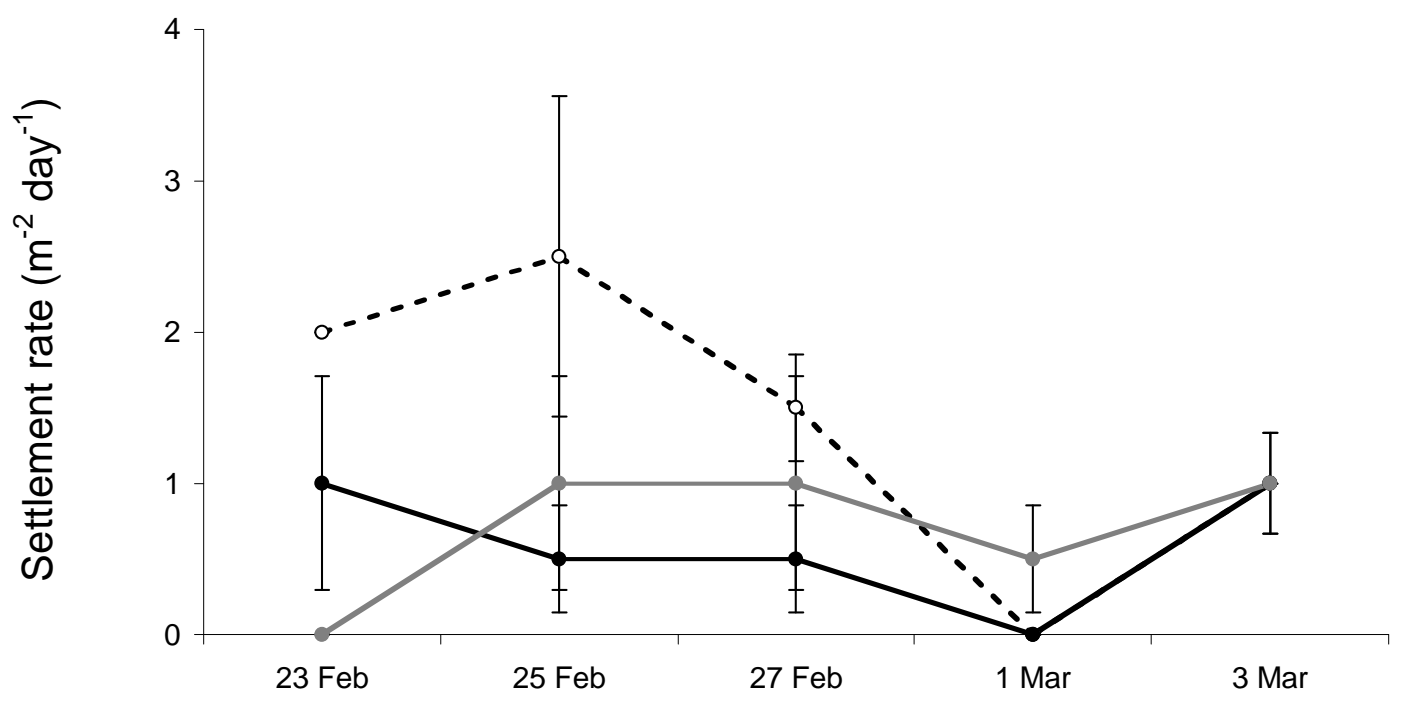

Figure 4.1. Mean settlement rate (fish $\mathrm{m}^{2} \mathrm{day}^{-1}$ ) of the common triplefin (Forsterygion lapillum) for three macroalgal treatments(Carpophyllum [open symbols/dotted line]: mixed [black symbols/black line]; and Cystophora [grey symbols/grey line]). Dates on which fish were sampled are given on the $\mathrm{x}$ axis. Error bars represent standard error. $\mathrm{n}=$ 4 for each treatment on each day.

between $0-30 \%$. F. lapillum within Carpophyllum patches (mean percent survival $=$ $12.9 \pm 0.14 \mathrm{SD})$ had 4.5 times higher survival than F. lapillum within Cystophora patches $($ mean percent survival $=2.9 \pm 0.05 \mathrm{SD}) . F$. lapillum within mixed macroaglal patches (mean percent survival $=8.7 \pm 0.12 \mathrm{SD}$ ) had 3 times higher survival than $F$. lapillum in Cystophora patches. 
For Carpophyllum and mixed macroalgal patches, survival rates declined with increasing densities of recently settled $F$. lapillum (aged <25 days post-settlement) (linear regression; $\mathrm{Ca}: \mathrm{R}^{2}=0.86, \mathrm{p}<0.01, \mathrm{M}: \mathrm{R}^{2}=0.64, \mathrm{p}<0.05$; Fig.4.2). The survival of juvenile fish within monospecific Cystpohora habitats was not correlated to fish density (linear regression; $\mathrm{R}^{2}<0.01, \mathrm{p}=0.90$; Fig.4.2). The survival of juvenile fish was not correlated to juvenile fish density (aged 25-40 days post-settlement) in any of the habitats (linear regressions; $\mathrm{R}^{2}<0.1, \mathrm{p}>0.60$ ). The permutation ANCOVAs indicated that both the survival of tagged $F$. lapillum and density of recently settled $F$. lapillum varied among macroalgal treatments $(P=0.004)$.

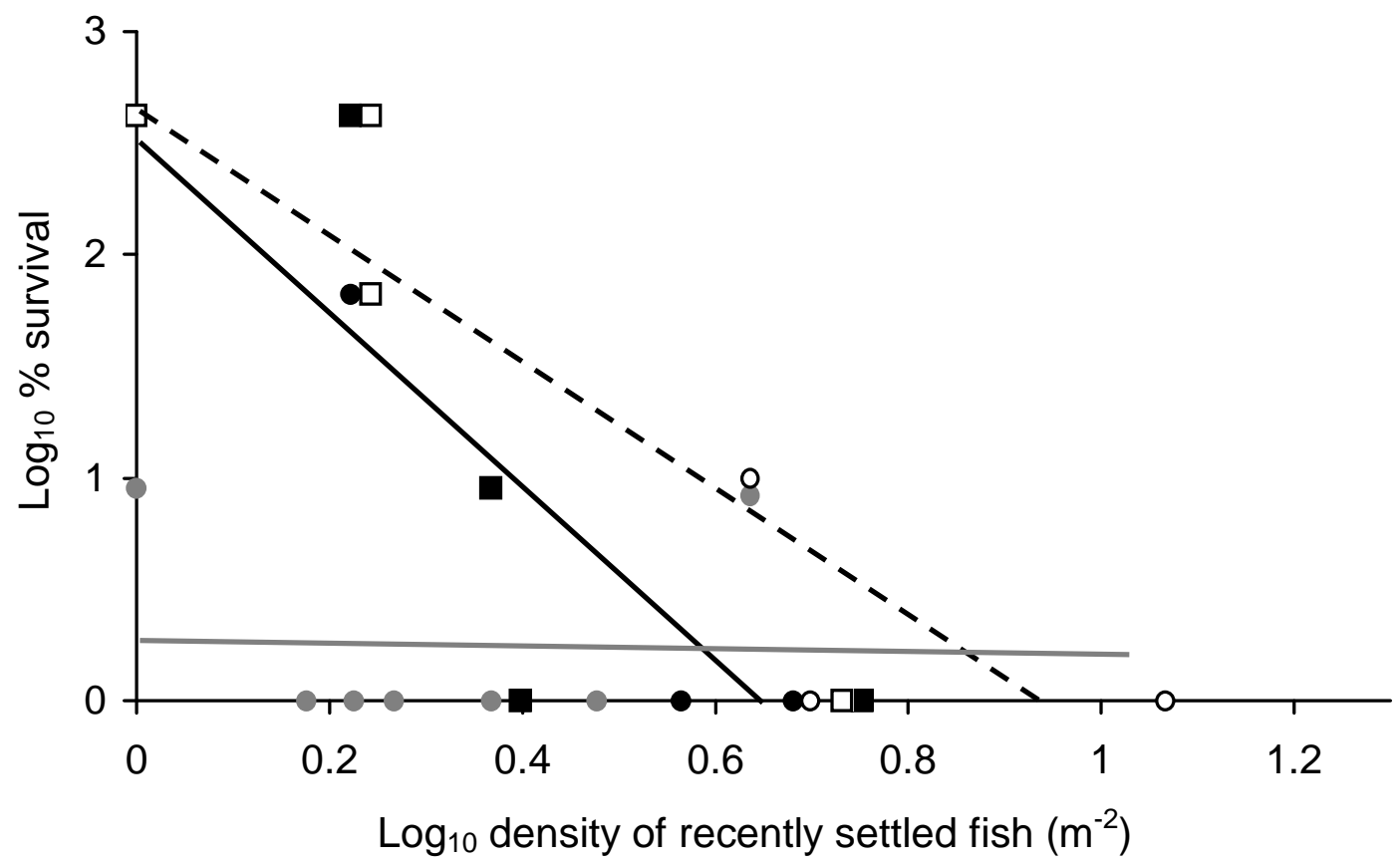

Figure 4.2. Relationship between survival and density of juvenile fish for three macroalgal treatments (Carpophyllum [open symbols/dotted line]: mixed [black symbols/black line]; and Cystophora [grey symbols/grey line]). Given are fitted regression lines from an ANCOVA. Sampling was conducted in two temporal blocks, beginning February 7 (circles) and February 252008 (squares). Survival corresponds to the number of tagged fish surviving 4 days after release. $n=7$ for each treatment. 
Table 4.1. Comparison of mean phenotypic traits of settlers (aged 0-5days old) among macraolgal treatments (Carpophyllum, mixed and Cystophora) for the common triplefin (Forsterygion lapillum). $\mathrm{N}=12,13$ and 10, respectively.

\begin{tabular}{|c|c|c|c|c|c|}
\hline \multirow[t]{2}{*}{ Phenotypic trait } & \multicolumn{3}{|c|}{ Mean \pm SD } & \multicolumn{2}{|c|}{ ANOVA } \\
\hline & Carpophyllum & Mixed & Cystophora & $F$ & $P$ \\
\hline Early larval growth $\left(\mu \mathrm{m}\right.$ day $\left.^{-1}\right)$ & $3.78 \pm 2.23$ & $3.81 \pm 2.87$ & $3.81 \pm 2.29$ & 1.62 & 0.22 \\
\hline Late larval growth $\left(\mu \mathrm{m}\right.$ day $\left.^{-1}\right)$ & $10.56 \pm 1.97$ & $10.64 \pm 0.63$ & $9.47 \pm 1.11$ & 0.71 & 0.50 \\
\hline PLD (days) & $52.16 \pm 7.13$ & $53.38 \pm 6.70$ & $48.70 \pm 7.22$ & 0.16 & 0.86 \\
\hline Size-at-settlement $(\mu \mathrm{m})$ & $37.81 \pm 2.52$ & $39.67 \pm 3.32$ & $39.67 \pm 3.02$ & 1.25 & 0.31 \\
\hline Mass (g) & $13.10 \pm 1.82$ & $13.25 \pm 2.80$ & $13.00 \pm 2.22$ & 0.01 & 0.98 \\
\hline Body condition & $0.03 \pm 0.12$ & $0.01 \pm 0.21$ & $-0.02 \pm 0.15$ & 0.45 & 0.64 \\
\hline
\end{tabular}




\section{Does juvenile growth vary with macroalgal composition?}

The ANCOVA revealed that fish in Carpophyllum and mixed patches had higher juvenile growth rates than fish in Cystophora patches (Fig.4.3; Table 4.2). The significant interaction between age and mass in the ANCOVA reveals that the rate of mass increase (i.e., the gradient) appears to differ among habitat treatments (Table 4.2). The rate of mass increase per day was 1.5 times higher in mixed patches compared to Cystophora patches, and 1.4 times higher in Carpophyllum patches compared to Cystophora patches (gradient; Carpophyllum $=0.010 \pm 0.001 \mathrm{SD}$, mixed $=0.011 \pm 0.001 \mathrm{SD}$, Cystophora $=0.007 \pm 0.001 \mathrm{SD})$. There appeared to be no significant difference in gradient between mixed and Carpophyllum patches. I found no significant relationship between growth rate and density for either age class.

Table 4.2. Results of an ANCOVA for effects of macroalgal treatment (Carpophyllum, mixed and Cystophora), referred to as 'habitat' in the table, on mass increase with post-settlement age for the common triplefin ((Forsterygion lapillum).

\begin{tabular}{|llrrr|}
\hline Source & DF & \multicolumn{1}{l}{ SS } & \multicolumn{1}{l|}{$F$} & \multicolumn{1}{l|}{$P$} \\
\hline Age & 1 & 4.10 & 177.68 & $<\mathbf{0 . 0 0 1}$ \\
Habitat & 2 & 1.01 & 21.98 & $<\mathbf{0 . 0 0 1}$ \\
Age x Habitat & 2 & 0.31 & 6.77 & $\mathbf{0 . 0 0 2}$ \\
Error & 173 & 3.87 & 1.77 & \\
\hline
\end{tabular}




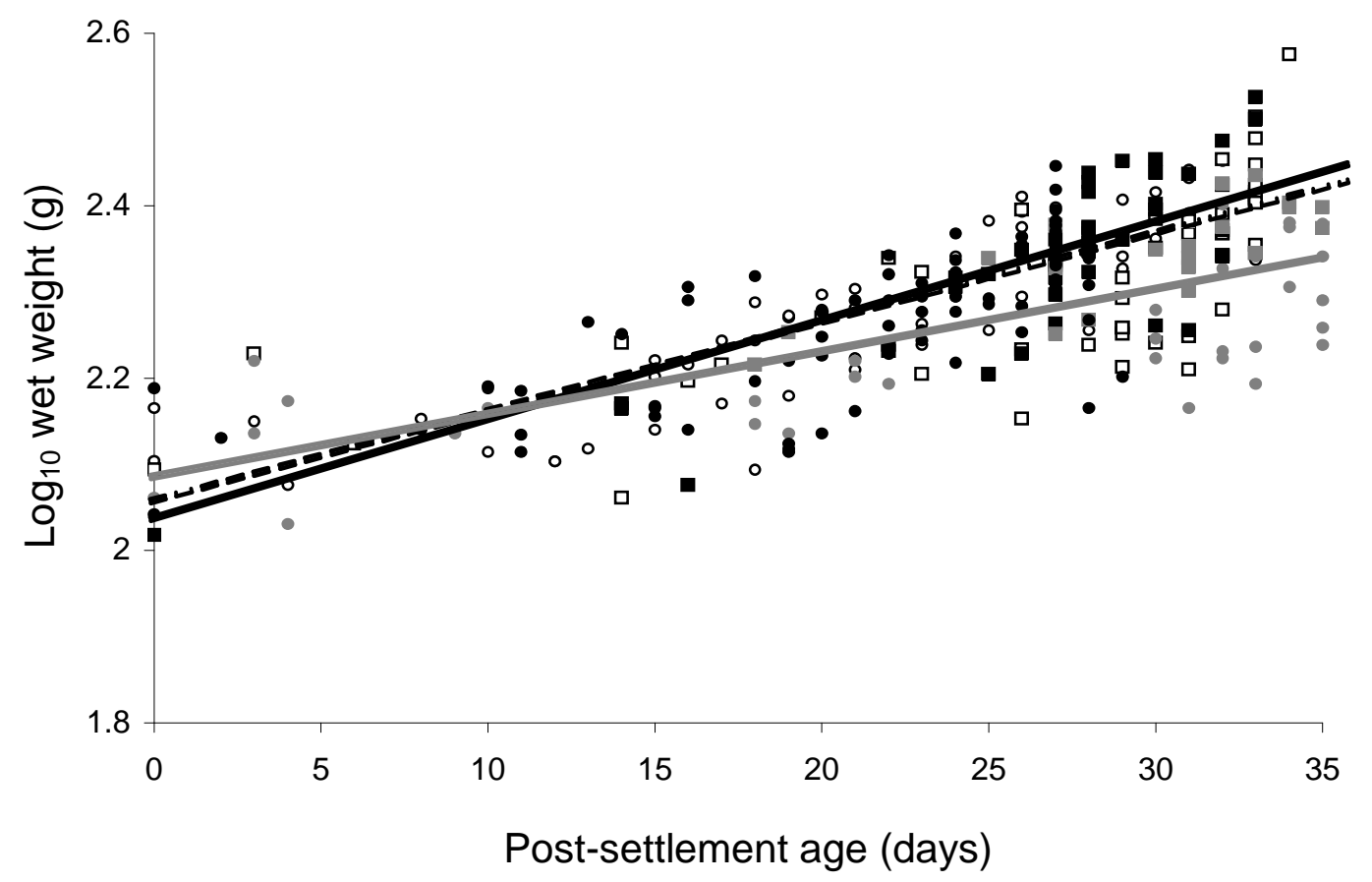

Figure 4.3. The relationship between wet weight and post-settlement age, used to represent growth rates of the common triplefin (Forsterygion lapillum) in three macroalgal treatments (Carpophyllum: $\mathrm{n}=111$ [open circles/dotted line]; mixed: $\mathrm{n}=117$ [black circles/black line]; and Cystophora: $\mathrm{n}=53$ [grey circles/grey line]). Given are fitted linear regression lines from an ANCOVA.

Incorporating density-dependent effects into quantitative estimates of nursery

\section{habitat value.}

Nursery value for each habitat type was estimated as a function of juvenile density (Fig.4.4). At low densities $\left(<3\right.$ fish $\left.\mathrm{m}^{-}{ }^{1}\right)$ nursery values were not greatly different among habitats, however as density increased differences became larger. Confidence intervals of mixed macroalgal and Carpophyllym habitats remain overlapped up to very high densities, where as the nursery value of Cystophora habitats are clearly significantly lower than both of these habitats. 


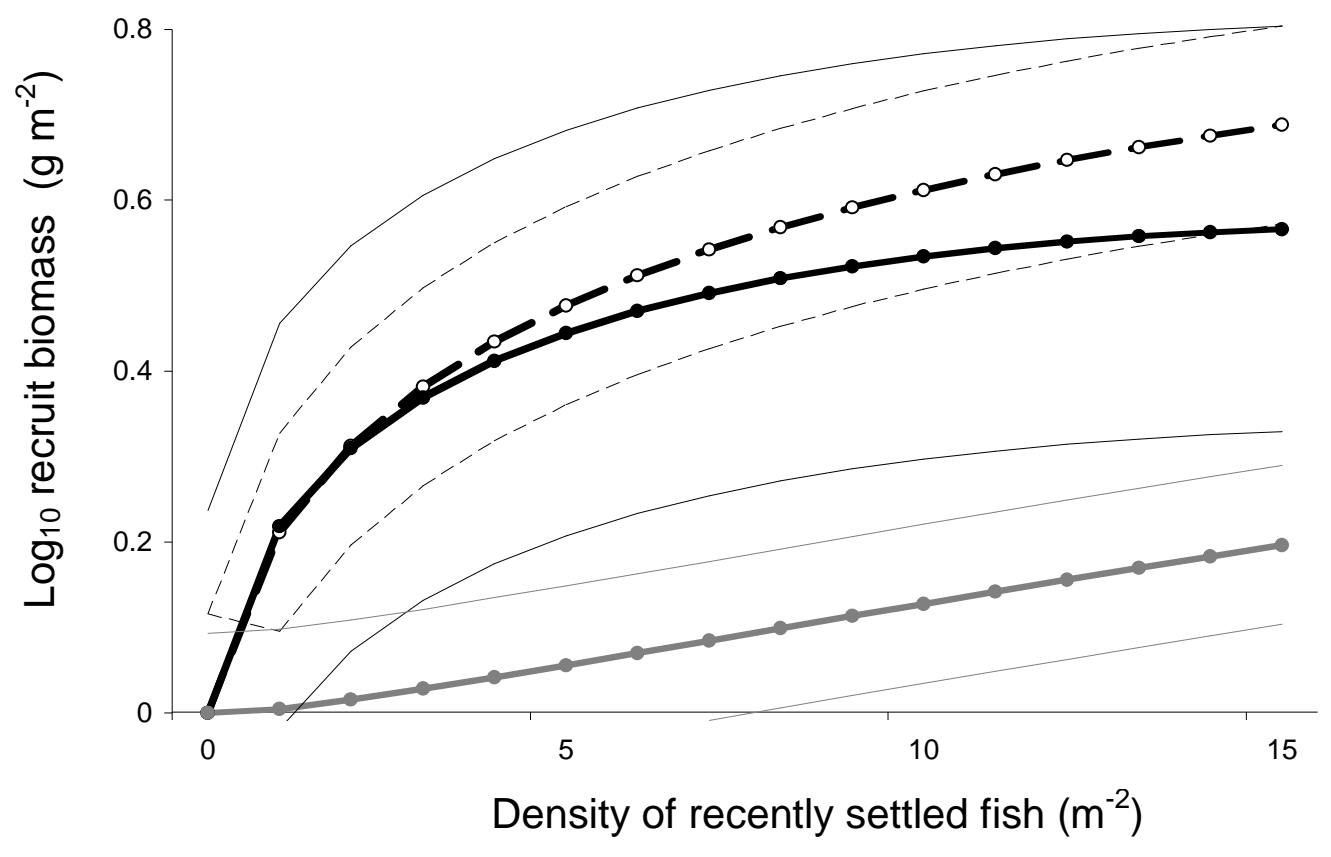

Figure 4.4. Nursery value $\pm 95 \%$ confidence intervals, estimated as total biomass of F. lapillum juveniles per $\mathrm{m}^{-2} 35$ days post-settlement for three macroalgal treatments (Carpophyllum [open circles, dotted line]: mixed [black circles, black line]; and Cystophora [grey circles, grey line]).

\subsection{Discussion}

Macroalgal beds are commonly referred to as nursery habitats due to the large numbers of juvenile fishes often found within them (e.g., flounder and tautog, Phelan et al. 2000; kelp perch, Anderson 1994; leopard grouper, Aburto-Oropeza et al. 2007; rock sole, Stoner et al. 2007; reef fish such as pinfish and spot, Powers et al. 2007). The nursery hypothesis states that nursery habitat is an area that recruits more individuals per unit area to the adult population than other habitats containing juveniles of the same species (Beck et al. 2001). This hypothesis clarifies that the nursery function of a habitat will not only depend on the density of animals present at any one time, but also on growth and survival rates of individuals, and the amount of successful movement of juveniles to adult habitats (Heck et al. 2003, Kraus and Secor 
2005, Shervette and Gelwick 2008). Few studies have examined how variation in macroalgal species composition and diversity may result in microhabitat-specific variation in juvenile density, growth and survival, and how these factors may interact to determine nursery value across habitat patches. In this study I observe a strong effect of macroalgal species composition of habitat patches on juvenile demographic rates. In particular, I identify variation among macroalgal habitats in growth rate and in the strength of density-dependent survival. I show that quantitative assessments of nursery value (i.e., the biomass of individuals recruiting to the adult population per unit area) may vary over small spatial scales with macroalgal species composition (i.e., among patches less than $2 \mathrm{~m}$ apart differing in species identity and diversity). Additionally I highlight the importance of incorporating density effects into assessments of nursery value, as variation in the density of conspecifics present within a habitat patch may influence its relative nursery value.

Density effects on growth and survival have been frequently reported for many species of reef fish, especially for recently settled juveniles (e.g., Johnson 2006, reviews in reviews by Jones 1991, Hixon and Webster 2002, Osenberg et al. 2002) ). Given that nursery habitats will potentially receive high numbers of larval recruits (Wennhage 2007), density-dependent processes may often play an important role in regulating populations within these habitats. Recruitment strength can vary considerably through time and space, on a range of different scales. For example, reef fish recruitment can vary largely between consecutive years, which may drive high temporal variation in juvenile abundance (e.g., Connell and Jones 1991). In the present study, I find that the density of recently settled individuals varies across on much smaller scales; between 1 - 11 indviduals per square meter across consecutive days and among habitat patches spaced only $2 \mathrm{~m}$ apart. I identify strong density- 
dependence at the lowest densities typically attained by F. lapillum, with density dependence resulting in mortality rates approaching $100 \%$ when natural densities of F. lapillum exceed 6 individuals per square meter. These results suggest that densitydependent survival may play an important role in shaping population dynamics of juvenile $F$. lapillum within macroalgal habitats. However this interpretation must be treated with caution as covariation of juvenile density with other factors not recorded in this study may be responsible for the observed pattern of mortality. For example, variation in adult abundance may have shown a simiar pattern of variation to juvenile density. Adult $F$. lapillum have been observed to exhibit aggressive and even cannabilistic behaviour towards recently settled conspecifics, thus higher densities of adults, or other competitive or predatory species, within patches also containing higher densities of juvenile fish, may have led the observed pattern of mortality. However data on the same habitat patches prior to the tagging experiment indicates that the density of adult triplefins, as well as the main predatory species such as Notolabrus celidotus and Parapercis colias, did not differ among patches (A. PerezMatus and A. Smith, unpublished data).

Predation is known to be a major source of mortality for most larval and juvenile fishes in the marine environment (Bailey and Houde 1989, Planes and Lecaillon 2001, Doherty et al. 2004). Predators of F. lapillum such as Parapercis colias were frequently observed inside the study site and the most commonly observed fish species Notolabrus celidotus was observed feeding on recently settled F. lapillum, indicating that predation pressure may be high at this site (A. Smith, unpublished data). However without further experimentation I cannot elucidate the mechanisms underlying variation in density-dependent mortality among habitats. 
Whatever the mechanism, it is interesting to find that observed patterns of survival varied with macroalgal species composition, as did growth rates. Several studies have suggested that fish abundance is higher in macroalgal habitat as opposed to other non-vegetated habitats due to increased habitat complexity resulting in differential predation (Gotceitas and Brown 1993, Tupper and Boutilier 1995a) and/or greater prey densities being present in algal habitats (Tupper and Boutilier 1995b, Meng 2004). The algal species used in this study do vary in structural complexity on a fine scale and support different communities of epifauna. Cystophora is expected to have a higher level of complexity but in northern New Zealand, Carpophyllum was reported as supporting a higher number and diversity of amphipods (i.e., a food source of F. lapillum; Feary et al. 2009) (Taylor and Cole 1994). Heterogeneity in macroalgal species identity and diversity within a patch may influence factors structural complexity and prey availability, both already known to be important in driving variation in fish growth and survival. Density-dependent mortality in marine fishes often results due to an interplay between predation and competition which are mitigated by such factors.

Previous reef fish studies have found that density dependent survival may occur indirectly, through density-dependent effects on growth (e.g. Vollestad and Olsen 2008). If small size increases susceptibility to predation, slow growing fish may be more vulnerable to predation as they remain smaller for longer (Miller et al 1988, Bailey and Houde 1989). I found no evidence of density-dependent effects on growth in any of the habitat treatments; however, the rate of juvenile growth did vary with macroalgal composition. These results are consistent with studies conducted in the previous year at Kau Bay, which also found fish had higher growth rates of fish within mixed macroalgal patches and monospecific Carpophyllum compared to 
monospecific Cystophora (Chapter 2). Slower growth rates of fish in monospecific Cystophora possibly may be indicative of less favourable conditions within this habitat type. In monospecific Cystophora patches, density-independent effects on survival appear to dominate over density-dependent effects. These initial findings support the theoretical prediction that density- independent effects on survival should predominate when environmental conditions are less favourable, while densitydependent effects should predominate when environmental conditions are benign (Haldane 1953, Vollestad and Olsen 2008). However, further experimentation is needed to test how conditions, such as prey availability and predator abundance, may vary among habitat types. It is possible that an increased growth rate may explain the stronger density-dependent effects observed within mixed macroalgal and monospecific Carpophyllum patches. Fish that are growing faster will be of a larger size, will have access to fewer refuges and for example, may therefore compete more strongly for space dependent resources such as refuges (Samhuori et al. 2009).

In contexts where survival is density-dependent, I demonstrate that nursery value may vary thorugh time and space as a function of settlement intensity. Other studies have reported high variation in nursery value of habitats among sites and years. Kraus and Secor (2005) reported that for an estuarine fish, high variation in inter-annual recruitment strength correlated to variation in nursery habitat function. In dominant year-classes of white perch, brackish habitats had the highest nursery value, whereas in all other year-classes, freshwater habitats had the highest nursery value. In caging experiements where fish were maintatined at a constant density, both winter flounder and tautog had higher growth rates in macroalgae compared to eelgrass and non-vegetated habitats, but only in one location, where as in other sites both species had higher growth rates in eelgrass, or no variation in growth among habitat types was 
found (Phelan et al. 2002). In other fish species, variation in growth and survival of fish among algal habitats (e.g., seagrass versus macroalgal beds) has been reported to be surprisingly low (Heck 2003). The contrasting findings from in these studies and the results reported here, may be due to the strong site-sttached behaviour demonstrated by $F$. lapillum, resulting in variation over smaller spatial scales. In a closely related species, Forsterygion varium, which also remains site-attached following settlement, strong variation in a juvenile growth and survival was reported among cobble habitats varying in structural complexity over relatively small scales (across metres; Connell and Jone 1991). The scale at which demographic rates vary will be dependent upon the scale of movement of the organism of interest (Williams et al. 2003). This study suggests that for more site-attached juveniles, fine-scale heterogeneity in habitat-specific demographic rates may be more ubiquitous than previously considered.

Clearly nursery value of habitats has the potential to be highly variable through space and time. This may be due to variation in fish density coupled with variation in the strength of density-dependence among habitats. Results from this study provide an example where the difference in nursery value between mixed macroalgal patches and monospecific Carpophyllum patches may only become apparent at high densities of young F. lapillum. Spatial and temporal variation in larval supply and larval history jointly affect the density of recently settled fish within nursery habitats. When fish settle in high condition (as a result of favourable conditions in the pelagic phase), a larger number of individuals may survive to the early juvenile stage (see Chapters 2 and 3). Additionally, the condition of individuals at settlement may affect the strength of density-dependent effects. For example, high condition reef fish can withstand increased levels of intraspecific competition as early 
juveniles (Johnsson 2008). Therefore, the importance of density-dependent processes may vary with spatial and temporal variation in pre-settlement processes, such as larval condition at settlement. Additionally variation in nursery value may occur due to interactions between the habitat and other the current environmental conditions, such as temperature, primary productivity and wave exposure.

Conservation and management strategies should potentially focus on those habitats identified to have the highest nursery value. This study demonstrates that the nursery value may be determined by demographic processes that vary with habitat heterogeneity over fine-scales. Additionally, density-dependent effects may have the potential to reduce, or magnify, this fine-scale variation. Fine-scale heterogeneity in the demographic rates of $F$. lapillum is likely to have important implications for largescale dynamics of adult populations. This study emphasizes the need to closely evaluate fine-scale spatial heterogeneity, even when larger scale responses are of interest. The incorporation of habitat specific demographic rates that vary over fine spatial scales may advance our ability to assess the mechanisms driving population dynamics, and help prioritise key areas for management and conservation. 


\section{Chapter 5}

\section{Variation in pre-settlement growth as a driver of morphological variation in a juvenile reef fish}

\subsection{Abstract}

The drivers of between-individual variation in phenotypic plasticity underlying observed trait-environment relationships are rarely considered, despite such variation having potentially large implications on population ecology. Patterns of morphological development can be condition dependent, for example lower growth rates may constrain plasticity due to lower available energy to produce and maintain plastic morphologies. Intrinsic variation in growth histories during early life stages have been shown to influence subsequent growth rates and performance of older stages in a range of organisms. Thus, spatial and temporal patterns of prior growth rates of colonizers may potentially influence phenotypic expression in response to environmental variation in the new habitat. Here, I evaluate how body morphology of a temperate reef fish varies in response to: (1) settlement habitat and geographic site; and (2) intrinsic variation in larval growth and subsequent post-settlement growth. Over a period of two years I sampled juvenile Forsterygion lapillum (the common triplefin) from 3 different macroalgal habitat types at two sites located in contrasting environments in the Wellington region, New Zealand. Using image analysis of otolith traits, I reconstructed growth trajectories of individuals prior to and after settlement. Although settlement habitat did not influence morphology, allometric growth rates of mouth morphology (maximum gape height and length) and tail length differed between sites. At both sites, mouth morphology was also correlated with larval 
growth rate - fish that grew faster prior to settlement had larger mouths with a greater maximum gape height and width. Furthermore the magnitude of individual variation exhibited in morphology within a local population, was observed to correlate to the level of intra-individual variation present in larval growth. Cohorts of fish that exhibited higher levels of individual variation in growth during the larval phase, also exhibited higher levels of individual variation in morphology following settlement. These results suggest that growth variation during early life-history stages may constrain the magnitude of morphological response exhibited within a population at later stages.

\subsection{Introduction}

An organism's ability to change its phenotype in response to environmental conditions can be critical for its survival (Scheiner 1993, Via et al. 1995). When there are reliable environmental cues, many organisms exhibit phenotypic plasticity in response to changes in their environment and improve their performance (Pigliucci 2001, West-Eberhard 2003, DeWitt and Scheiner 2004). This phenomenon can be seen throughout the natural world and can result in genetically identical individuals differing in morphology. For example, some plants produce leaves of different size or shape when grown in the shade and when grown in full sun (Bjorkman 1981). Theoretical studies have shown that adaptive trait change can have unpredictable impacts on multispecies interactions and may be important for determining the longterm dynamics and persistence of populations and communities (Abrams 1982, 1992, Holt 1984, Matsuda et al. 1994, Bolker et al. 2003).

Recently, the importance of between-individual variation in plasticity in mediating population dynamics has received considerable attention (Nussey et al. 
2005a, Nussey et al. 2005b, Reed et al. 2006, Nussey 2007, Brommer et al. 2008, Williams 2008, Williams et al. 2009). Phenotypic plasticity may involve costly energy demands (DeWitt et al. 1998), including maintenance costs of sustaining the sensory pathways that induce plastic responses, and production costs associated with morphological changes (Relyea 2002). A potential constraint to the level of morphological response to environmental conditions shown by an individual might be limitations in available energy, as indicated by individuals with lower growth rates exhibiting less extreme forms of morphology (Olsson et al. 2005, Olsson et al. 2006). For organisms with complex life cycles, growth and performance of juvenile and adult stages can be dependent on performance experienced previous life-history stages. For example, growth rate experienced by individuals during the larval stage have been shown to influence subsequent performance and growth of fishes (e.g., Searcy and Sponaugle 2001, Hoey and McCormick 2004), amphibians (e.g., Goater 1994, Altwegg and Reyer 2003), terrestrial invertebrates (e.g., Jannot 2009), and aquatic invertebrates (Qian and Pechenik 1998, Wacker and von Elert 2002). Despite spatio-temporal patterns of between-individual phenotypic variation in early lifehistory stages having been documented in a number of systems (e.g. Juterbock 1990, Sweeney and Vannote 1986, Weiss et al. 1993, Phillips 2002), the potential for this variation to influence the ability of an individual to change its phenotype in response to environmental conditions in later life-history stages has yet to be thoroughly investigated.

The majority of species in marine systems have a dispersive pelagic larval phase and at settlement larval fish may show high between-individual variation in larval growth rate, pelagic larval duration and size at settlement (Wellington and Victor 1989, McCormick and Molony 1993, McCormick 1994, Sponaugle and Cowen 
1994, 1997, Kerrigan 1996, Searcy and Sponaugle 2000, Shima and Swearer 2009). Variation in growth during early life history is largely a reflection of parental contributions and environmental variation such as temperature and food availability (Green and McCormick 1995). Recent studies of reef fishes have found that growth advantages manifested in the larval phase are maintained upon settlement in the benthic habitat (Searcy and Sponaugle 2001, Shima and Findlay 2002, Vigliola and Meekan 2002, Hoey and McCormick 2004, Raventos and Macpherson 2005, Jenkins and King 2006, Johnson 2006). Following settlement, fish species often exhibit plasticity in body shape in response to a variety of environmental influences, including temperature (Martin 1949, Beacham 1990, Loy et al. 1996), water velocity (Imre et al. 2002), quantity of food (Currens et al. 1989) and type of food or feeding mode (e.g. Meyer 1987, Wimberger 1992, Day et al. 1994, Robinson and Wilson 1995). Thus, reef fish provide an exciting opportunity to investigate how natural variation in intrinsic growth rates prior to and after settlement may influence patterns of morphological plasticity in body shape in response to environmental influences.

In this study, I focused on the plastic morphological responses of a juvenile temperate reef fish (Forsterygion lapillum). I examined morphological variation at two sites differing in environmental conditions (wave exposure, temperature, density of conspecifics and predators) and among microhabitats differing in macroalgal composition (monospecific algal patches versus mixed algal patches). I examine whether patterns of growth rate prior to and after settlement can explain the magnitude and distribution of morphological variation observed. I predicted that body morphology would vary between sites and to a lesser extent between microhabitats within each site. Furthermore, I predicted that allometric growth rates of morphological traits would vary with growth rate experienced immediately prior to 
settlement. Specifically, that individuals experiencing faster growth prior to settlement will maximise allometric growth rates of functionally adaptive traits, for example to grow larger jaws relative to body size, during the initial period following settlement. This may be due to faster larval growth rates resulting in increased growth following settlement, and therefore I expect patterns of allometry to also correlate to juvenile growth rate. Finally, I expect the magnitude of morphological variation among individuals within a site and microhabitat will be positively correlated to the level of intrinsic variation in growth rate before and after settlement.

\subsection{Methods}

\section{Study system and sampling}

Our work examines phenotypic variation in the common triplefin, Forsterygion lapillum (Family: Tripterygiidae). Forsterygion lapillum is one of the most abundant species in shallow rocky reef habitats of New Zealand (Clements 2003, Feary and Clements 2006, Wellenreuther et al. 2007) Forsterygion lapillum feeds upon a range of small invertebrates (Feary 2001, Clements 2003) and is likely an important prey species for larger reef predators. Females spawn benthic egg masses on cobbles which are defended and cared for by males for $\sim 2$ weeks before hatching (Thompson 1979, Francis 2001, A. Smith, unpublished data). Larvae complete development in the pelagic water column, where they are patchily distributed (Kingsford and Choat 1989). In the Wellington region, juveniles settle to the fronds of macrophytic brown algae (McDermott and Shima 2006) between December and March, after a mean pelagic larval duration of $52 \mathrm{~d}$ (SD: $8 \mathrm{~d}$; A.Smith, unpublished data).

To quantify temporal and spatial patterns of variation in growth trajectories and fish morphology, juvenile $F$. lapillum were sampled between January and March in 
2007 and 2008, from two sites: Kau Bay $\left(41^{\circ} 17^{\prime}\right.$ S, $174^{\circ} 50$ E) and Island Bay (41 ${ }^{\circ} 20^{\prime}$ S, $174^{\circ} 46^{\prime}$ E), Wellington, New Zealand. These sites were chosen because: (1) they are known to be replenished by larvae with different phenotypes (Shima and Swearer 2009, in press); and (2) they differ in local environmental conditions, including temperature, turbidity, densities of potential predators and competitors (A. Smith and J. Shima, unpublished data). Kau Bay is located within Wellington harbour; a sheltered, well-mixed, nutrient-rich, semi-enclosed body of water supporting a higher abundance of juvenile and adult $F$. lapillum and also a higher abundance of other potentially predatory fish species (A. Perez-Matus and A. Smith, unpublished data). By comparison Island Bay is located on the adjacent high-energy, very exposed open coast with low productivity (Bowman et al. 1983). The Island Bay site is partially protected from periodic large southerly swells by a small offshore island (Taputeranga Island) and supports lower population densities of $F$. lapillum and lower overall fish densities (A.C.Smith, personal observation). Macroalgal canopy (i.e., the settlement habitat for F. lapillum) is patchily distributed within both sites and is predominately comprised of two species of fucalean brown algae: Carpophyllum maschalocarpum and Cystophora torulosa (A. Smith, personal observation). At each site, I identified a representative area of reef $\sim 10 \mathrm{~m}$ long (parallel to the shore), $5 \mathrm{~m}$ wide, and at a depth of $\sim 6 \mathrm{~m}$. From within these areas I collected recently settled $F$. lapillum (individuals <40mm standard length) with hand nets (aided by the use of SCUBA). In 2007, all fish were collected from artificially created $2.25 \mathrm{~m}^{2}$ habitat patches. The habitat patches represented one of three settlement habitat types: (1) monocultures of Carpophyllum; (2) monocultures of Cystophora; or (3) mixed algal stands (comprised of Carpophyllum and Cystophora). In 2008, fish were collected in the same area from natural habitat patches, and sampling areas were delineated by haphazard placement 
of $1 \mathrm{~m}^{2}$ quadrats. Two types of settlement habitat were sampled: (1) monospecific Carpophyllum; or (2) mixed algal stands (comprised of Carpophyllum and Cystophora).

I collected fish on dates paired (as closely in time as weather and sea conditions would permit) between locations (Harbour: 2-Feb-07, 15-Feb-07, 29-Feb07, 26-Mar-07, 21-Jan-08, 13-Feb-08, 22-Feb-08; South coast: 21-Jan-07, 13-Feb-07, 22-Feb-07, 21-Mar-07, 16-Jan-08, 15-Feb-08, 29-Feb-08).

\section{Quantifying age and growth histories}

To quantify age and growth histories of individuals, I analyzed the otolith record of 267 juvenile $F$. lapillum. Otoliths of many fishes (including $F$. lapillum) form in daily growth increments that can be used to infer stage-specific age and growth patterns of individuals (e.g. Campana and Thorrold 2001, Hare and Cowen 1995, Shima and Findlay 2002, Sponaugle et al. 2006). Otoliths were prepared following the methods of Shima and Swearer (2009). I used an image analysis system consisting of a compound microscope, a digital camera, and computer-based image analysis software (Image Pro Plus v5.0), to measure sequences of daily otolith increment widths from different stages of the life history of each sampled fish. Briefly, a conspicuous settlement mark is formed in this species (Kohn 2007) and was used as a reference point for the division between larval and post-settlement increments. Late larval growth was estimated as the mean increment width across the final 7 days of larval growth before settlement. Using 'post-settlement age', calculated as the number of daily growth increments following the settlement mark, I back-calculated 'settlement date' from the known date of collection. I estimated juvenile growth rate as the average increment width $\left(\mu \mathrm{m} \mathrm{d}^{-1}\right)$ across the entire 
juvenile period (i.e., from settlement to capture; mean post-settlement age of sampled fish $=18.20 \mathrm{~d}, S D=14.31)$.

\section{Variation in morphology among sites, microhabitats and sampling days}

In order to assess how juvenile body morphology varied between sites and microhabitats I measured key morphological traits of all sampled individuals. Fish were lightly blotted dry and weighed to the nearest $1 \mathrm{mg}$ (wet weight) using a mass balance. Electronic calipers were used to measure four morphological variables to the nearest mm. 1) Gape height (MH): the height of the gape when the mouth is fully open. 2) Gape width (MW): the width of the gape when the mouth is fully open. 3) Body depth (BH): from base of dorsal fin to base of anal fin at the deepest part of the body. 4) Tail length (TL): the distance from the caudal peduncle to the furthest edge of the caudal fin. I selected these four morphological traits as they are related to the ability to escape predation and/or maximise feeding success and have important functional implications for juvenile fish performance (Webb 1984). Additionally, these traits are subject to plasticity in other fish species (e.g., Webb and Blake 1985, Wimberger 1992, Walker 1997, Heerman et al. 2007, Domenici et al 2008).

To understand the effects of phenotypic plasticity it is important to be able to reliably estimate the magnitude of morphological variation, which is difficult while organisms are still undergoing development, and commonly involves the removal of size effects. A wide range of taxa exhibit allometric growth rates, whereby different morphological traits within an organism grow at different rates (Huxley 1932, Thompson 1942, Loy et al. 1998, Birch 1999, Tokeshi et al. 2000, Rosas and Bastir 2002, Cardini and Tongiorgi 2003). Hence, if populations exhibit different allometric growth rates, controlling for body size across a population may no longer be 
appropriate (McCoy et al 2006, McCoy 2007). Phenotypic differences may be occurring via changes in growth trajectories of morphological traits relative to body size, and therefore it is important to quantify this relationship rather than remove it.

To test if fish from different sites and habitats exhibited similar patterns of allometric growth (and therefore whether traits could be accurately size-corrected), I used a Common Principal Components Analysis approach (CPCA: McCoy et al. 2006). CPCA is a generalization of PCA for comparisons of multiple groups or populations and can be used to test whether groups share common patterns of allometry (Flury 1988, Klingenberg and Spence 1993, Klingenberg and Zimmermann 1992, McCoy et al. 2006, Phillips and Arnold 1999, Steppan 1997a, b). If groups share a common size axis (i.e., share their first CPC), then the data can be standardized for size and subsequently analyzed (Bartoletti et al. 1999, Flury 1988, Klingenberg 1996). Sites did not share a common body axis, however microhabitats within each site did (see Results). Therefore I analysed variation in morphological traits (maximum gape height and width, body depth and tail length) among microhabitats separately for each site. I used Burnaby's back project method to obtain size-corrected trait values and compared these size-corrected trait values among microhabitats (monocultures of Carpophyllum, monocultures of Cystophora and mixed algal stands) for each site using an analysis of variance (McCoy et al. 2006). I also used the same procedure to test for variation in morphological traits among sampling days at each site.

Since size-correct measurements of morphology could not accurately be achieved across sites, I explored the variation in allometric growth rates of morphological traits between sites. When two groups lack a common body axis, the 
exponent of the scaling relationships (i.e., slope of a log-log linear regression between morphological variables) can be used as the response variable (McCoy 2007).

\section{Growth rates as drivers of morphological variation among individuals}

As sites did not share a common size axis (see Results) I investigated variation in morphology separately for each site (Kau Bay and Island Bay). I examined variation in body morphology (jaw height, jaw width, body depth and tail length) as a function of body mass and two possible predictor variables. In order to avoid problems with collinearity, as larval and juvenile growth are expected to be positively correlated, I investigate the affect of these predictor variables on morphology using two independent MANCOVA and ANCOVA models. In each model either larval growth or juvenile growth was used as a continuous independent variable, and body mass was included as a covariate. Sample day was included as a random effect in the model. Due to the relationship between body morphology and mass being allometric, I $\log _{10}$ transformed each measure of body morphology (jaw height, jaw width, body depth and tail length; dependent variables) and body mass (covariate). In all cases the interaction term ('larval growth x mass' or 'juvenile growth $\mathrm{x}$ mass') was insignificant $(\mathrm{P}>0.45)$ and therefore removed from the model.

\section{The magnitude of morphological variation}

I examined whether the magnitude of morphological variation among individual fish sampled from within a quadrat, varied between sites, habitats and in relation to the level of intrinsic variation in growth prior to and following settlement. The coeffecient of variation ( $\mathrm{CV}$; standard deviation/mean) is a relative measure of variation. This index of variation has the additional advantage of allowing 
standardized comparison of traits between sites as mean trait values are not compared directly and therefore size-correction is not required. CV values of each morphological trait (jaw height, jaw width, body depth and tail length) were calculated from each quadrat and used to compare among-individual morphological variation between sites (Island Bay and Kau Bay) and habitats (monocultures of Carpophyllum, monocultures of Cystophora and mixed algal stands), and in relation to varying levels of variation in larval and juvenile growth rates.

First, I calculated the CV of each morphological trait for fish collected from each quadrat on each sampling day. Second, I calculated the CV of larval and juvenile growth rates in the same way, for each quadrat on each sampling day. I used two separate ANCOVA analyses to assess whether the magnitude of variation in morphology (CV) was varied between habitats and sites and with (1) the magnitude of variation in larval growth rates and (2) the magnitude of variation in juvenile growth rates. Habitat type and site were included as fixed effects and in each model either $\mathrm{CV}$ of larval growth or $\mathrm{CV}$ of juvenile growth was included as continuous independent variable. All statistical analyses were performed using the EMS procedure in JMP 7.0 (SAS Institute Inc., Cary, NC, USA).

\subsection{Results}

\section{Variation in morphology between sites, microhabitats and sampling days}

Fish from the two sites (Kau Bay and Island Bay) did not share a common PC1 axis $(P=0.002)$, indicating that patterns of allometry varied between the sites (i.e., fish at each site did not share a common body size axis). Therefore I directly examined the slope of the log-log relationship of traits to body weight, in order to quantify variation in allometric growth rates (McCoy 2007). Mouth height and mouth 
width grew on average twice as fast at Kau Bay relative to fish at Island Bay (Fig.

5.1A and B). There was no clear difference in body depth allometry between sites

(Fig. 5.1C). Tail length grew on average 1.4 times faster in fish at Kau Bay relative to fish at Island Bay (Fig. 5.1D).

Fish from different microhabitats and different sampling days within each site share a common $\mathrm{PC} 1$ axis $(\mathrm{P}=0.42$ and $\mathrm{P}=0.66$, respectively), indicating that fish had the same patterns of allometric scaling. Once body size was removed using Burnaby's back projection method, there were no detectable differences in fish morphology with microhabitat or sampling day ( $\mathrm{P}>0.2$ for all traits).

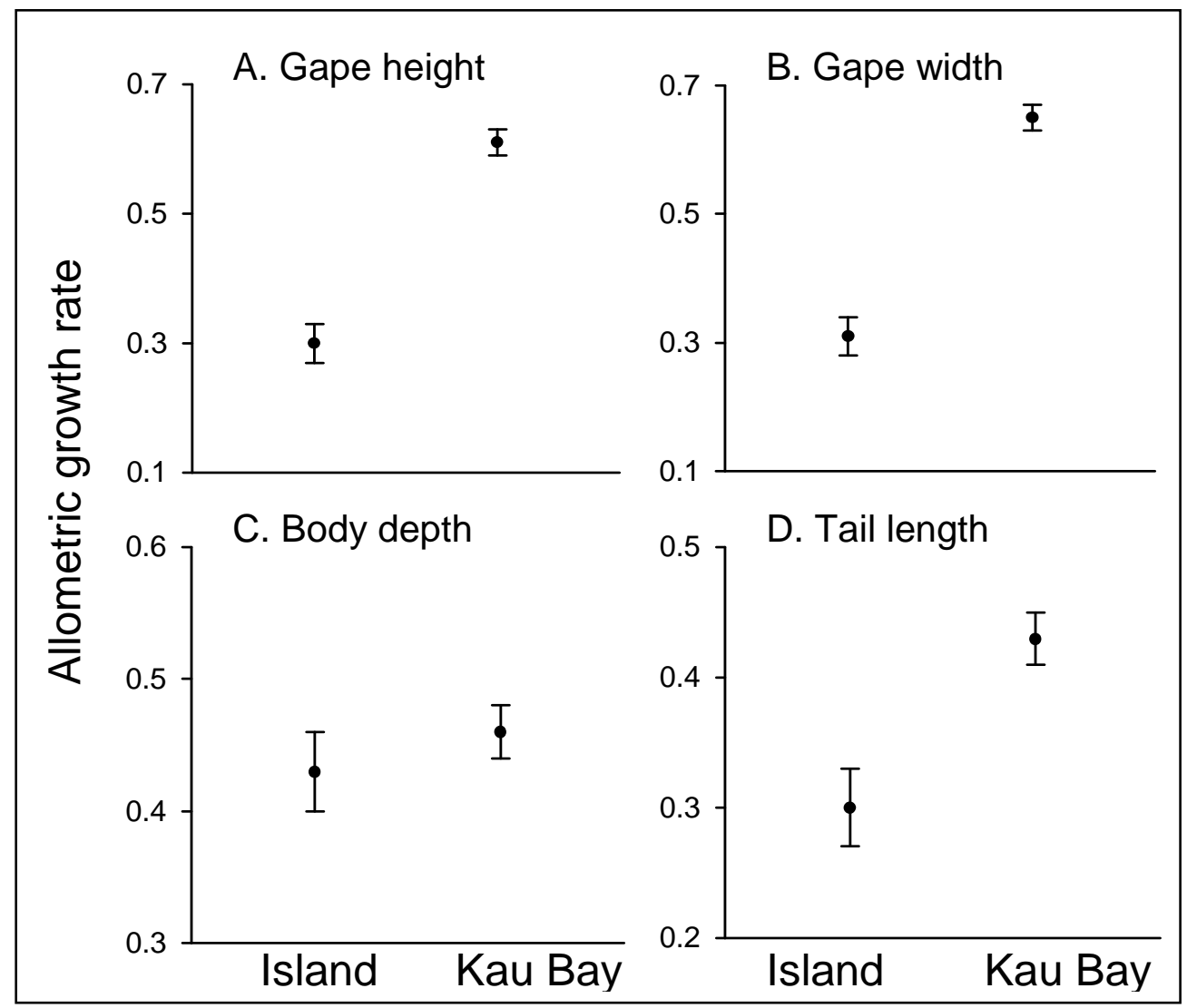

Figure 5.1. Allometric growth relationships of traits from fish at each site (Kau Bay and Island Bay). Each point indicates the estimated slope $( \pm \mathrm{SE})$ from the log-log plot of body mass and A. gape height, B. gape width, C. body depth and D. tail length. 


\section{Growth rates as drivers of morphological variation among individuals}

MANCOVA analyses revealed that, as expected, a strong positive linear relationship existed between morphology and body mass (Table 5.1 and 5.2), with each morphological trait (gape height, gape width, body depth and tail length) exhibiting a strong positive correlation to body mass (Table 5.3). At both sites, larval growth rate had a significant effect on morphology (Table 5.1), where as juvenile growth rate had no effect (Table 5.2). At Island Bay, fish that grew faster as larvae immediately prior to settlement had larger mouths, with a greater maximum gape height and width, following settlement (Table 5.3, Fig. 5.2). At Kau Bay, fish that grew faster during the larval stage also developed a larger maximum gape height following settlement (Table 5.3, Fig. 5.2), but there was no effect of larval growth on maximum gape width at this site (Table 5.3, Fig. 5.2).

Table 5.1. MANCOVA results examining how the morphology (jaw height, jaw width, body depth and tail length) of juvenile fish were affected by larval growth at each site. Significant $P$-values $(P<0.05)$ are displayed in bold.

\begin{tabular}{|lccc|}
\hline Factor & $d f$ & $F$ & $P$ \\
\hline A. Island Bay & & & \\
Mass & 1,24 & 12.809 & $<\mathbf{0 . 0 0 0 1} * * *$ \\
Larval growth rate & 1,24 & 44.119 & $\mathbf{0 . 0 1 7 5} * *$ \\
& & & \\
B. Kau Bay & & & \\
Mass & 1,96 & 12.809 & $<\mathbf{0 . 0 0 0 1}$ **** \\
Larval growth rate & 1,96 & 44.119 & $<\mathbf{0 . 0 0 0 1} * * *$ \\
\hline
\end{tabular}

Table 5.2. MANCOVA results examining how the morphology (jaw height, jaw width, body depth and tail length) of juvenile fish were affected by larval growth at each site.

\begin{tabular}{|lccc|}
\hline Factor & $d f$ & $F$ & $P$ \\
\hline A. Island Bay & & & \\
Mass & 1,24 & 12.809 & $<\mathbf{0 . 0 0 0 1 * * *}$ \\
Juvenile growth rate & 1,24 & 44.119 & 0.8644 \\
& & & \\
B. Kau Bay & & & \\
Mass & 1,96 & 12.809 & $<\mathbf{0 . 0 0 0 1} * * * *$ \\
Juvenile growth rate & 1,96 & 44.119 & 0.9989 \\
\hline
\end{tabular}


Table 5.3. ANCOVA (univariate) results ( $P$-values) of the effect of late larval growth rate on each individual trait, with mass as a covariate, at each site for the data in Table 5.1 .

\begin{tabular}{|lclll|}
\hline Factor & Gape height & Gape width & Body depth & Tail length \\
\hline A. Island Bay & & & & \\
Mass & $<\mathbf{0 . 0 0 0 1} * * *$ & $\mathbf{0 . 0 0 0 8} * *$ & $<\mathbf{0 . 0 0 0 1} * * *$ & $\mathbf{0 . 0 0 2 1} * *$ \\
Larval growth rate & $\mathbf{0 . 0 3 0 5}^{* *}$ & $\mathbf{0 . 0 2 1 8} *$ & 0.6027 & 0.0816 \\
& & & & \\
B. Kau Bay & & & & \\
Mass & $<\mathbf{0 . 0 0 0 1} * * *$ & $\mathbf{< 0 . 0 0 0 1} * * *$ & $<\mathbf{0 . 0 0 0 1} * * *$ & $<\mathbf{0 . 0 0 0 1} * * *$ \\
Larval growth rate & $<\mathbf{0 . 0 0 0 1} * * *$ & 0.3676 & 0.9989 & 0.0536 \\
\hline
\end{tabular}

\section{The magnitude of morphological variation}

The magnitude of morphological variation did not differ among habitats or between sites for any trait (gape height, gape width, body depth and tail length), and this result did not differ whether larval or juvenile growth was included as the covariate ( $\mathrm{P}>0.2$ in all cases). Sampling date also did not have a significant effect on relative variation observed for any of the morphological traits for either covariate $(\mathrm{P}>0.5)$. However, I observed a significant increase in the magnitude of relative variation in jaw height with increasing relative variation in late larval growth rate (larval growth as main effect; $\mathrm{F}_{1,32}=10.61, \mathrm{P}=0.004$; Fig. 5.3). Groups of individuals that had experienced high levels of among-individual variation in pre-settlement growth, also exhibited a greater magnitude of variation in maximum gape height (Fig. $5.3)$. 


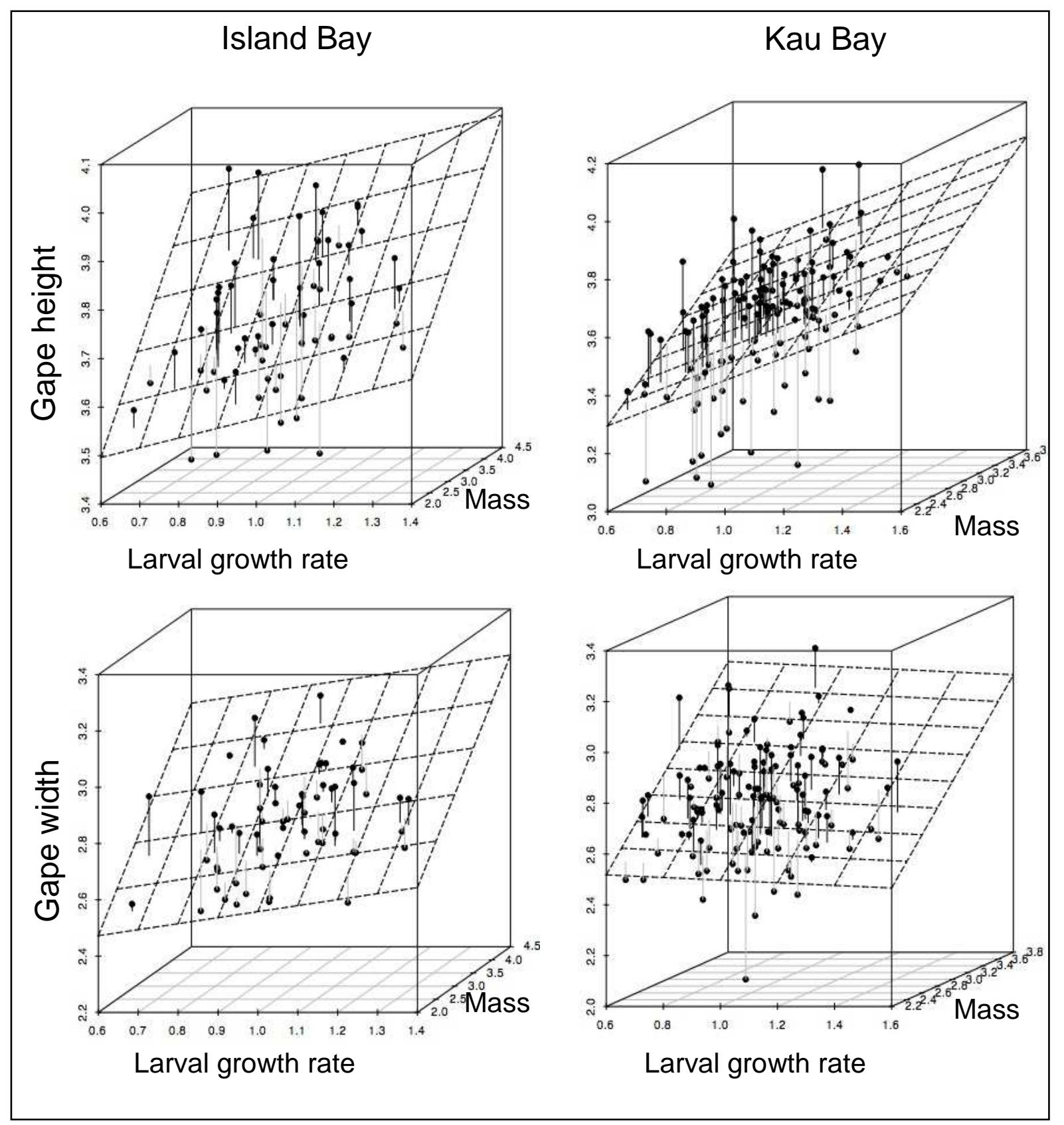

Figure 5.2. Fitted surfaces for gape height and gape width ( $\log _{10}$-transformed) with mass ( $\log _{10}$-transformed) and larval growth rate at two different sites (Island Bay and Kau Bay). In these 'lollipop' plots, observed gape height and gape width are represented by spheres and the residuals from the fitted surfaces are represented by solid grey lines. These fitted surfaces correspond to the ANCOVA models given in Table 5.3. 


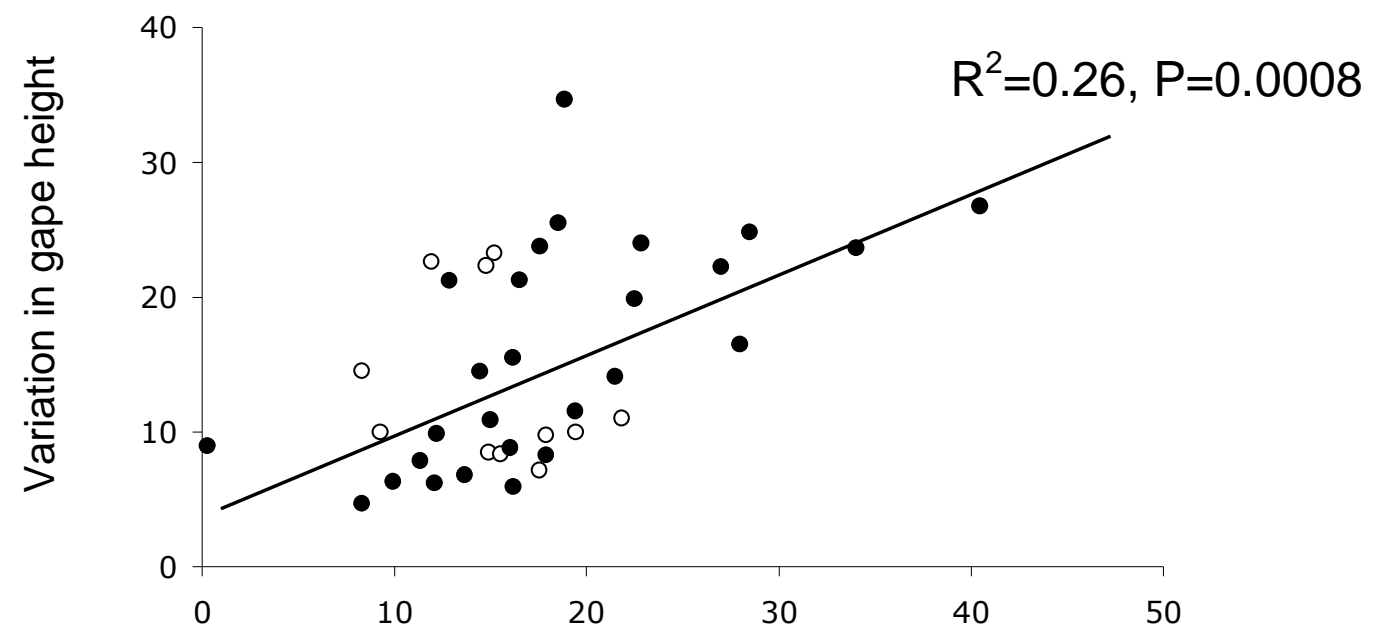

Variation in larval growth rate

Figure 5.3. The relationship between relative variation among fish in gape height and relative variation in larval growth rate. Each symbol represents fish collected from a single quadrat at either Island Bay (open symbols) or Kau Bay (closed symbols).

No relationship was observed with variation in larval growth rate and any of the other traits (gape width, body depth and tail length; $\mathrm{P}>0.2$ in all cases), and no relationship was observed between juvenile growth rate and morphology (gape height, gape width, body depth and tail length; $\mathrm{P}>0.2$ in all cases).

\subsection{Discussion}

Although phenotypic linkages between life-history stages have been described in a wide variety of organisms (reviewed in Moran 1994, Pechenik 1998, Giménez 2004, 2006, Marshall 2008), the implications of between-individual variation in performance during early life-history stages on the morphological characteristics of individuals at later stages, has yet to be thoroughly investigated. Here, I found that juvenile morphology is influenced by the growth rate that individuals experienced during the larval phase. Individuals that grew faster as larvae grew larger mouths 
relative to body size during the initial period (up to 30 days post-settlement) following settlement. Furthermore the magnitude of individual variation exhibited in morphology within a local population, was observed to correlate to the level of between-individual variation present in larval growth. Cohorts of fish that exhibited higher levels of individual variation in growth during the larval phase, also exhibited higher levels of individual variation in morphology following settlement. These results suggest that performance during early life-history stages has the potential to constrain the magnitude of morphological response exhibited within a population at later stages.

Given the highly dispersive nature of pelagic larvae, coupled with the small geographical separation of the local populations in this study, high gene flow may be assumed to occur between the two local populations of F. lapillum examined here (Palumbi 1992, 2003). I therefore assume the differences in morphology exhibited by fish between the sites was primarily a response to variation in environmental influences. An environmental, rather than genetic, basis for the observed pattern is further supported by the known capacity of fishes to undergo a morphologically plastic response to environmental factors (e.g., predator presence, food size). Justifications for changes in patterns of allometry through ontogeny and between individuals can be provided via ecomorphological hypotheses about the allocation of energy during growth. This hypothesis states that the patterns of development and growth reflect successive functional priorities at different sizes and in different environments (Osse and van der Boogaart 1995, 1999, Osse et al. 1997, van Snik et al. 1997, Russo et al. 2007). Radical changes in allometric growth within regions of the head and tail are expected to occur following settlement, due to the major ecological transition in feeding habits and swimming behavior as individuals move 
toward a benthic habitat and broaden their trophic niche (Bauchot and Hureau 1986). In the current study, both mouth morphology (maximum gape height and width) and tail length were observed to differ between the two sites. Both of these phenotypes may be related to performance measures which can mediate mortality risk in youngof-the-year fish. For example under conditions of high predation risk, increased growth of the tail may be expected because predation risk decreases with increasing size and escape velocity (Langerhans et al. 2004). Similarly, more rapid development of mouth morphology may occur when the availability of larger prey items increases (Magnhagen and Heibo 2001).

Little is currently known about the causes of between-individual variation in plasticity in the wild (Nussey et al. 2007). Current physiological condition is expected to constrain the ability of organisms to produce morphologically plastic phenotypes, possibly because plasticity is energetically costly and high growth rates are needed in order to modulate morphology (Olsson et al. 2005, Olsson et al 2006, Chivers et al. 2008). In this study juvenile growth rate was not found to constrain morphology and this may be due to the complexity of the relationship between juvenile growth and fitness during the first few weeks following settlement (Gagliano et al. 2007, Gagliano and McCormick 2007). During this time the maintenance of rapid larval growth rates following settlement can be detrimental to small reef fish, and in some cases a change from rapid larval growth to slower growth rates of reef fish after settlement can actually increase individual fitness and survival (Gagliano et al. 2007, Gagliano and McCormick 2007). This is thought to be due to the strong trade-off experienced by small fish between foraging rate and predator avoidance. Fish that have higher energy stores at settlement may go through an initial phase of slow growth until they become physiologically better developed (e.g., increased jaw 
musculature and/or increased tail musculature), and are able to then feed and/or avoid predators more efficiently.

Rapid late larval growth may be correlated with a range of post-settlement physiological and phenotypic traits such as higher energetic reserves as measured by lipid concentrations (Hovenkamp and Witte 1991, McCormick and Molony 1993, Suthers et al. 1992, Green and McCormick 1999) and/or increased competitive ability (Johnson 2008). Additionally, late larval growth rate may be indicative of patterns of morphological development of fish larvae during the pelagic phase. At settlement, fish larvae undergo rapid morphogenesis and differentiation processes to change their body shape and morphology as they transform into a juvenile form (Osse and van den Boogart 1995, van Snik et al. 1997, Gisbert 1999, Koumoundouros et al. 1999). These processes involve tissue remodeling, as opposed the formation of postsettlement structures from undifferentiated cell lineages, and consequently greater linkage between larval and adult traits (Moran, 1994). Variation in the level of tissue growth prior to settlement, such as faster growing larvae developing a larger head relative to body size (Lema and Nevitt 2006), may be maintained into the juvenile stage resulting in variation in morphology. A variety of alternative explanations exist, but whatever the underlying mechanisms, the role of early-life history stages in constraining the level of morphological variation exhibited at later stages has implications for the way we interpret morphological plasticity within populations.

Analyses of individual plasticity in the wild, where organisms experience naturally occurring ranges of environmental conditions (rather than those imposed in the lab), are still extremely rare (reviewed in Nussey et al. 2007). The evolution of phenotypic plasticity appears tos be favoured in organisms with a high dispersal rate, and may maximise fitness across the greater range of environments they may 
encounter (Hollander 2008, Sultan and Spencer 2002). For example, relative to marine species with direct development, marine species with a pelagic developmental phase exhibit twice the amount of phenotypic plasticity in response to environmental heterogeneity (Hollander 2008). These species, for whom plasticity is likely to play a major role in determining survival, are also likely to exhibit the highest levels of spatial and temporal variation in larval condition. This highlights the potentially profound implications of early life history variation on patterns of phenotypic response to environment variables. Given the prevalence of phenotypic plasticity in nature, and the growing concern over the long-term consequences of anthropogenic effects on both habitats and climate for wild populations of animals, it seems clear we need to build on our understanding of how and why populations respond to the environment. Assessing factors that may promote or constrain phenotypic plasticity, such as the performance experienced during dispersal stages, may greatly advance our understanding of population dynamics. 


\section{Chapter 6}

\section{General Discussion}

Knowledge of how environmental and demographic conditions may mediate the interaction between pre-settlement, settlement and post-settlement processes is critical for understanding the dynamics of natural populations. By examining heterogeneity present within settlement habitats, concurrently with natural phenotypic variation present within, and among, cohorts at settlement, I have identified how dynamic and variable processes that determine growth and survival can be through time and space.

My key findings demonstrate that the composition of macroalgal habitat patches used by settling fish can influence (i) post-settlement growth trajectories, (ii) the strength of density dependent survival, and (iii) the intensity of selective mortality. On a population-level, I found that (i) variation among cohorts in larval quality at settlement may alter the relative importance of pre-settlement processes that shape recruitment and (ii) regional variation in the larval history of settlers can impact on patterns morphological variation.

\section{Macroalgal habitat composition}

Entry into a new environment or habitat is often associated with periods of high mortality. Researchers studying the ecology of fishes often assume that mortality is highest at the time of, and soon after, settlement to the benthic habitat (Hixon 1991, Caley 1998). Environmental factors that mediate mortality during this period may have a disproportionate effect on the number of settling individuals that will reach 
maturity. In this study I highlight the role of biological heterogeneity within settlement habitat, specifically macroalgal species composition and diversity, which affects survival of reef fish during the first 10 days following settlement (chapter 4), and alters the phenotypic characteristics of survivors within a single generation (e.g., size and body condition; chapter 2, 3 and 4). Overall I find evidence that mortality rates were highest in Cystophora habitats, in which fish also have the lowest growth rates. Fish within mixed macroalgal habitats (consisting of both Cystophora and Carphopyllum) sometimes fared better than fish within monospecific Carphopyllum habitats, growing to a larger size and having a higher body condition, though this pattern is variable through the settlement season and between two locations.

It is well understood that physical condition and size can affect reproductive performance. Parents in good condition can commence breeding earlier, often have higher reproductive output, and their offspring may fair better during embryogenesis and as juveniles, compared to parents in poorer condition (Donelson et al 2008, Raventos and Planes 2008). Furthermore, Taborsky (2006) found that the allocation of resources to growth versus reproduction and to offspring number versus size were shaped by environmental conditions experienced in the juvenile phase, rather than the adult phase, for a cichlid fish. Spatial and temporal variation among individuals in the number or quality of offspring they produce is an important consideration for fisheries scientists and managers (reviewed in Green 2008). Further studies which investigate how conditions experienced during both the juvenile and the adult stages affect patterns of parental investment may provide insight into patterns of reproductive output through time and space.

The extent to which the adult population will reflect initial differences at settlement (abundance and phenotypic characteristics) will depend on the strength of 
post-settlement processes such as density-dependence and selective mortality based on phenotypic characteristics (such as growth and size). I found that habitat could mediate the intensity of selection based on larval growth by influencing the relationship between post-settlement growth and larval growth during the first 10 days following settlement (chapters 2 and 3). The intensity of density-independent and density-dependent mortality varied among habitats, with the lowest quality (Cystophora) habitats experiencing the strongest level of density-independent mortality (chapter 4). The mediation of post-settlement processes by conditions in benthic habitat has important implications for how settlement and post-settlement processes are integrated into a common framework (e.g., see Schmitt et al. 1999, Wilson and Osenberg 2002, Shima and Osenberg 2003).

There is increasing recognition of the importance of the long-lasting demographic consequences of phenotypic variation induced in early life, both at the individual and population level (e.g. Pechenik et al . 1998, Madsen and Shine 2000, Lummaa and Clutton-Brock 2002, Beckerman et al 2002, De Roos et al. 2003, Reid et al. 2003, van de Pol et al. 2006, Taborsky 2006). Unfortunately, for many marine organisms, we have a relatively limited understanding of how the effect of phenotypic variation on subsequent performance varies with environmental conditions. By exploring the links between larval and juvenile stages in F. lapillum, my study shows that habitat composition may mediate the relationship between post-settlement growth and larval growth, and in turn, the intensity of selective mortality. Although differences in post-settlement growth may not be sufficient to allow individuals settling at smaller size to catch up in size (chapter 2), increased growth rates during the initial period following settlement may be indicative of physiological condition (e.g. energy acquisition). Fish with higher energy levels immediately following 
settlement may have better predator avoidance skills (e.g. faster swimming speed; Holmes and McCormick 2009) and/or competitive ability (e.g. have more energy available for aggressive behaviour; Johnson 2008). As post-settlement performance (e.g. energy acquisition) is a complex and dynamic process that is affected by many interacting variables (e.g. competition, predation, food availability), these results highlight that the propagation of phenotypic variation through successive life stages may also be highly variable and dynamic. Further studies are needed to determine the range of benthic conditions under which larval experiences might be important for juvenile survival.

There is growing desire to develop an ecosystem-based approach to management and conservation, which incorporates spatial and temporal variation in habitat productivity at multiple scales and life-history factors (Thrush et al. 2005, Drew and Eggleston 2008). I observe that the effect of macroalgal species composition on patterns of juvenile abundance and condition appears to differ among local populations and through the settlement season. This may be due to spatiotemporal variation in resources within habitats, due to interactions with broad scale environmental features such as temperature. Alternatively, demographic variation (i.e. the density and phenotypic characteristics) among cohorts of settlers may be altering the effect of habitat variation. Further studies are needed to determine the specific characteristics of habitat patches with varying macroaglal composition (.e.g abundance of epibiota, structural complexity) that influence post-settlement processes, and how they may vary with broad scale variation in environmental conditions. 


\section{Demographic variation among local populations}

Marine species commonly show a high degree of spatial and temporal variation among cohorts in settlement intensity (Luckhurst and Luckhurst 1977, Doherty 1983, Williams 1983, McFarland et al. 1985, Robertson et al. 1988, 1993, Robertson 1990, Sponaugle and Cowen 1994, 1997) and physiological condition at settlement (Jarret and Pechenik 1997, Radtke et al. 2001, Jarrett 2003, Phillips and Gaines 2002, Phillips 2006, Shima and Swearer 2009). Fluctuating levels of settlement intensity have been viewed as extremely important for population dynamics (e.g. Doherty 1981, Victor 1986). While a large number of recent studies have also documented the importance of larval quality on post-settlement growth, condition and survival (e.g. Sogard 1997, Searcy and Sponaugle 2001, Phillips 2002, 2004, Marshall et al. 2003, Hoey and McCormick 2004, Gagliano et al. 2007, Vigliola et al. 2007, Hamilton et al. 2008), the consequences of spatio-temporal patterns of larval quality to population dynamics remain relatively unexplored in marine populations (but see Vigliola et al. 2007, Hamilton 2008, Shima and Swearer 2009).

Oceanographic forces can strongly affect the movement of planktonic marine larvae, often producing predictable spatial patterns of larval delivery. In particular, in some coastal systems, certain locations consistently receive higher (or lower) larval supplies (Roberts et al. 2003). Recent empirical evidence suggests that geographical patterns of larval dispersal may also be an important source of heterogeneity in larval quality (Shima and Swearer 2009). In this study I primarily focused on two sites that are located within a harbour and on an adjacent south coast and these regions exhibit distinct patterns of coastal geomorphology. It has been suggested that larvae developing within semi-enclosed embayments are often of higher quality (Gaines and Bertness 1992) and in particular that larvae of F. lapillum developing with the 
nutrient enriched, warmer waters of Wellington harbour are of higher larval quality, compared to those developing on the south coast (Shima and Swearer 2009). I observed higher settlement intensity within the harbour and also higher quality settlers (i.e. fish had a faster late larval growth rate and shorter PLD at settlement), compared to the south coast, although the origin of settlers was not explicitly examined in this study. This pattern of spatial variation in larval history traits was not consistent through the settlement season, however the overall pattern (averaged across the settlement season) was consistent across two years.

In this study I find evidence that variation in density and condition of settlers, among cohorts and locations, may have a large impact on subsequent post-settlement processes, such as the intensity of selective mortality. I found that cohorts of overall higher condition (i.e. faster larval growth) showed little intra-cohort variation in survival or growth in relation to individual variation in larval history. However further work is needed to explore possible covariation between settlement processes and environmental conditions within the benthic environment that may affect postsettlement dynamics. Results from this study raise questions about how consistent spatial variation in the larval quality may have important consequences on the nature of post-settlement processes. As intraspecific competition may be largely determining performance of recently settled fish (e.g. by affecting growth, predation risk), the question should possibly not be "how does larval history affect subsequent performance?", but rather "how does an individual's larval history, relative to conspecifics with which it interacts, affect performance?".

The possibility that the impacts of events occurring early in life may be transmitted across multiple generations, leading to long-term effects on population dynamics (e.g. Hercuss and Hoffman 2000, Beckerman et al. 2002, Benton et al. 
2005), remains relatively unexplored in marine populations. Consideration of how phenotypic variation will act over multiple generations may help to illuminate patterns more congruent with phylogeographic patterns that geneticists routinely measure over evolutionary timescales. For example, breeding females can influence offspring phenotype and their subsequent dispersal ability, in response to changes in current environmental conditions, which has implications for understanding the dynamics of range expansion (Duckworth 2009). In chapter 5 I discuss the possibility that conditions experienced during dispersal (e.g. larval duration and environmental conditions) can influence the extent to which organisms demonstrate developmental plasticity in response to a new environment following settlement. Although individual morphological variation due to conditions experienced during the larval phase has been reported (Basch and Pearse 1996, Relyea and Hoverman 2003), consequences of this have yet to be explored at the population level. My results suggest that spatio-temporal variation in larval history among cohorts at settlement may influence variation in subsequent morphological patterns within a species.

\section{Concluding remarks}

Interest in conserving and managing marine habitats is intense and widespread (Nicholls 2004, Leslie 2005), however limited human and financial capital impacts on the realized form of these efforts. Although the incorporation of life-history factors into assessments of population dynamics be logistically demanding, it may aid of assessments of how and why certain habitats are vital for the sustainability of fish populations. Inshore habitats often take the brunt of human impacts (e.g. land reclamation, pollution, eutrophication and introduction of invasive species; Antunes and Santos 1999, Elliott and Hemingway 2002, McLusky and Elliott 2004), due to 
their close proximity to the terrestrial environment. At a time when most adult fish stocks are stressed by fisheries (Worm et al., 2006), the role of these inshore habitats for persistence of local fish populations, must be addressed. Focus in the past has been given to developing quick and easy tools to assess habitat suitability and quality to identify 'nursery' or 'essential juvenile habitats'(e.g. Able 1999). For this reason, nursery studies have been slow to recognize species-habitat relationships as complex, multivariate and multi-scale. Understanding the complex interactions between the environmental variability and the biology of fish species is a key question for fisheries research and management, and research will be greatly enhanced by the development of sophisticated techniques which unlock the enormous store of life history information contained within fish ear bones. 


\section{Appendix 1}

Table A1.1. The relative AICc weights of multiple regression models for the growth rate in the first 10 days after settlement. The full initial model included independent variables; pelagic larval duration (PLD), early larval growth, size at settlement (size), late larval growth (LG) and settlement date (SM). Variables were then sequentially removed in a backward-step and forward-step fashion. See 'Methods: Correlations between larval history and juvenile growth and body condition for more detail. Only models that had a AICc weight of $>0.10$ are presented in this table. $\mathrm{N}=33$.

\begin{tabular}{|lccc|}
\hline Model & AICc & AICc weight & Adj. R \\
\hline LG & & & \\
\hline LG + SM & -27.73 & 0.42 & 0.20 \\
LG + Size + SM & -26.73 & 0.25 & 0.18 \\
\hline
\end{tabular}

Table A1.2. The relative AICc weights of ANCOVA models for the dependent variable; juvenile growth rate. The full initial model included independent variables; habitat treatment (habitat), larval growth (LG), settlement date (SM), all interactions of these three variables (habitat x LG, habitat x SM, LG x SM, habitat x LG x SM) and replicate (i.e., row of the grid). Variables were then removed in a step-backward fashion. Only models that had a AICc weight of $>0.10$ are presented in this table. $\mathrm{N}=$ 66.

\begin{tabular}{|lccc|}
\hline Model & AICc & AICc weight & Adj. R $^{2}$ \\
\hline Habitat + LG & & & \\
LG & -63.18 & 0.47 & 0.42 \\
Habitat + LG + SM & -62.22 & 0.29 & 0.38 \\
\hline
\end{tabular}


Appendix 2

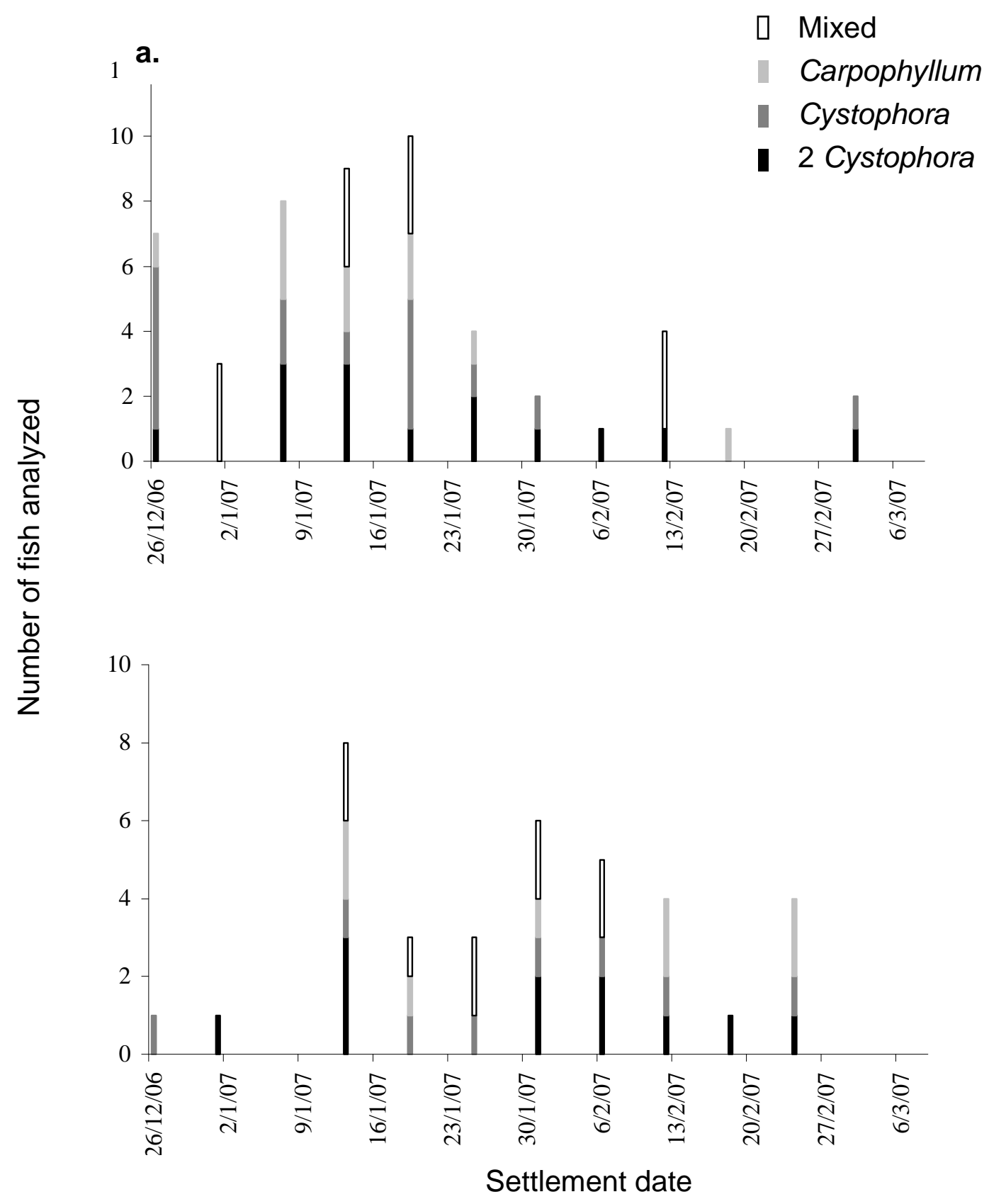

Figure A2.1. The distribution of settlement dates of fish within (a) settler group (010d) and (b) survivor group (20-50d), used to assess selective mortality of larval traits. Different coloured sections of each bar represent number of fish analyzed from each habitat treatment. 


\section{References}

Able KW (1999) Measures of juvenile fish habitat quality: examples from a national estuarine research reserve. In: Benaka LR (ed) Fish habitat: essential fish habitat and rehabilitation. Am Fish Soc Symp 22. Bethesda, Maryland, p 134-147

Abrams PA (1982) Functional-responses of optimal foragers. Am Nat 120:382-390

Abrams PA (1992) Adaptive foraging by predators as a cause of predator prey cycles. Evol Ecol 6:56-72

Aburto-Oropeza O, Sala E, Paredes G, Mendoza A, Ballesteros E (2007)

Predictability of reef fish recruitment in a highly variable nursery habitat. Ecology 88:2220-2228

Agrawal AA (2001) Phenotypic Plasticity in the Interactions and Evolution of Species. Science 294:321-326

Akaike H (1974) A new look at the statistical model identification. IEEE Transactions on Automatic Control 19:716-723

Alexander RM (1974) Functional design in fishes. London, UK: Hutchinson Publishers. Andersson, J., Johansson, F.

Almany GR (2004) Does increased habitat complexity reduce predation and competition in coral reef fish assemblages? Oikos 106: 275-284

Altwegg R, Reyer HU (2003) Patterns of natural selection on size at metamorphosis in water frogs. Evolution 57:872-882

Alvarez D, Nicieza AG (2002) Effects of induced variation in anuran larval development on post-metamorphic energy reserves and locomotion. Oecologia 131:186-195

Anderson O (1984) Optimal foraging by largemouth bass in structured environments. Ecology 65:851-861

Anderson TW (1994) Role of macroalgal structure in the dsitribition and abundance of a temperate reef fish. Mar Ecol Prog Ser 113: 279-290

Anderson TW (2001) Predator responses, prey refuges, and density-dependent mortality of a marine fish. Ecology 82: 245-257

Andersson J, Johansson F, Soderlund, T (2006) Interactions between predator- and diet-induced phenotypic changes in body shape of crucian carp. Proc R Soc B 273:431-437 
Arlt D, Forslund P, Jeppsson T, Pärt T (2008) Habitat-specific population growth of a farmland bird. PLoS ONE 3(8): e3006

Auster PJ, Malatesta RJ, LaRosa SC (1995) Patterns of microhabitat utilization by mobile megafauna on the southern New England (USA) continental shelf and slope. Mar Ecol Prog Ser 127:77-85

Bailey KM, Houde ED (1989) Predation on eggs and larvae of marine fishes and the recruitment problem. Adv Mar Biol 25:1-67

Bainbridge R (1963) Caudal fin and body movement in the propulsion of some fish. J. Exp Biol 40:23-56

Bartoletti S, Flury BD, Nel DG (1999) Allometric extension. Biometrics 55:12101214

Basch LV, Pearse JS (1996) Consequences of larval feeding environment for settlement and metamorphosis of a temperate echinoderm. Oceanologica Acta 19:273-285

Bauchot ML, Hureau JC (1986) Sparidae. In: Whitehead PJ, Bauchot ML, Hureau JC, Nielsen J, Tortonese E, editors. Fishes of the North-Eastern Atlantic and Mediterranean, Vol. 2. Paris: UNESCO. pp 605-626.

Beacham TD (1990) A genetic analysis of meristic and morphometric variation in chum salmon (Oncrhynchus keta) at three different temperatures. Can J Zool 68:225229

Beck MW, Heck KL Jr, Able KW, Childers DL and 9 others (2001) The identification, conservation, and management of estuarine and marine nurseries for fish and invertebrates. BioScience 51:633-641

Becker U, Dostal P, Jorritsma-Wienk LD, Matthies D (2008) The spatial scale of adaptive population differentiation in a wide-spread, well-dispersed plant species. Oikos 117:1865-1873

Beckerman A, Benton TG, Ranta E, Kaitala V, Lundberg P (2002) Population dynamic consequences of delayed life-history effects. Trends Ecol Evol 17:263-269

Bell SS, Hall MO, Robbins BD (1995) Toward a landscape approach in seagrass beds: using macroalgal accumulation to address questions of scale. Oecologia 104:163-168

Bergenius MAJ, McCormick MI, Meekan MG, Robertson DR (2005) Environmental influences on larval duration, growth and magnitude of settlement of a coral reef fish. Mar Biol 147:291-300

Bergenius MAJ, Meekan MG, Robertson DR, McCormick MI (2002) Larval growth predicts the recruitment success of a coral reef fish. Oecologia 131:521-5 
Berven KA (1990) Factors affecting population fluctuations in larval and adult stages of the wood frog (Rana sylvatica). Ecology 71:1599-1608

Beukers JS, Jones GP (1997) Habitat complexity modifies the impact of piscovores on a coral reef fish. Oecologia 114:50-59

Birch J-M (1999) Skull allometry in the marine toad, Bufo marinus. J. Morphol. 241:115-126

Bjorkman O (1981) Response to different quantum flux densities. In OL Lang \& PS Nobel \& CB Osmond \& H Ziegler (Eds.), Encyclopedia of Plant Physiology (pp. 571517). Berlin: Springer-Verlag.

Blake RW (1983) Fish locomotion. Cambridge, UK: Cambridge University Press

Bolker B, Holyoak M, Krivan V, Rowe L, Schmitz O (2003) Connecting theoretical and empirical studies of trait-mediated interactions. Ecology 84:11011114

Bolnick DI (2001) Intraspecific competition favours niche width expansion in Drosophila melanogaster. Nature 410:463-466

Bolnick, D. I., Svanback, R., Fordyce, J. A. et al. 2003. The ecology of individuals: incidence and implications of individual specialization. Am Nat 161:1-28

Bologna PA, Steneck RS (1993) Kelp beds as habitat for American lobster Homarus americanus. Marine Ecology Progress Series 100:127-134

Bonin MC, Srinivasan M, Almany GR, Jones GP (2009) Interactive effects of interspecific competition and microhabitat on early post-settlement survival in a coral reef fish. Coral Reefs 28:265-274

Booth DJ, Wellington G (1998) Settlement preferences in coral-reef fishes: Effects on patterns of adult and juvenile distributions, individual fitness and population structure. Aust J Ecol 23:274-279

Booth JD (1975) Seasonal and tidal variations in the hydrology of Wellington Harbour. NZ J Mar Freshw Res 9:333-354

Bowman MJ, Kibblewhite AC, Chiswell SM, Murtagh RA (1983) Circulation and mixing in greater Cook Strait, New Zealand. Oceanol Acta 6:383-391

Brodie JW (1958) A note on tidal circulation in Port Nicholson, New Zealand. NZ J Geol Geophys 1:684-702

Brommer JE, Rattiste K, Wilson AJ (2008) Exploring plasticity in the wild: laying date-temperature reaction norms in the common gull Larus canus. Proc R Soc Lond B 275:687-693 
Brown AF, Kann LM, Rand DM (2001) Gene flow versus local adaptation in the northern acorn barnacle, Semibalanus balanoides: insights from mitochondrial DNA variation. Evolution 55:1972-1979

Brown JH, Gillooly JF, Allen AP, Savage VM, West GB (2004) Toward a metabolic theory of ecology. Ecology 85:1771-1789

Brunton BJ, Booth DJ (2003) Density- and size-dependent mortality of a settling coral-reef damselfish (Pomacentrus moluccensis Bleeker). Oecologia 137:377-84

Burnham KP, Anderson DR (1998) Model selection and inference: a practical information-theoretic approach. Springer-Verlag, New York

Caley MJ, Buckley KA, Jones GP (2001) Separating ecological effects of habitat fragmentation, degradation, and loss on coral commensals. Ecology 82:3435-3448

Caley MJ, Carr MH, Hixon MA, Hughes TP, Jones GP, Menge BA (1996)

Recruitment and the local dynamics of open marine populations. Annu Rev Ecol Syst 27:477-500

Calsbeek R, Smith TB (2003) Ocean currents mediate evolution in island lizards. Nature 426:552-555

Campana SE, Thorrold SR (2001) Otoliths, increments, and elements: keys to a comprehensive understanding of fish populations? Can J Fish Aquat Sci 58:30-38

Casazza TL and Ross SW (2008) Fishes associated with pelagic Sargassum and open water lacking Sargassum in the Gulf Stream off North Carolina. Fish Bull 106:348363

Cardini A, Tongiorgi P (2003) Yellow-bellied marmots (Marmota flaviventris) “ in the shape space'" (Rodentia, Sciuridae): sexual dimorphism, growth and allometry of the mandible. Zoomorphology 122:11-23

Carr MH (1991) Habitat selection and recruitment of an assemblage of temperate zone reef fishes. J Exp Mar Biol Ecol 146:113-137

Carr MH (1989) Effects of macroalgal assemblages on the recruitment of the temperate zone reef fishes. J Exp Mar Biol Ecol 126:59-76

Chapman ARO, Johnson CR (1990) Disturbance and organization of macroalgal assemblages in the Northwest Atlantic. Hydrobiologia 192:77-121

Chiba S, Arnott SA, Conover DO (2007) Coevolution of foraging behavior with intrinsic growth rate : risk-taking in naturally and artificially selected growth genotypes of Menidia menidia. Oecologia 237:246

Chivers DP, Zhao X, Brown GE, Marchant TA, Ferrari MCO (2008) Predatorinduced changes in morphology of a prey fish: the effects of food level and temporal frequency of predation risk. Evol Ecol 22:561-574 
Clements KC (2003) Triplefins. In: Andrew N, Francis M (eds) The living reef. The ecology of New Zealand's rocky reefs. Craig Potton Publishing, Nelson, pp 160-167

Connell SD (2000) Is there safety-in-numbers for prey? Oikos 88:527-532

Connell SD, Jones GP (1991) The influence of habitat complexity on postrecruitment processes in a temperate marine fish population. J Exp Mar Biol Ecol 151: 271-294

Connell SD, Kingsford MJ (1998) Spatial, temporal and habitat- related variation in the abundance of large predatory fish at One Tree Reef, Australia. Coral Reefs 17:4957

Crowder LB et al. (1992) Empirical and theoretical approaches to size-based interactions and recruitment variability in fishes. - In: D. L. DeAngelis and L. J. Gross, editors. Individual-based models and approaches in ecology. Chapman \& Hall, New York, New York, USA, pp 237-255.

Currens KP, Sharpe CS, Hjort R, Schreck CB, Li HW (1989) Effects of different feeding regimes on the morphometrics of chinook salmon (Oncorhynchus tshawytscha) and rainbow trout (O. mykiss). Copeia 3:689-695

Dahlgreen CP, Eggleston DB (2000) Ecological processes underlying ontogenetic habitat shifts in a coral reef fish. Ecology 81:2227-2240

Damsgaard B, Dill LM (1998) Risk-taking behavior in weight compensating coho salmon, Oncorhynchus kisutch. Behav Ecol 9:26-32

Day T, Pritchard J, Schluter D (1994) A comparison of two sticklebacks. Evolution 48:1723-1734

Dayton PK, Tegner MJ (1984) Catastrophic storms, El Nino, and patch stability in a Southern California kelp community. Science 224:283-285

De Roos AM, Persson L, McCauley E (2003) The influence of size-dependent lifehistory traits on the structure and dynamics of populations and communities. Ecology Lett 6:473-487

DeWitt TJ, Sih A, Wilson DS (1998) Costs and limits of phenotypic plasticity. Trends Ecol Evol 13:77-81

DeWitt TJ, Scheiner SM (2004) Plasticity. Functional and Conceptual Approaches. Oxford University Press

Doebeli M, Dieckmann U (2000) Evolutionary branching and sympatric speciation caused by different types of ecological interactions. Am Nat 156:S77-S101

Doherty, P. J. 2002. Variable replenishment and the dynamics of reef fish populations. Pages 327-355 in P. F. Sale, editor. Coral Reef Fishes: Dynamics and Diversity of Complex Ecosystems. Academic Press, San Diego. 
Doherty PJ, Dufour V, Galzin R, Hixon MA, Meekan MG, Planes S (2004) High mortality during settlement is a population bottleneck for a tropical surgeonfish. Ecology 85:2422-2428

Doherty P, Fowler A (1994) Demographic consequences of variable recruitment to coral reef fish populations: a congeneric comparison of two damselfishes. Bull Mar Sci 54:297-313

Dolinsek IJ, Grant JWA, Biron PM (2007) The effect of habitat heterogeneity on the population density of juvenile Atlantic salmon Salmo salar L. J Fish Biol 70:206-214

Domenici P (2003) Habitat, body design and the swimming performance of fish. In Vertebrate biomechanics and evolution (eds V. L. Bels, J.-P. Gasc and A. Casinos), pp. 137-160. Oxford, UK: BIOS Scientific Publishers Ltd.

Domenici P, Blake RW (1997) The kinematics and performance of fish fast-start swimming. J Exp Biol 200:1165-1178

Domenici P, Turesson H, Brodersen J, Bronmark C (2008) Predator-induced morphology enhances locomotion in crucian carp. Proc Biol Sci 22:195-201

Donelson JM, Munday PL, McCormick MI (2009) Parental effects on offspring life histories: when are they important? Biol Lett 5:262-265

Dufour V, Galzin R (1993) Colonization patterns of reef fish larvae to the lagoon at Moorea Island, French Polynesia. Mar Ecol Prog Ser 102:143-152

Edgar GJ, Moore PG (1986) Macro-algae as habitats for motile macrofauna. Monogr Biol 4:255-277

Feary DA, Clements KD (2006) Habitat use by triplefin species (Tripterygiidae) on rocky reefs in New Zealand. J Fish Biol 69:1031-1046

Feary DA, Wellenreuther M, Clements KD (2009) Trophic ecology of New Zealand triplefin fishes (Family Tripterygiidae). Mar Biol 156:1703-1714

Figueira WF, Booth DJ, Gregson MA. (2008) Selective mortality of a coral reef damselfish: role of predator-competitor synergisms. Oecologia 156:215-226

Figueira WF, Crowder LB (2006) Defining patch contribution in source-sink metapopulations: the importance of including dispersal and its relevance to marine systems. Popul Ecol 48:215-224

Flury BD (1988) Common principal components and related multivariate models. Wiley, New York

Forrester GE (1990) Factors influencing the juvenile demography of a coral reef fish. Ecology 71:1666-1681 
Forrester GE (1995) Strong density-dependent survival and recruitment regulate the abundance of a coral reef fish Oecologia 103:275-282

Forrester GE, Steele MA (2000) Variation in the presence and cause of densitydependent mortality in three species of reef fishes. Ecology 81:2416-2427

Francis M (2001) Coastal fishes of New Zealand. Auckland: Reed.

Frederick JL (1997) Evaluation of fluorescent elastomer injection as a method for marking small fish. B Marin Sci 61:399-408

Fricke R (1994) Tripterygiid fishes of Australia, New Zealand and the southwest Pacific Ocean (Teleostei). Theses Zool 24:1-585

Gagliano M, McCormick MI (2007) Compensating in the wild: is flexible growth the key to early juvenile survival? Oikos 116:111-120

Gagliano M, McCormick MI, Meekan MG (2007) Survival against the odds: ontogenetic changes in selective pressure mediate growth - mortality trade-offs in a marine fish. Proc R Soc Lond B 274:1575-1582

Gaines S, Brown S, Roughgarden, J (1985) Spatial variation in larval concentrations as a cause of spatial variation in settlement for the barnacle, Balanus glandula.

Oecologia 67:267-272

Gimenez L (2004) Marine community ecology: importance of trait-mediated effects propagating through complex life cycles. Mar Ecol Prog Ser 283:303-310

Giménez L (2006) Phenotypic links in complex life cycles: conclusions from studies with decapod crustaceans. Int Comp Biol 46:615-622

Gisbert E (1999) Early development and allometric growth patterns in Siberian sturgeon and their ecological significance. J Fish Biol 54:852-862

Goater CP (1994) Growth and survival of postmetamorphic toads: interactions among larval history, density and parasitism. Ecology 758:2264-2274

Good PI. 2000. Permutation tests: a practical guide to resampling methods for testing hypotheses, 2nd ed. New York: Springer.

Gossling, S. (2007) Ecotourism and global environmental change. In: Critical Issues in Ecotourism: Understanding a Complex Tourism Phenomenon, ed. J.E.S. Higham, pp. 70-84. Oxford, UK: Elsevier.

Gotceitas V and Brown JA (1993) Substrate selection by juvenile Atlantic cod (Gadus morhua): effects of predation risk. Oecologia 93:31-37

Green BS and McCormick MI (1999) Influence of larval feeding history on the body condition of Amphiprion melanopus. J Fish Biol 55:1273-1289 
Grorud-Colvert K, Sponaugle S (2006) Influence of condition on behavior and survival potential of a newly settled coral reef fish, the bluehead wrasse Thalassoma bifasciatum. Mar Ecol Prog Ser 327:279-288

Guidetti P (2000) Differences among fish assemblages associated with nearshore Posidonia oceanica seagrass beds, rocky-algal reefs and unvegetated sand habitats in the Adriatic Sea. Estuar Coast Shelf Sci 50:515-529

Halpern BS (2004) Habitat bottlenecks in stage-structured species: hermit crabs as a model system. Mar Ecol Prog Ser 276:197-207

Hamilton SL, Regetz J, Warner RR (2008) Post-settlement survival linked to larval life in a marine fish. Proc Natl Acad Sci USA 105:1561-1566

Hamrin SF and Persson L (1986) Asymmetrical competition between age classes as a factor causing population oscillations in an obligate planktivorous fish. Oikos 47:223232

Hare JA, Cowen RK (1997) Size, growth, development, and survival of the planktonic larvae of Pomatomus saltatrix (Pisces: Pomatomidae). Ecology 78:24152431

Hayse JW, Wissing TE (1996) Effects of stem density of artificial vegetation on abundance and growth of age- 0 bluegills and predation by largemouth bass. Trans Am Fish Soc 1251:422-433

Heath RA (1977) Circulation and hydrology of Wellington Harbour. NZ Oceanogr Inst Summary No. 12:1- 8

Heck Jr. KL, Hays G and Orth RJ (2003) Critical evaluation of the nursery role hypothesis for seagrass meadows. Mar Ecol Prog Sers 253:123-136

Hellriegel B (2000) Single- or multistage regulation in complex life cycles: does it make a difference? Oikos 88:239-249

Hixon MA (1991) Predation as a process structuring coral reef fish communities. In: The Ecology of Fishes on Coral Reefs. Sale PF (ed), Academic Press, San Diego, pp 475-508

Hixon MA, Carr MH (1997) Synergistic predation, density dependence, and population regulation in marine fish. Science 227:946-949

Hixon MA, Jones GP (2006) Competition, predation, and density-dependent mortality in demersal marine fishes. Ecology 86:2847-2859

Hixon MA, Pacala SW, Sandin SA (2002) Population regulation: historical context and contemporary challenges of open vs. closed systems. Ecology 83:1490-1508 
Hixon MA, Webster MS (2002) Density dependence in reef fish populations. Pages 303-325 in P. F. Sale, editor. Coral reef fishes: dynamics and diversity in a complex eco system. Academic Press, San Diego, California, USA

Hoey AS and McCormick MI (2004) Selective predation for low body condition at the larval-juvenile transition of a coral reef fish. Oecologia 139:23-29

Holbrook SJ, Schmitt RJ, Ambrose RF (1990) Biogenic habitat structure and characteristics of temperate reef fish assemblages. Aust J Ecol 15:489-503

Holbrook SJ, Schmitt RJ (2002) Competition for shelter space causes densitydependent predation mortality in damselfishes. Ecology 83:2855-2868

Hollander J (2008) Testing the grain-size model for the evolution of phenotypic plasticity. Evolution 62:1381-1389

Holmes TH, McCormick MI (2006) Location influences size-selective predation on newly settled reef fish. Mar Ecol Prog Ser 317:203-209

Holt RD (1984) Spatial heterogeneity, indirect interactions, and the coexistence of prey species. Am Nat 124:377-406

Hothorn T, Hornick K, van de Wiel MA, Zeileis A (2008) Implementing a class of permutation tests: the coin package. J Stat Soft 28:1-23

Houde ED (1987) Fish early life dynamics and recruitment variability. American Fisheries Society Symposium Series 2:17-29

Hovel KA, Lipcius RN (2001) Habitat fragmentation in a seagrass landscape: patch size and complexity control blue crab survival. Ecology 82:1814-1829

Hovenkamp F, Witte JIJ (1991) Growth, otolith growth and RNA/DNA ratios of larval plaice Pleuronectes platessa in the North Sea 1987-1989. Mar Ecol Prog Ser 70:105-116

Hunter JR (1981) Feeding ecology and predation of marine fish larvae. In: Marine fish larvae; Morphology, Ecology and Relation to Fisheries. Wash. Sea Grant Progr, Univ. Wash. Press Seattle: pg 33-72

Huxley J (1932) Problems of relative growth. Dial Press, New York.

Imre I, McLaughlin RL, Noakes DLG (2002) Phenotypic plasticity in brook charr: changes in caudal fin induced by water flow. J Fish Biol 61:1171-1181

Jannot JE (2009) Life history plasticity and fitness in a caddisfly in response to proximate cues of pond-drying. Oecologia 161:267-277

Jarrett JN (2003) Seasonal variation in larval condition and postsettlement performance of the barnacle Semibalanus balanoides. Ecology 84:384-90 
Jarrett JN, Pechenik JA (1997) Temporal variation in cyprid quality and juvenile growth capacity for the barnacle Semibalanus balanoides. Ecology 78:1262-1265

Jaunes F (2007) Role of habitat in mediating mortality during the post-settlement transition phase of temperate marine fishes. J Fish Biol 70:661-677

Jenkins GP, King D (2006) Variation in larval growth can predict the recruitment of a temperate, seagrass-associated fish. Oecologia 147:641-649

Johnson DW (2006) Density dependence in marine fish populations revealed at small and large spatial scales. Ecology 87:319-327

Johnson DW (2007) Habitat complexity modifies post-settlement mortality and recruitment dynamics of a marine fish. Ecology 88:1716-1725

Johnson DW (2008) Combined effects of condition and density on post-settlement survival and growth of a marine fish. Oecologia 155:43-52

Jones GP (1991) Post-recruitment processes in the ecology of coral reef fish populations: a multi-factorial perspective. Pages 294-328 in P. F. Sale, editor. The ecology of fishes on coral reefs. Academic Press, New York.

Jones GP (1984a) Population ecology of the temperate reef fish Pseudolabrus celidotus Bloch and Schneider (Pisces: labridae). I. Factors influencing recruitment. J Exp Mar Biol Ecol 75:257-276

Jones GP (1984b) Population ecology of the temperate reef fish Pseudolabrus ceIidotus Bloch and Schneider (Pisces: labridae). II. Factors influencing adult density. J Exp Mar Biol Ecol 75:277-303

Jones GP (1984c) The influence of habitat and behavioural interactions on the local distribution of the wrasse, Pseudolabrus celidotus. Env Biol Fish 10:43-58

Jones GP (1986) Food availability affects growth in a coral reef fish. Oecologia 70:136-139

Jones GP, McCormick MI (2002) Numerical and energetic processes in the ecology of fish populations on coral reefs. In: "Coral Reef Fishes. Dynamics and diversity in a complex ecosystem" (P.F. Sale, ed.), Academic Press, San Diego.

Jones GP (1988) Experimental evaluation of the effects of habitat structure and competitive interactions on the juveniles of two coral reef fishes. J Exp Mar Biol Ecol $123: 115-126$

Jones GP (1991) Postrecruitment processes in the ecology of coral reef fish populations: a multifactorial perspective. Pages 293-328 in P. F Sale, editor. The ecology of fishes on coral reefs. Academic Press, London, UK.

Jutterbock JE (1990) Variation in larval growth and metamorphosis in the salamander Desmognathus fuscus. Herpetologia 46:291-303 
Kerrigan BA (1996) Temporal patterns in the size and condition of settlement in two tropical reef fishes (Pomacentridae: Pomacentrus amboinensis and P. nagasakiensis). Mar Ecol Prog Ser 135:27-41

Kingsford MJ, Leis JM, Shanks A, Lindeman K, Morgan S, Pineda J (2002) Sensory environments, larval abilities and local self-recruitment. Bull Mar Sci 70:309- 340

Kingsolver JG, Gomulkiewicz R (2003) Environmental variation and selection on performance curves. Integr Comp Biol 43:470-477

Klingenberg CP (1996) Multivariate allometry. In: Marcus LF, Corti M, Loy A, Naylor GJP, Slice DE (eds) Advances in morphometrics. Plenum, New York, pp 2349

Klingenberg CP, Spence JR (1993) Heterochrony and allometry-lessons from the water strider genus Limnoporus. Evolution 47:1834-1853

Kohn YY (2007) Pelagic larval duration in New Zealand triplefin fishes (Family Tripterygiidae). Masters Thesis, University of Auckland, New Zealand. 91p.

Koops MA, Hutchings JA and McIntyre TM (2004) Testing hypotheses about fecundity, body size, and maternal condition in fishes. Fish Fish 5:120-130

Koumoundouros G, Divanach P, Kentouri M (1999) Ontogeny and allometric plasticity of Dentex dentex (Osteichthyes: Sparidae) in rearing conditions. Mar Biol 135:561-572

Kraufvelin P, Salovius S (2004) Animal diversity in Baltic rocky shore macroalgae: can Cladophora glomerata compensate for lost Fucus vesiculosus? Estuar Coast Shelf Sci 61:369-378

Kraus RT, Secor DH (2005) Application of the nursery-role hypothesis to an estuarine fish. Mar Ecol Prog Sers 291:301-305

Langerhans RB, Layman CA, Shokrollahiab AM, DeWitt TJ (2004) Predator-driven phenotypic diversification in Gambusia Affinis. Evolution 58:2305-2318

Lambert WJ, Levin PS, Berman J (1992) Changes in the structure of a New England (USA) kelp bed: the effects of an introduced species? Mar Ecol Prog Ser 88:303-307

Lema SC and Nevitt GA (2006) Testing an ecophysiological mechanism of morphological plasticity in pupfish and its relevance to conservation efforts for endangered Devils Hole pupfish. J Exp Biol 209:3499-3509

Letourner Y, Chabanet P, Vigliola L, Harmelin-Vivien, M (1998) Mass settlement and post-settlement mortality of Epinephelus merra (Pisces: Serranidae) on Reunion coral reefs. J Mar Biol Assoc UK 78:307-319 
Levin PS (1994) Small-scale recruitment variation in a temperate fish - the roles of macrophytes and food supply. Environ Biol Fish 40:271-281

Levin PS (1991) Effects of microhabitat on recruitment variation in a Gulf of Maine reef fish. Mar Ecol Prog Ser 75:183-189

Levin PS (1993) Habitat structure, conspecific presence and spatial variation in the recruitment of a temperate reef fish. Oecologia 94:176-185

Levin PS, Hay ME (1996) Responses of temperate reef fishes to alterations in algal structure and species composition. Mar Ecol Prog Ser 134:37-47

Lima SL (1998) Stress and decision making under the risk of predation: recent developments from behavioral, reproductive, and ecological perspectives. Adv Stud Behav 27:215-290

Lindholm JB, Auster PJ, Kaufman LS (1999) Habitat-mediated survivorship of juvenile (0-year) Atlantic cod Gadus morhua. Mar Ecol Prog Ser 180:247-255

Litvak MK, Leggett CW (1992) Age and size-selective predation on larval fishes: the bigger-is-better hypothesis revisited. Mar Ecol Prog Ser 81:13-24

Loy A, Cataudella S, Corti M. (1996) Shape changes during the growth of the sea bass, Dicentrarchus labrax (Teleostea: Perciformes), in relation to different rearing conditions. In: Marcus L.F, Corti M, Loy A, Naylor G.J.P, Slice D, editors. Advances in morphometrics. Plenum Press; New York: pp. 399-405

Loy A, Mariani, L, Bertelletti M, Tunesi L (1998). Visualizing allometry: geometric morphometrics in the study of shape changes in the early stages of the two-banded sea bream, Diplodus vulgaris (Perciformes, Sparidae). J Morphol 237:137-146

Madsen T, Shine R (2000) Silver spoons and snake body sizes: prey availability early in life influences long-term growth rates of free-ranging pythons. J Anim Ecol 69:952 958

Magnhagen C, Heibo E (2001) Gape size allometry in pike reflects variation between lakes in prey availability and relative body depth. Func Ecol 15:754-762

Main KL (1987) Predator avoidance in seagrass meadows: prey behavior, microhabitat selection, and cryptic coloration. Ecology 68:170-180

Marshall DJ (2008) Transgenerational plasticity in the sea: context-dependent maternal effects across the life-history. Ecology 89:418127

Marshall DJ, Bolton TF and Keough MJ (2003) Offspring size affects the post metamorphic performance of a colonial marine invertebrate. Ecology 84:3131-3137

Marshall DJ, Keough MJ (2004) Variable effects of larval size on post-metamorphic performance in the field. Mar Ecol Prog Ser 279:73-80 
Martin WR (1949) The mechanics of environmental control of body form in fishes. Publ. Ont. Fish. Res. Lab. 70:1-93

Matsuda H, Hori M, Abrams PA (1994) Effects of predator-specific defence on community complexity. Evol Ecol 8:628-638

Mayr E (1963) Animal Species and Evolution. Harvard University Press, Cambridge, MA.

McCormick MI (1994) Variability in age and size at settlement of the tropical goatfish Upeneus tragula (Mullidae) in the northern Great Barrier Reef lagoon. Mar Ecol Prog Ser 103:1-15

McCormick MI (1998) Condition and growth of reef fish at settlement: is it important? Aust J Ecol 23:258-264

McCormick MI (2003) Consumption of coral propagules after mass spawning enhances larval quality of a damselfish through maternal effects. Oecologia 136:37-45

McCormick MI, Hoey AS (2004) Larval growth history determines juvenile growth and survival in a tropical marine fish. Oikos 106:225-242

McCormick MI, Meekan MG (2007) Social facilitation of selective mortality. Ecology 88:1562-1570

McCormick MI, Molony BW (1993) Quality of the reef fish Upeneus tragula (Mullidae) at settlement: is size a good indicator of condition? Mar Ecol Prog Ser 98:45-54

McCormick MI, Molony BW (1995) Influence of water temperature during the larval stage on size, age and body condition of a tropical reef fish at settlement. Mar Ecol Prog Ser 118:59-68

McCoy MW (2007) Conspecific density determines the magnitude and character of predator induced phenotype. Oecologia 153:871-878

McCoy MW, Bolker BM, Osenberg CW, Miner B, Vonesh JR (2006) Size correction: comparing morphological traits among populations and environments. Oecologia 148 $: 547-554$

McDermott CJ, Shima JS (2006) Ontogenetic shifts in microhabitat preference of the temperate reef fish Forsterygion lapillum: implications for population limitation. Mar Ecol Prog Ser 320:259-266

McPeek MA, Grace M, Richardson JML (2001) Physiological and behavioral responses to predators shape the growth/predation risk trade-off in damselflies. Ecology 82:1535-1545 
Meekan MG, Carleton JH, McKinnon AD, Flynn K, Furnas M (2003) What determines the growth of tropical reef fish larvae in the plankton: food or temperature? Mar Ecol Prog Ser 256:193-204

Mesa MG, Poe TP, Gadomski DM. and others (1994) Are all prey created equal : a review and synthesis of differential predation on prey in substandard condition. J Fish Biol 45:81-96

Meng L, Cicchetti G and Chintala M (2004) Nekton habitat quality at shallow water sites in two Rhode Island coastal systems. Estuaries 27:740-751

Meyer A (1987) Phenotypic plasticity and heterochrony in Cichlasoma managuense (Pisces Cichlidae) and their implications for speciation in cichlid fishes. Evolution 41:1357-1369

Miller TJ, Crowder LB, Rice JA and Marshall EA (1988) Larval size and recruitment mechanisms in fishes: towards a conceptual framework. Can J Fish Aquat Sci 45:1657-1670

Moran AL, Emlet RB (2001) Offspring size and performance in variable environments: field studies on a marine snail. Ecology 82:1597-1612

Moran NA (1994) Adaptation and constraint in the complex life cycle of animals. Annu Rev Ecol Syst 25:573-600

Morgan MJ, Lilly GR (2006) The impact of condition on reproduction in Flemish Cap cod. J Northw Atl Fish Sci 37:81-86

Nislow KH, Einum S, Folt CL (2004) Testing predictions of the critical period for survival concept using experiments with stocked Atlantic salmon. J Fish Biol. 65 (Suppl. A):188-200

Nussey DH, Clutton-Brock TH, Elston DA, Albon SD, Kruuk LEB (2005a) Phenotypic plasticity in a maternal trait in red deer. J Anim Ecol 74:387-396

Nussey DH, Postma E, Gienapp P, Visser ME (2005b) Selection on heritable phenotypic plasticity in a wild bird population. Science 310:304-306

Nussey DH, Wilson AJ, Brommer JE (2007) The evolutionary ecology of individual phenotypic plasticity in wild populations. J Evol Biol 20:831-844

Ohgushi T (2008) Consequences of adult size for survival and reproductive performance in a herbivorous ladybird beetle. Ecol Entomol 21:47-55

Olsson J, Svanbäck R, Eklöv P (2005) Effects of resource level and habitat type on behavioral and morphological plasticity in Eurasian perch. Oikos 152:48-56

Olsson J, Svanbäck R, Eklöv P (2006) Growth rate constrain divergence when driven by competition. Oikos 115:15-22 
Osenberg CW, St. Mary CM, Schmitt RJ, Holbrook SJ, Chesson PL, Byrne B (2002) Rethinking ecological inference: density dependence in reef fishes. Ecol Lett 5:715721

Osse JWM (1990) Form changes in fish larvae in relation to changing demands of function. Neth J Zool 40:362-385

Osse JWM, van den Boogaart JGM (1995) Fish larvae, development, allometric growth, and the aquatic environment. ICES Mar Sci Symp 201:21-34

Osse JWM, van den Boogaart JGM, van Snik GMJ, van der Sluys L (1997) Priorities during early growth of fish larvae. Aquaculture 155:249-258

Palumbi SR (1992) Marine speciation on a small planet. Trends Ecol. Evol. 7:114-118

Palumbi SR (2003) Population genetics, demographic connectivity, and the design of marine reserves. Ecol. Ap. 13:S146-S158

Peacor SD, Schiesari L, Werner EE (2007) Mechanisms of nonlethal predator effect and cohort size variation: ecological and evolutionary implications. Ecology 88:15361547

Pechenik JA, Rice ME (2001) Influence of delayed metamorphosis on postsettlement survival and growth in the Sipunculan Apionsoma Misakianum. Invert Biol 120:5057

Pechenik JA, Wendt DE, Jarrett JN (1998) Metamorphosis is not a new beginning. BioScience 48:901-910

Persson L, Eklov P (1995) Prey refuges affecting interactions between piscivorous perch and juvenile perch and roach. Ecology 76:70-81

Pfister CA, Stevens FR (2002) The genesis of size variability in plants and animals. Ecology 83:59-72

Phelan BA, Goldberg R, Bejda AJ, Pereira J and 5 others (2000) Estuarine and habitat-related differences in growth rates of young-of-the-year winter flounder (Pseudopleuronectes americanus) and tautog (Tautoga onitis) in three northeastern US estuaries. J Exp Mar Biol Ecol 247:1-28

Phillips NE (2006) Natural variability in size and condition at settlement of three species of marine invertebrates. Int Comp Biol 46:598-604

Phillips NE (2004) Variable timing of larval food availability has consequences for early juvenile performance in a marine mussel. Ecology 85:2341-2346

Phillips NE (2002) Effects of nutrition-mediated larval condition on juvenile performance in a marine mussel. Ecology 83:2562-2574 
Phillips NE, Gaines SD (2002) Spatial and temporal variability in size at settlement of intertidal mytilid mussels from around Pt. Conception, California. Invert Rep Dev 41:171-177

Phillips PC, Arnold SJ (1999) Hierarchical comparison of genetic variancecovariance matrices. I. Using the Flury hierarchy. Evolution 53:1506-1515

Pigliucci M (2001) Phenotypic Plasticity. Evolutionary Ecology: Concepts and Case Studies. C. W. Fox, D. A. Roff and D. J. Fairbairn. Oxford, Oxford University Press: 58-69.

Pigliucci M, Murren CJ (2003) Perspective: genetic assimilation and a possible evolutionary paradox: can macroevolution sometimes be as fast as to pass us by? Evolution 57:1455-1464

Planes S, Jouvenel JY, Lenfant P (1998) Density dependence in post-recruitment processes of juvenile sparids in the littoral of the Mediterranean Sea. Oikos 83:293300

Planes S, Lecaillon G (2001) Caging experiment to examine mortality during metamorphosis of coral reef fish larvae. Coral Reefs 20:211-218

Powers MJ, Peterson CH, Summerson HC and Powers SP (2007) Macroalgal growth on bivalve aquaculture netting enhances nursery habitat for mobile invertebrates and juvenile fishes. Mar Ecol Prog Sers 339:109-122

Price TD, Qvarnstrom A, Irwin DE (2003) The role of phenotypic plasticity in driving genetic evolution. Proc R Soc Lond B Biol Sci 270:1433-1440

Qian PY, Pechenik JA (1998) Effects of larval starvation and delayed metamorphosis on juvenile survival and growth of the tube-dwelling polychaete Hydroides elegans (Haswell). J Exp Mar Biol Ecol 227:169-185

Radtke RL, Kinzie RA, Shafer DJ (2005) Temporal and spatial variation in length of larval life and size at settlement of the Hawiian amphidromous goby Lentipes concolor. J Fish Biol 59:928-938

Raventos N, Macpherson E (2005) Effect of pelagic larval growth and size-athatching on post-settlement survivorship in two temperate labrid fish of the genus Symphodus. Mar Ecol Prog Sers 285:205-211

Reed TE, Wanless S, Harris MP, Frederiksen M, Kruuk LEB, Cunningham EJA (2006) Responding to environemental change: plastic responses vary little in a synchronous breeder. Proc R Soc Lond B. 273:2713-2719

Relyea RA (2001) Morphological and behavioral plasticity of larval anurans in response to different predators. Ecology 82:523-540

Relyea RA (2002) Costs of phenotypic plasticity. Am Nat 159:272-282 
Relyea RA and Hoverman JT (2003) The impact of larval predators and competitors on the morphology and fitness of juvenile tree frogs. Oecologia 134:569-604

Relyea RA, Hoverman JT (2003) The impact of larval predators and competitors on the morphology and fitness of juvenile treefrogs. Oecologia, 134:596-604

Renaud PE, Riggs SR, Ambrose WG, Schmid K, Snyder SW (1997) Biologicalgeological interactions: storm effects on macroalgal communities mediated by sediment characteristics and distribution. Cont Shelf Res 17:37-56

Robbins BD, Bell SS (1994). Seagrass landscapes: a terrestrial approach to the marine subtidal environment. Trends Ecol Evol 9:301-304

Robinson BW, Wilson DS (1995) Experimentally induced morphological diversity in Trinidadian guppies (Poecilia reticulata). Copeia 1995:294-305

Roff DA (1992) The evolution of life histories. Chapman and Hall, New York

Rosas A, Bastir M (2002) Thin-plate spline analysis of allometry and sexual dimorphism in the human craniofacial complex. Am J Phys Anthropol 117:236-245

Roughgarden J, Iwasa Y (1986) Dynamics of a metapopulation with space-limited subpopulations. Theor Pop Biol 29:235-261

Roughgarden J, Gaines S, Possingham H (1988) Recruitment dynamics in complex life cycles. Science 241:1460-1466

Russo T, Pulcini D, Bruner E, Cataudella S (2009) Shape and size variation: growth and development of the Dusky Grouper (Epinephelus marginatus Lowe, 1834). J Morph 270:83-96

Ryer CH, Stoner AW, Titgen RH (2004) Behavioral mechanisms underlying the refuge value of benthic habitat structure for two flatfishes with differing anti-predator strategies. Mar Ecol Prog Ser 268:231-243

Sale PF (1991) Reef fish communities: open nonequlibrial systems. Pages 564-598, in P. F. Sale, editor. The ecology of fishes on coral reefs. Academic press, San Diego, California, USA.

Sale PF, Douglas WA (1984) Temporal variability in the community structure of fish on coral patch reefs and the relation of community structure to reef structure. Ecology 65:409-422

Sale PF (1980) The ecology of fishes on coral reefs. Ocean Mar Biol Annu Rev 118:367-421

Samhouri JF, Steele MA, Forrester GE (2009) Inter-cohort competition drives density dependence and selective mortality in a marine fish. Ecology 90:1009-1020 
Scheiner SM (1993) Genetics and evolution of phenotypic plasticity. Annu Rev Ecol Syst 24:35-68

Scheiner SM and Goodnight CJ (1984) The comparison of phenotypic plasticity and genetic variation in populations of the grass Danthonia spicata. Evolution 38:845855

Schluter D (2000) The Ecology of Adaptive Radiation. Oxford University Press, Oxford, UK

Schmitt R and Holbrook S (1999) Mortality of juvenile damselfish: implications for assessing processes that determine abundance. Ecology 80:35-50

Schmitt RJ, Holbrook SJ (1996) Local-scale patterns of larval settlement in a planktivorous damselfish—do they predict recruitment? Mar Fresh Res 47:449-463

Schmitt RJ, Holbrook SJ (1999a) Mortality of juvenile damselfish: implications for assessing processes that determine abundance. Ecology 80:35-50

Schmitt RJ, Holbrook SJ (1999b) Settlement and recruitment of three damselfish species: larval delivery and competition for shelter space. Oecologia 118:76-86

Schneider CJ, Smith TB, Larison B, Moritz C (1999) A test of alternative models of diversification in tropical rainforests: ecological gradients vs. rainforest refugia. Proc Nat Acad Sci USA 96:13869-13873

Schoeppner NM. Relyea RA (2008) Detecting small environmental differences: Riskresponse curves for predator-induced behavior and morphology. Oecologia 154:743754

Schreiber S, Rudolf V. (2008) Crossing habitat boundaries: coupling dynamics of ecosystems through complex life cycles. Ecol Lett 11:576-587

Scott DE, Casey ED, Donovan MF, Lynch TK (2007) Amphibian lipid levels at metamorphosis correlate to post-metamorphic terrestrial survival. Oecologia 153:521-532

Searcy SP, Eggleston DB, Hare JA (2007) Environmental influences on the relationship between juvenile and larval growth of Atlantic croaker Micropogonias undulates. Mar Ecol Prog Ser 349:81-88

Searcy SP, Sponaugle S (2000) Variable larval growth in a coral reef fish. Mar Ecol Prog Ser 206:213-226

Searcy SP, Sponaugle S (2001) Selective mortality during the larval-juvenile transition in two coral reef fishes. Ecology 82:2452-2470

Shervette VR and Gelwick F (2008) Relative nursery function of oyster, vegetated marsh edge, and nonvegetated bottom habitats for juvenile white shrimp Litopenaeus setiferus. Wetlands Ecol Manage16:405-419 
Shima JS (1999) Variability in relative importance of determinants of reef fish recruitment. Ecol Lett 2:304-310

Shima JS (2001a) Regulation of local populations of a coral reef fish via joint effects of density- and number-dependent mortality. Oecologia 126:58-65

Shima JS (2001b) Recruitment of a coral reef fish: roles of settlement, habitat, and postsettlement losses. Ecology 82:2190-2199

Shima JS, Findlay AM (2002) Pelagic larval growth rate impacts benthic settlement and survival of a temperate reef fish. Mar Ecol Prog Ser 235:303-309

Shima JS, Osenberg CW (2003) Cryptic density dependence: effects of spatiotemporal covariation between density and site quality in reef fish. Ecology 84:46-52

Shima JS, Osenberg CW, St. Mary CM (2008). Quantifying site quality in a heterogeneous landscape: recruitment of a reef fish. Ecology 89:86-94

Shima JS, Osenberg, CW, St. Mary CM, Rogers L (2006) Implication of changing coral communities: do larval traits or habitat features drive variation in densitydependent mortality and recruitment of juvenile reef fish? Proc 10th Int Coral Reef Symp, Okinawa, JP. p 226-231

Shima JS, Swearer SE (2009) Larval quality is shaped by matrix effects: implications for connectivity in a marine metapopulation. Ecology 90:1255-67

Sih A, Crowley P, McPeek, M. and others (1985) Predation, competition, and prey communities: a review of field experiments. Annu Rev Ecol Syst 16:269-311

Sinclair M. (1987) Marine populations: An essay on population regulation and speciation. Books in Recruitment Fishery Oceanography. Univ. Washington Press, Seattle. 252 p.

Skulason, S. and Smith, T. B. 1995. Resource polymorphisms in vertebrates. Trends Ecol Evol 10:366-370

Smith AC, Koper N, Francis CM and Fahrig L (2009) Confronting collinearity: comparing methods for disentangling the effects of habitat loss and fragmentation. Landscape Ecol 24:1271-1285

Smith TB, Sklason S (1996) Evolutionary significance of resource polymorphism in fishes, amphibians and birds. Annu Rev Ecol Syst 27:111-133

Smith TB, Wayne RK, Girman DJ, Bruford MW (1997) A role for ecotones in generating rainforest biodiversity. Science 276:1855-1857

Sogard SM (1992) Variability in growth rates of juvenile fishes in different estuarine habitats. Mar Ecol Prog Ser 85:35-53 
Sogard SM (1997) Size-selective mortality in the juvenile stage of teleost fishes: a review. Bull Mar Sci 60:1129-1157

Sokal RR, Rohlf FJ (2001) Biometry: The Principles and Practice of Statistics in Biological Research. 7th ed. W.H. Freeman and Company, New York

Sponaugle S, Cowen RK (1994) Larval durations and recruitment patterns of two Caribbean gobies (Gobiidae): Contrasting early life histories in demersal spawners. Mar Biol 120:133-143

Sponaugle S, Cowen RK (1997) Early life history traits and recruitment patterns of Caribbean wrasses (Labridae). Ecol Monogr 67:177-202

Sponaugle S, Grorud-Covert K (2006) Environmental variability, early life-history traits, and survival of new coral reef fish recruits. Integr Comp Biol 46:623-633

Sponaugle S, Grorud-Colvert K, Pinkard D (2006) Temperature-mediated variation in early life history traits and recruitment success of the coral reef fish Thalassoma bifasciatum in the Florida Keys. Mar Ecol Prog Ser 308:1-15

Srinivasan M (2003) Depth distributions of coral reef fishes: the influence of microhabitat structure, settlement, and post-settlement processes. Oecologia 137:7684

Stamps JA (2006) The silver spoon effect and habitat selection by natal dispersers. Ecol Lett 9:1179-1185

Steele MA (1997a) The relative importance of processes affecting recruitment of two temperate reef fishes. Ecology 78:129-145

Steele MA (1997b) Population regulation by post-settlement mortality in two temperate reef fishes. Oecologia 112:64-74

Steele MA, Forrester GE (2002) Early postsettlement predation on three reef fishes: effects on spatial patterns of recruitment. Ecology 83:1076-1091

Steinberg PD, Estes JA, Winter FC (1995) Evolutionary consequences of food chain length in kelp forest communities. Proc Natl Acad Sci USA 92:8145-8148

Steppan SJ (1997a) Phylogenetic analysis of phenotypic covariance structure .1. Contrasting results from matrix correlation and common principal component analyses. Evolution 51:571-586

Stevenson DK, Campana SE (1992) Otolith microstructure examination and analysis. Can Spec Publ Fish Aquat Sci 117:126-131

Stoner AW, Spencer ML, Ryer CH (2007) Flatfish-habitat associations in Alaska nursery grounds: Use of continuous video records for multi-scale spatial analysis. J. Sea Res 57:137-150 
Subedar, K (2009) Homing in two New Zealand triplefins (Forsterygion varium and Forsterygion lapillum). Masters Thesis, University of Auckland, New Zealand. 103p.

Sultan SE, Spencer HG (2002) Metapopulation structure favors plasticity over local adaptation. Am Nat 160:271-283

Suthers IM, Fraser AJ, Frank KT (1992) A lipid condition index of post-larval cod (Gadus morhua) off southwestern Nova Scotia; comparison with otolith and morphometric indices. Mar Ecol Prog Ser 84:31-40

Suthers IM (1998) Bigger? Fatter? Or is faster growth better? Considerations on condition in larval and juvenile coral-reef fish. Aust J Ecol 23:265-273

Sweeney BW, Vannote RL (1986) Growth and production of stream stonefly: influences of diet and temperature. Ecology 67:1396-1410

Syms C, Jones GP (2000) Disturbance, habitat structure, and the dynamics of a coralreef fish community. Ecology 81:2714-2729

Taborsky B (2006) Mothers determine offspring size in response to own juvenile growth conditions. Biol Lett 2:225-228

Taylor RB, Cole RG (1994) Mobile epifauna on subtidal brown seaweeds in northeastern New Zealand. Mar Ecol Prog Ser 115:271-282

Thompson DAW (1942) On growth and form. Cambridge Univ. Press, Cambridge, U.K

Thompson SM (1979) Ecological and behavioural factors influencing the distribution and abundance patterns of tripterygiid fishes with particular reference to Tripterygion varium. MSc thesis, Zoology, Auckland

Thompson SM (1983) Homing in a territorial reef fish. Copeia 3:832-834

Thorrold SR, Hare JA (2002) Otolith applications in reef fish ecology. In: Sale PF (ed) Coral reef fishes: dynamics and diversity in a complex ecosystem. Academic Press, San Diego, CA, p 243-264

Tokeshi M, Ota N, Kawai T (2000). A comparative study of morphometry in shellbearing molluscs. J Zool 251:31-38

Tupper M, Boutilier RG (1995a) Size and priority influence growth and competitive success of newly settled Atlantic cod. Mar Ecol Prog Sers 118:295-300

Tupper M, Boutilier RG (1995b) Effects of habitat on settlement, growth and postsettlement mortality of age 0+ Atlantic cod, Gadus morhua, Can J Fish Aquat Sci $52: 1834-1841$ 
Tuya T, Wernberg T, Thomsen MS (2008) The spatial arrangement of reefs alters the ecological patterns of fauna between interspersed algal habitats. Estuar Coast. Shelf Sci 78:774-782

van Snik GMJ, van den Boogaart JGM, Osse JWM (1997) Larval growth patterns in Cyprinus carpio and Clarias gariepinus with attention to the finfold. J Fish Biol 50:1339-1352

Via S, Gomulkiewicz R, De Jong G, Scheiner SM, Schlichting CD, Van Tienderen PH (1995) Adaptive phenotypic plasticity: consensus and controversy. Trends Ecol. Evol. 10:212-217

Videler JJ (1993) Fish swimming. London, UK: Chapman and Hall

Vigliola L, Meekan MG (2002) Size at hatching and planktonic growth determine post-settlement survivorship of a coral reef fish. Oecologia 131:89-93

Vigliola LP, Doherty J, Meekan MG, Drown DM, Jones ME and Barber PH (2007) Genetic identity determines risk of post-settlement mortality of a marine fish. Ecology 88:1263-1277

Vogel S (1994) Life in moving fluids: the physical biology of flow, 2nd edn. Princeton University Press, Princeton, NJ

Vollestad LA, Olsen EM (2008) Non-additive effects of density-dependent and density-independent factors on brown trout vital rates. Oikos 117:1752-1760

von Bertalanffy L (1957) Quantitative laws in Metabolism and Growth. Q Rev Biol $32: 217-231$

Vonesh JR and De la Cruz O (2002) Complex life cycles and density dependence: assessing the contribution of egg mortality to amphibian declines. Oecologia $133: 325-333$

Wacker A, von Elert E (2002) Strong influences of larval diet history on subsequent post-settlement growth in the freshwater mollusk Dreissena polymorpha. Proc R Soc Lond B 269:2113-2119

Walker JA (1997) Ecological morphology of lacustrine threespine stickleback Gasterosteus aculeatus L. (Gasterosteidae) body shape. Biol J Linn Soc 61:3-50

Wañkowski (2006) Morphological limitations, prey size selectivity, and growth response of juvenile Atlantic salmon, Salmo salar. J Fish Biol 14:89-100

Ward AJW, Webster MM, Hart PJB (2006) Intraspecific food competition in fishes. Fish Fisheries 7:231-261

Warton, DI, IJ Wright, DS Falster, Westoby M (2006) Bivariate line-fitting methods for allometry. Biol. Reviews 81:259-291 
Webb PW (1982) Avoidance responses of fathead minnow to strikes by four teleost predators. J. Comp. Physiol. 147A:371-378

Webb PW (1986) Effect of body form and response threshold on the vulnerability of four species of teleost prey attacked by largemouth bass (Micropterus salmoides).

Can. J. Fish. Aquat. Sci. 43:763-771

Webb PW, Blake RW (1985) Swimming. In Functional Vertebrate Morphology (eds. Hildebrand, M., Bramble, D. M., Liem, K. and Wake, D. B.), pp. 110-128. Harvard University Press

Webb PW, Blake RW (1985) Swimming. Pp. 110-128 in M. Hildebrand, D. M. Bramble, K. F. Liem, and D. B. Wake, eds. Functional vertebrate morphology. Harvard Univ. Press, Cambridge, MA

Wellenreuther M, Barrett PT, Clements KD (2007) Ecological diversification in habitat use by subtidal triplefin Wshes (Tripterygiidae). Mar Ecol Prog Ser 330:235246

Wellenreuther M, Clements KD (2008) Determinants of habitat association in a sympatric clade of marine fishes. Mar Biol 154:393-402

Wellington GM, Victor BC (1989) Planktonic larval duration of one hundred species of Pacific and Atlantic damselfishes (Pomacentridae). Mar Biol 101:557-567

Wennhage H, Pihl L and Stål J (2007) Distribution and quality of plaice (Pleuronectes platessa) nursery grounds on the Swedish west coast. J Sea Res 57:218229

Werner EE, Gilliam JF (1984) The ontogenetic niche and species interactions in sizestructured populations. Annu Rev Ecol Syst 15:393-425

West GB, Brown JH, Enquist BJ (2001) A general model for ontogenetic growth. Nature 413:628-631

West-Eberhard MJ (1989) Phenotypic plasticity and the origins of diversity. Annu Rev Ecol Syst 20:249-278

Weiss SB, Murphy DD, Ehrlich PR, Metzler CF (1993) Adult emergence phenology in checkerspot butterflies: the effects of macroclimate, topoclimate, and population history. Oecologia 96:261-270

Wilbur HM (1980) Complex life cycles. Annu Rev Ecol Syst 11:67-93

Williams AJ, Davies CR, Mapstone BD, Russ GR (2003) Scales of spatial variation in demography of a large coral-reef fish — an exception to the typical model? Fish Bull 101:673-683

Williams TD (2008) Individual variation in endocrine systems: moving beyond the 'tyranny of the Golden Mean'. Phil Trans R Soc Lond B 363:1687-1698 
Williams TD, Vezina F, Speakman JR (2009) Individually variable energy management during egg production is repeatable across breeding attempts. J Exp Boil 212:1101-1105

Wilson DT, Meekan MG (2002) Growth-related advantages for survival to the point of replenishment in the coral reef fish Stegastes partitus (Pomacentridae). Mar Ecol Prog Ser 231: 247-260

Wilson RS (2001) Geographic variation in thermal sensitivity of jumping performance in the frog Limnodynastes peronii. J Exp Biol 204: 4227-4236

Wilson J, Osenberg CW (2002) Experimental and observational patterns of densitydependent settlement and survival in the marine fish Gobiosoma. Oecologia 130:205215

Wimberger PH (1992) Plasticity of fish body shape. The effects of diet, development, family and age in two species of Geophagus (Pisces: Gichlidae). Biol J Linn Soc 45:197-218

Wheeler A (1980) Fish-algal relations in temperate waters. In: Price, JH, Irvine DEG, Farnham WF (eds) The shore environment, vol. 2, Ecosystems, Academic Press, London, pp 677-698

Wu TY (1977) Introduction to the scaling of aquatic locomotion. In: Pedley TJ (ed) Scale effects in animal locomotion. Academic Press, London, p 203-232

Zar JH (1984) Biostatistical analysis. 2nd edn, Prentice-Hall, New Jersey

Ziemba RE, Collins JP (1999) Development of size structure in tiger salamanders: the role of intraspecific interference. Oecologia 120:524-552 